\title{
An eQUEST Based Building Energy Modeling Analysis for Energy Efficiency of Buildings
}

\author{
Saroj Lamichhane \\ West Virginia University, s10101@mix.wvu.edu
}

Follow this and additional works at: https://researchrepository.wvu.edu/etd

Part of the Energy Systems Commons, and the Industrial Engineering Commons

\section{Recommended Citation}

Lamichhane, Saroj, "An eQUEST Based Building Energy Modeling Analysis for Energy Efficiency of Buildings" (2021). Graduate Theses, Dissertations, and Problem Reports. 8266.

https://researchrepository.wvu.edu/etd/8266

This Thesis is protected by copyright and/or related rights. It has been brought to you by the The Research Repository @ WVU with permission from the rights-holder(s). You are free to use this Thesis in any way that is permitted by the copyright and related rights legislation that applies to your use. For other uses you must obtain permission from the rights-holder(s) directly, unless additional rights are indicated by a Creative Commons license in the record and/ or on the work itself. This Thesis has been accepted for inclusion in WVU Graduate Theses, Dissertations, and Problem Reports collection by an authorized administrator of The Research Repository @ WVU. For more information, please contact researchrepository@mail.wvu.edu. 


\title{
An eQUEST Based Building Energy Modeling Analysis for Energy Efficiency of Buildings
}

\author{
Saroj Lamichhane \\ Thesis submitted \\ to the Benjamin M. Statler College of Engineering and Mineral Resources at West Virginia \\ University \\ in partial fulfillment of the requirements for the degree of \\ Master of Science in \\ Industrial Engineering \\ Bhaskaran Gopalakrishnan, Ph.D., P.E., Chair \\ Ashish Nimbarte, Ph.D. \\ Derek Johnson, Ph.D., P.E. \\ Department of Industrial and Management Systems Engineering
}

Morgantown, West Virginia 2021

Keywords: Energy Efficiency, eQUEST, Energy Consumption, Building Energy Modeling Copyright 2021- Saroj Lamichhane 


\section{Abstract \\ An eQUEST Based Building Energy Modeling Analysis for Energy Efficiency of Buildings}

\section{Saroj Lamichhane}

Building energy performance is a function of numerous building parameters. In this study, sensitivity analysis on twenty parameters is performed to determine the top three parameters which have the most significant impact on the energy performance of buildings. Actual data from two fully operational commercial buildings were collected and used to develop a building energy model in eQUEST. The model is calibrated using Normalized Mean Bias Error (NMBE) and Coefficient of Variation of Root Mean Square Error (CV(RMSE)) method. The model satisfies the NMBE and CV(RMSE) criteria set by the American Society of Heating, Refrigeration, and AirConditioning (ASHRAE) Guideline 14, Federal Energy Management Program (FEMP), and International Performance Measurement and Verification Protocol (IPMVP) for building energy model calibration. The values of the parameters are varied in two levels, and then the percentage change in output is calculated. Fractional factorial analysis on eight parameters with the highest percentage change in energy performance is performed at two levels in a statistical software JMP.

For Building A, top 3 parameters from percentage change method are: Heating setpoint, cooling setpoint and server room. From fractional factorial design, top 3 parameters are: heating setpoint $(p$-value $=0.00129)$, cooling setpoint $(p-v a l u e=0.00133)$, and setback control $(p-v a l u e=0.00317)$. For Building B, top 3 parameters from both methods are: Server room ( $p$-value $=0.0000$ ), heating setpoint $(p$-value $=0.00014)$, and cooling setpoint $(p$-value $=0.00035)$. If the best values for all top three parameters are taken simultaneously, energy efficiency improves by $29 \%$ for Building A and $35 \%$ for Building B. 


\section{Acknowledgment}

I would like to wholeheartedly express my sincerest gratitude to my research advisor and committee chair, Dr. Bhaskaran Gopalakrishnan. This research could not have been possible without his immense guidance and support. I would forever cherish his mentorship throughout my graduate studies. I would also like to sincerely thank my committee member Dr. Ashish Nimbarte for assisting me academically and professionally during my studies and research. I would also like to sincerely thank my committee member, Dr. Derek Johnson, for his feedback and support throughout this research. I am forever grateful to all my committee members for their immense help and support in making this research possible. I would also like to acknowledge my friends and family, who were always there for me. 


\section{Table of Contents}

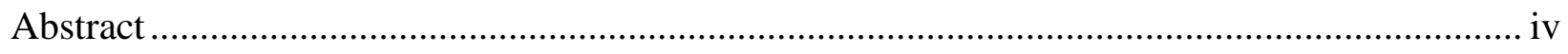

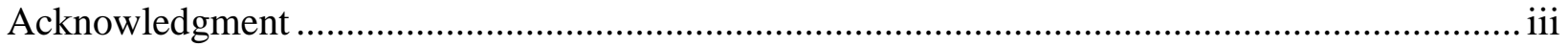

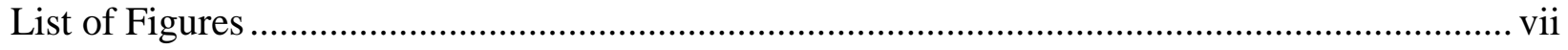

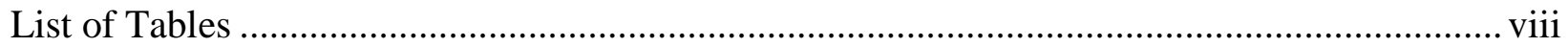

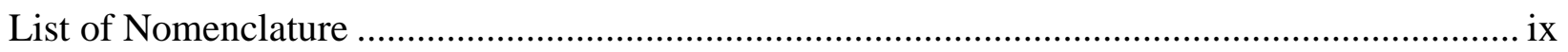

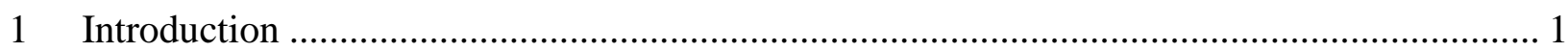

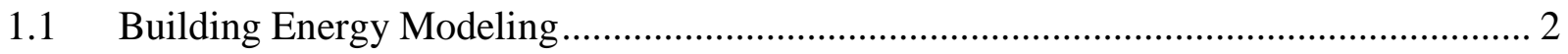

1.1.1 Advantages of Building Energy Modeling ....................................................... 3

1.1.2 Energy Modeling Approaches [5] [6] .................................................... 3

1.1.3 Energy Modeling Software ........................................................................ 4

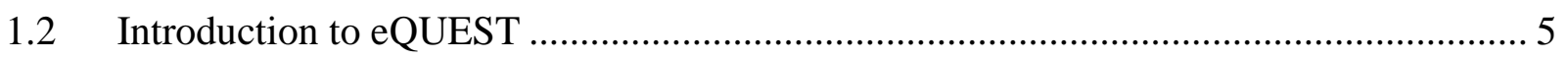

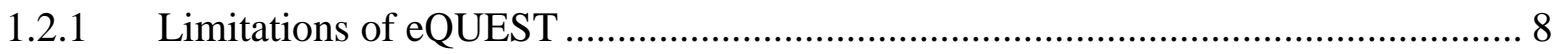

1.3 Effective Modeling Capability of eQUEST ............................................................ 8

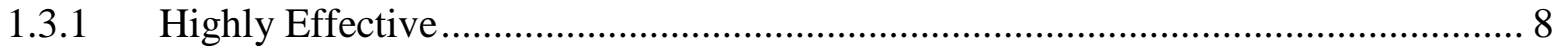

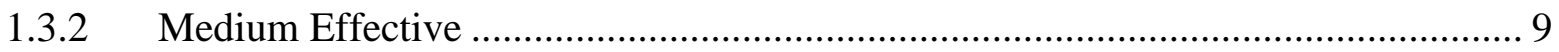

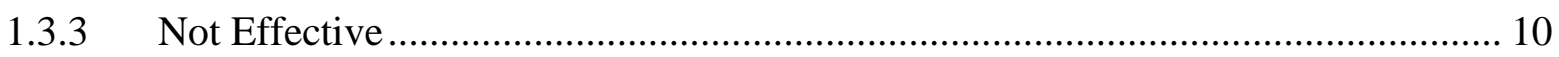

1.4 Major Energy Consuming Sources in Buildings .................................................. 11

1.4.1 Heating, Ventilation, and Air-conditioning (HVAC) ....................................... 11

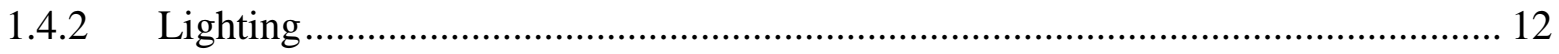

1.4.3 Domestic Water Heating and Plug loads ....................................................... 12

1.5 Major Drivers of Energy Consumption in Buildings ............................................ 13

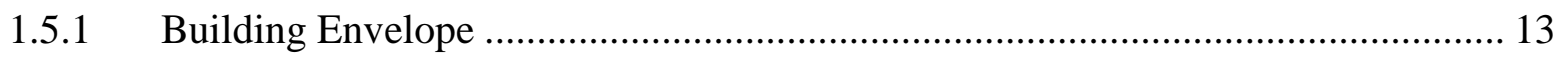

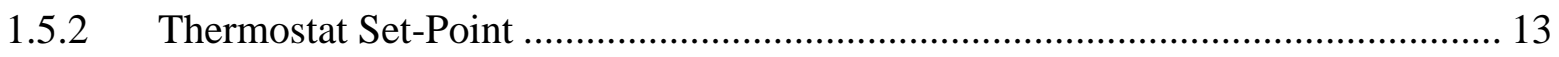

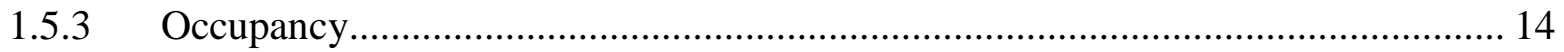

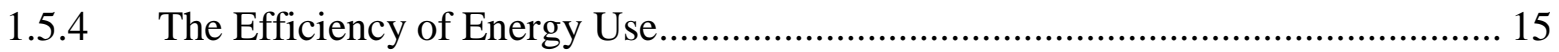

1.5.5 Building Size, Orientation, and Weather Profile ............................................. 15

1.6 Need for Research ........................................................................................ 15

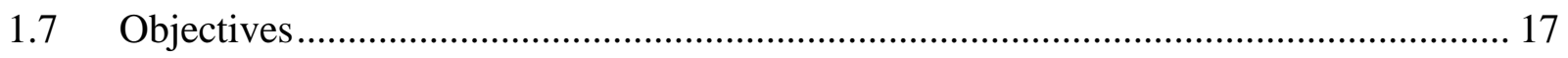

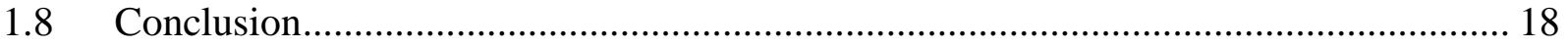

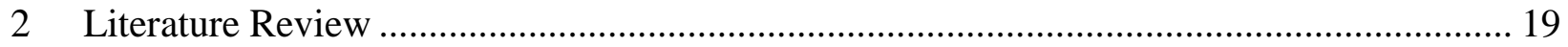


2.1 Heating, Ventilation, and Air-Conditioning System .................................................. 19

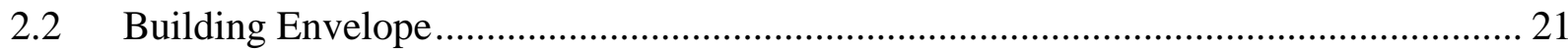

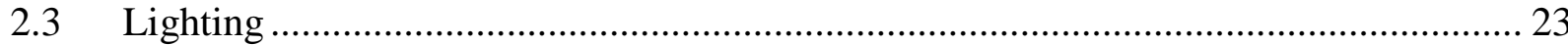

2.4 Miscellaneous Parameters and Controls .................................................................. 24

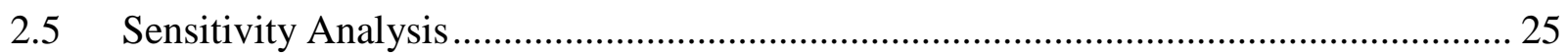

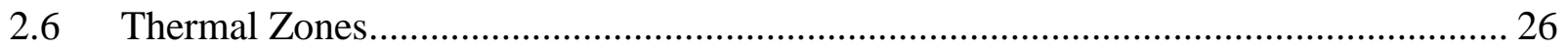

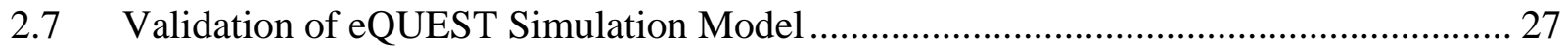

2.8 Energy Efficiency of Building Codes .......................................................................... 29

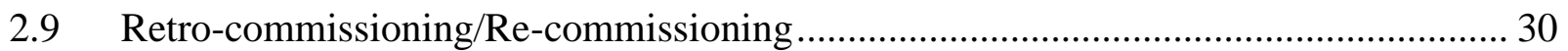

2.10 Degradation Aspects of Building Parameters .............................................................. 31

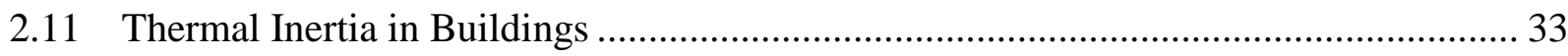

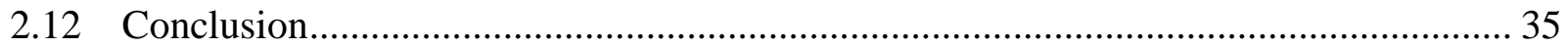

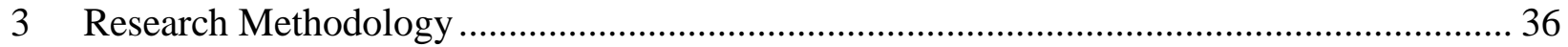

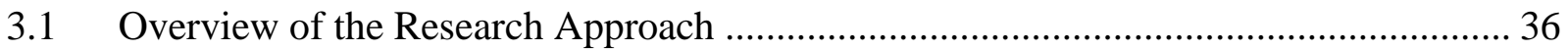

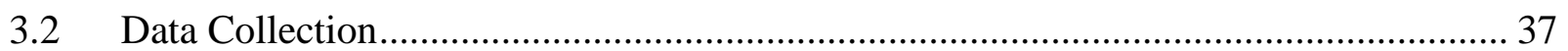

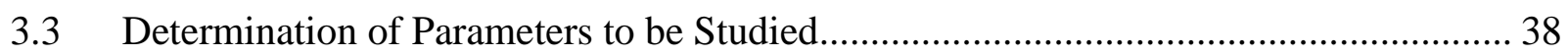

3.3.1 Dependent and Independent Parameters ........................................................... 39

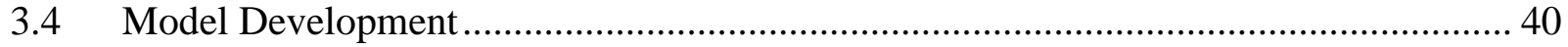

3.4.1 Design Development Wizard (DDW) ........................................................... 42

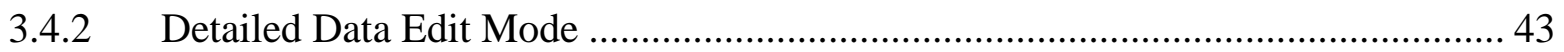

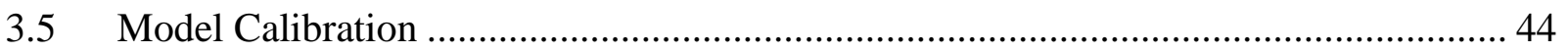

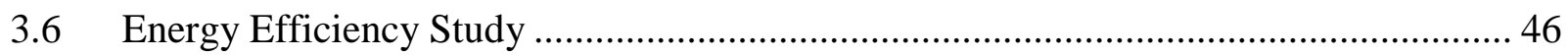

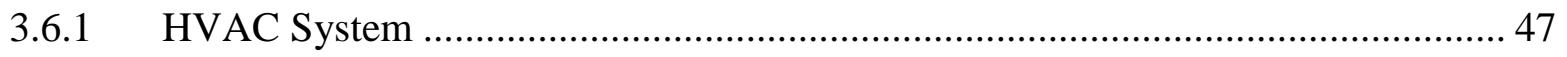

3.6.2 Building Envelope …………......................................................................... 48

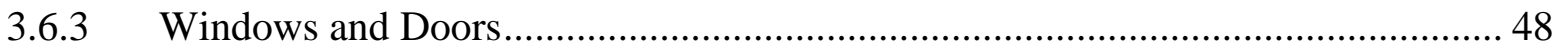

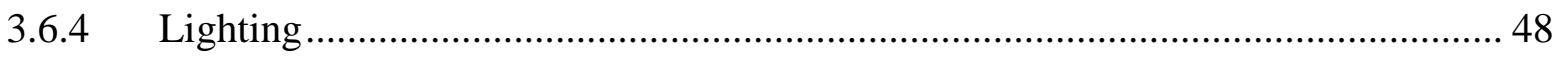

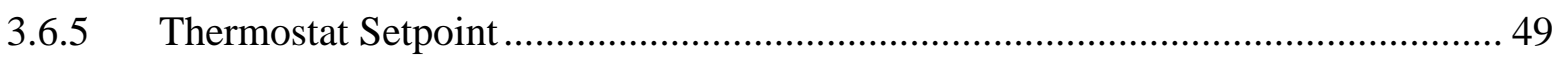

3.6.6 Demand-Controlled Ventilation (DCV) .......................................................... 49

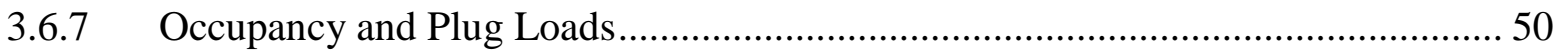

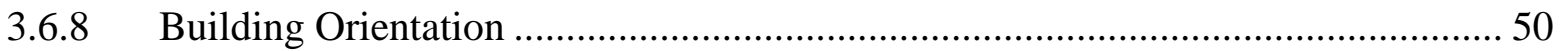

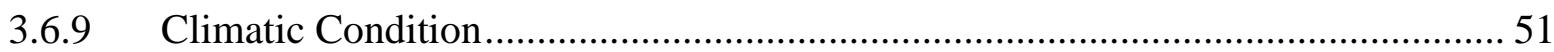

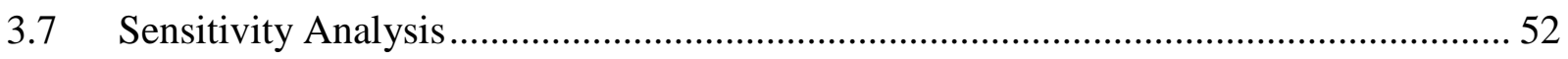




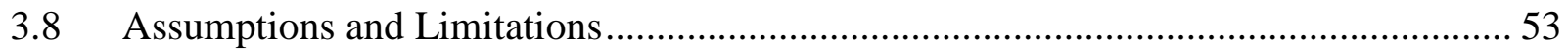

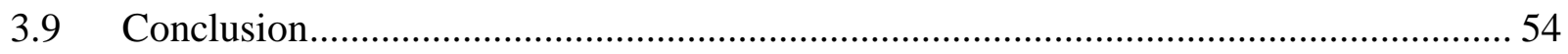

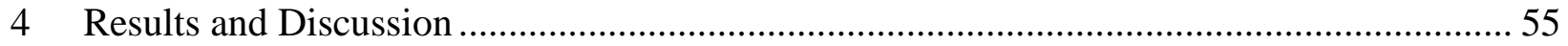

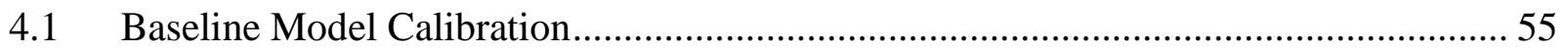

4.2 Sensitivity Analysis Using Percentage Change Method ............................................. 56

4.3 Sensitivity Analysis Using Fractional Factorial Design .......................................... 58

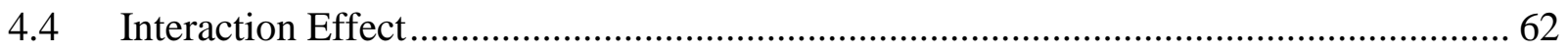

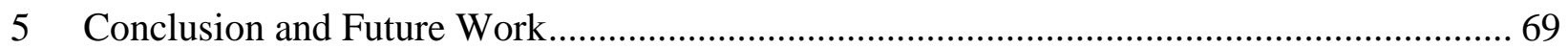

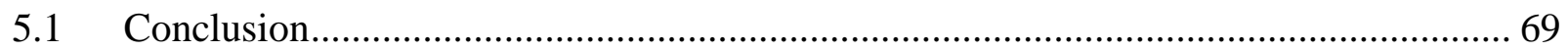

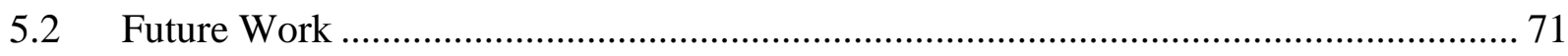

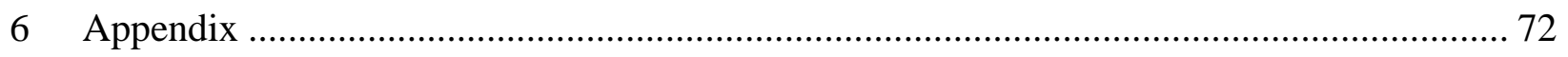

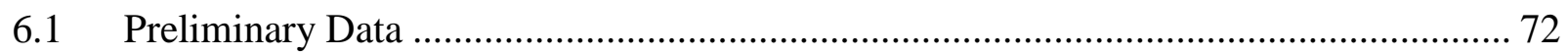

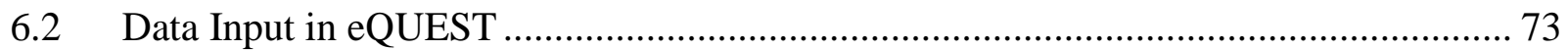

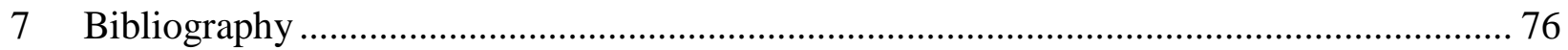




\section{List of Figures}

Figure 1: U.S. Energy Consumption by Sector in 2018 [3] ............................................. 2

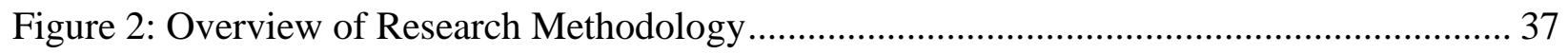

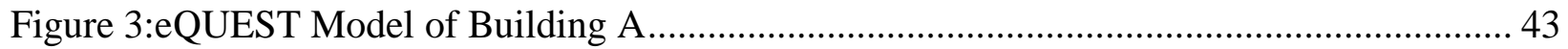

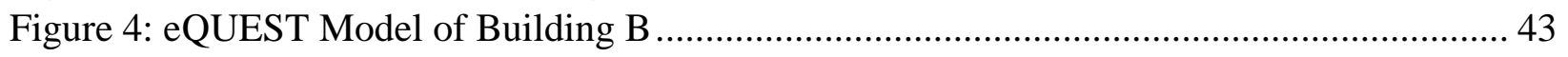

Figure 5: Actual vs Simulated Energy Consumption of Building A ....................................... 45

Figure 6: Actual vs Simulated Energy Consumption of Building A ...................................... 45

Figure 7: Fractional Factorial Design For Building A ..................................................... 53

Figure 8: Fractional Factorial Design For Building B ........................................................... 53

Figure 9: Baseline Simulation Result for Building A ......................................................... 55

Figure 10: Baseline Simulation Result for Building B ...................................................... 56

Figure 11: Sensitivity Analysis of Main Parameters of Building A ....................................... 57

Figure 12: Sensitivity Analysis of Main Parameters of Building B ....................................... 58

Figure 13: Fractional Factorial Analysis Result for Building A ........................................... 58

Figure 14: Fractional Factorial Analysis Result for Building B ........................................... 59

Figure 15: Sorted Parameters for Building A ....................................................................... 59

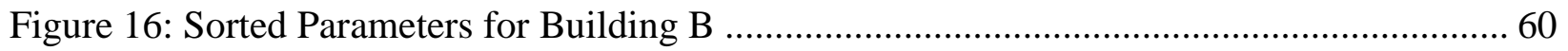

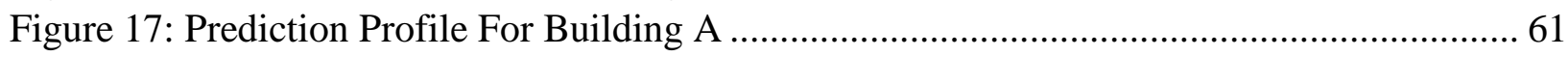

Figure 18: Prediction Profile For Building B ..................................................................... 62

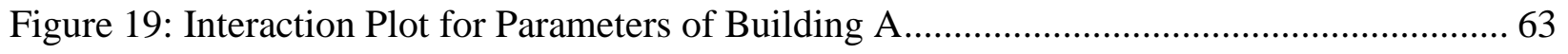

Figure 20: Interaction Plot for Parameters of Building B .................................................... 64

Figure 21: Energy Consumption vs Building Orientation for Building A................................ 65

Figure 22: Energy Consumption vs Building Orientation for Building B ................................ 66

Figure 23: Energy Performance of Building A When Windows and Doors are Absent in Certain

Face of the Building ....................................................................................................... 67

Figure 24: Energy Performance of Building B When Windows and Doors are Absent in Certain

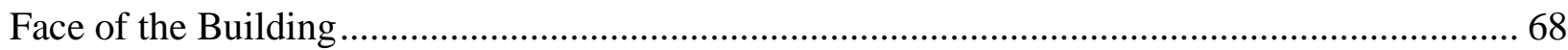

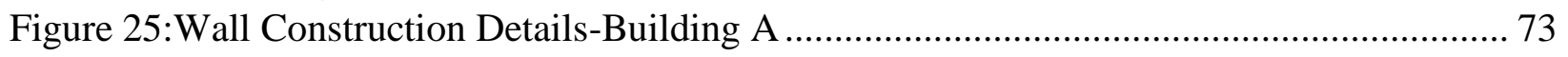

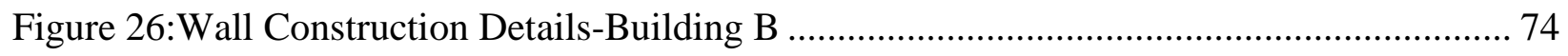

Figure 27:Roof Construction Details-Building A .............................................................. 74

Figure 28:Roof Construction Details-Building B .......................................................... 75 


\section{List of Tables}

Table 1:Energy modeling capabilities of eQUEST [7] ....................................................... 7

Table 2:Energy Consumption in Offices by End-Use [10] ................................................ 11

Table 3:Rates of Heat Gain For Different Activities [11] ..................................................... 14

Table 4: Power Adjustment Percentages for Automatic Lighting Controls, ASHRAE 90.1 Table

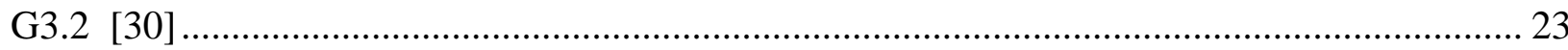

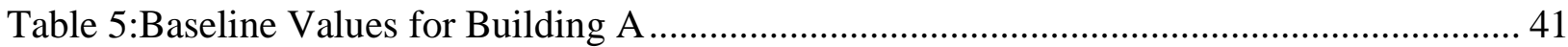

Table 6:Baseline Values for Building B ........................................................................... 42

Table 7: Calibration Criteria of the FEMP, ASHRAE guideline 14 and IPMVP...................... 45

Table 8: Parameter Values At Two Levels for Building A ..................................................... 46

Table 9: Parameter Values At Two Levels for Building B .................................................. 47

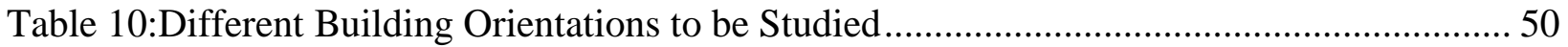

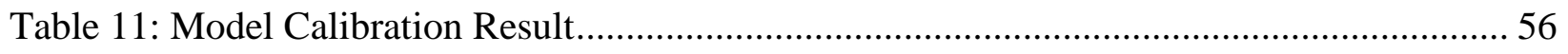

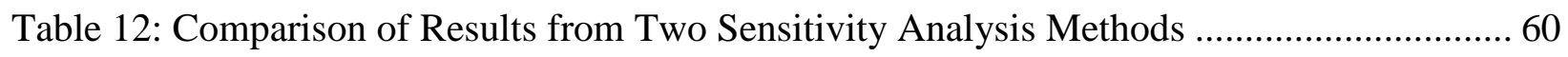

Table 13: General Information about the Building A .............................................................. 72

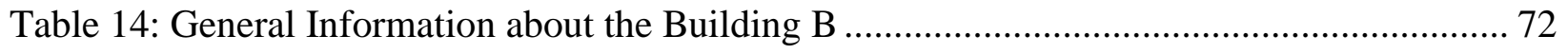




\section{List of Nomenclature}

AC - Air Conditioning

BAS - Building Automation System

BEM-Building Energy Modeling

BEMS - Building Energy Management System

COP - Coefficient of Performance

CT - Current Transducer

DCV - Demand Controlled Ventilation

DOE - Deaprtment of Energy

EE - Energy Efficiency

EEM - Energy Efficiency Measure

EER - Energy Efficiency Ratio

EIA - Energy Information Administration

$\mathrm{Ft}-$ Feet

GHG - Green House Gas

HVAC - Heating, ventilation, and Air Conditioning

IPMVP-International Performance Measurement and Verification Protocol

kW - Kilowatt

kWh - Kilowatt-hour

MMBtu - Metric Million British Thermal Unit

$\mathrm{M} \& \mathrm{~V}-$ Measurement and Verification

PT - Pressure Transducer

R-value - Resistance value

SEER - Seasonal Energy Efficiency Ratio

SHGC-Solar Heat Gain Coefficient

SPP - Simple Payback Period

U.S. - United States

WWR - Window to Wall Ratio

VLT - Visible Light Transmittance 


\section{Introduction}

Buildings can be primarily divided into three categories: residential buildings, commercial buildings, and specialty buildings. Residential buildings can be classified as buildings where more than $50 \%$ of the floor space is used for dwelling purposes. Commercial buildings include facilities with more than $50 \%$ of floor space used for commercial activities, including warehouses, manufacturing facilities, stores, offices, clinics, theaters, and data centers, and many more. Specialty buildings include different sub-categories like educational buildings, religious buildings, government buildings, military buildings, transport buildings, and many more.

There have been significant changes in building designs over time. In the past, only structural and aesthetics were considered for building design without much attention to energy efficiency. However, it is equally essential for today's buildings to be energy-efficient to minimize energy usage costs and reduce greenhouse gas (GHG) emissions. The rise in global energy consumption attributed to residential and commercial buildings and the growing concern of energy security and GHG has mandated the need to curb global energy consumption and enhance the energy efficiency measures in the building sector. With the help of advanced technology, the concept of passive buildings and net-zero buildings is now realized. The passive buildings have very high energy efficiency and have minimal energy requirements. The net-zero buildings produce as much energy as it consumes thus balancing its energy requirements.

Over time, residential and commercial buildings have increased in number and size and have increased their energy consumption. In 2018, the residential and commercial building sector accounted for $20 \%$ of the global energy consumption [1] and about $40 \%$ of U.S. annual energy consumption. In the U.S., buildings contribute to $76 \%$ of electricity usage and $40 \%$ of the total energy consumption and associated greenhouse gas emissions [2]. The building sector's electricity consumption has grown immensely in the past five decades, from $25 \%$ of U.S. annual electricity consumption in the 1950 s to $40 \%$ in the early 1970 s to more than $76 \%$ by 2012 [2]. The U.S. Energy Information Administration (EIA) projects that global building energy consumption will grow by $1.3 \%$ per year on average from 2018 to 2050. In countries that are not part of the

Organization for Economic Cooperation and Development (OECD), EIA projects that energy 
consumed in buildings will grow by more than $2 \%$ per year or about five times the rate of OECD countries [1]. Hence, enhancing the building sector's energy efficiency can result in opportunities to save energy, reduce greenhouse gas emissions, and reduce building operating costs.

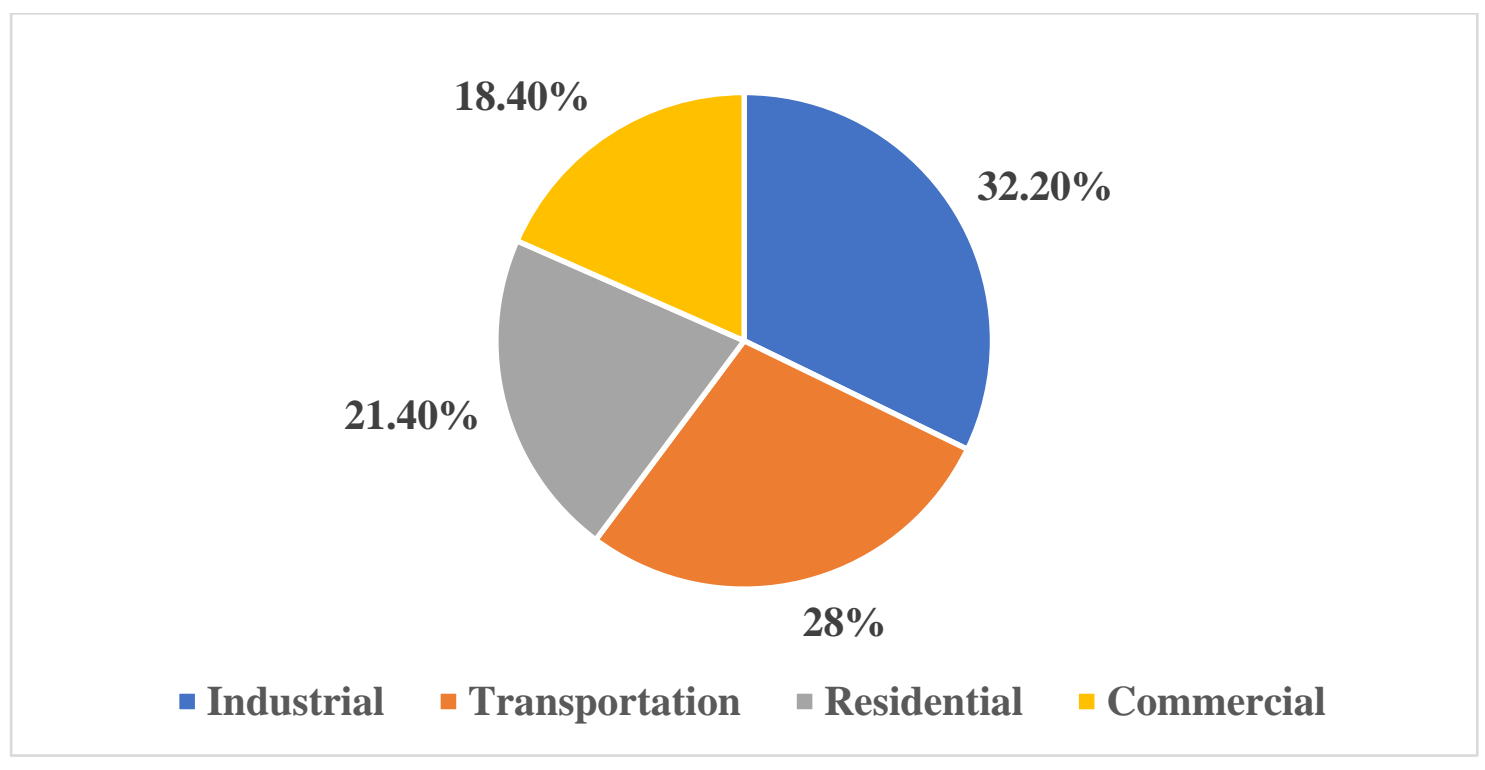

Figure 1: U.S. Energy Consumption by Sector in 2018 [3]

There is considerable potential in reducing the building energy consumption by improving the building's energy performance. The building sector can generate annual energy savings up to 14.72 x $10^{12} \mathrm{kWh}$ by 2050 by implementing energy efficiency measures [4]. By 2030, building energy use could be cut more than $20 \%$ using technologies known to be cost-effective today and by more than $35 \%$ if research goals are met [2].

Building energy modeling can play a huge role in helping the building sector achieve such energy efficiency targets by enabling engineers to design and evaluate energy-efficient buildings. The advancement in technology has made it possible to measure, monitor, and analyze building energy performance. With the development of energy modeling software, new and existing buildings can be designed to be energy efficient, and well-informed decisions regarding building envelope, fenestration, heating and cooling capacities, and many more can be made.

\subsection{Building Energy Modeling}

Building energy modeling involves creating a virtual replica of an actual or proposed building using computer software to simulate its energy performance. All the characteristics and features of the building such as building shape and size, construction materials, Heating, Ventilation, and 
Air Conditioning (HVAC) systems, internal plug-loads, domestic water heaters, window, and door types, insulation, utility rates, weather profile, location, occupancy and schedules of equipment, and many more parameters are entered into the energy modeling software to replicate the building and its operation. The software can simulate the thermal load and determine estimated building energy usage from these inputs. Today, many energy modeling software can produce output reports in life-cycle analysis, system feasibility, and GHG emissions.

\subsubsection{Advantages of Building Energy Modeling}

Building energy modeling is a special tool for determining how and where a building's energy is being used, which helps determine the building's energy-saving opportunities. Some of the advantages of building energy modeling are listed below:

$>$ Predict the energy consumption, energy cost, and carbon dioxide emissions associated with buildings.

$>$ Compare varying energy efficiency options to facilitate decision-making.

$>$ Perform life cycle analysis.

$>$ Determine which energy efficiency measures are most cost-effective.

Estimate size and capacity of HVAC, lighting, and other energy-consuming systems.

$>$ Apply for LEED certification, tax credits, and utility incentives.

$>$ Check for compliance with building codes.

\subsubsection{Energy Modeling Approaches [5] [6]}

\subsubsection{Physics-Based or White Box Approach}

The physics-based approach is based on physical principles for modeling the building components. Various mathematical equations are used to simulate and calculate the building energy consumption. The white box method's main drawback is that the simulation process is slow as numerous parameters must be entered into the software. This approach is used by simulation software like the Department of Energy's DOE-2 and EnergyPlus [5].

\subsubsection{Empirical or Black-Box Approach}

The empirical model uses statistical tools such as regression analysis, Fourier series, and artificial neural networks to provide quick and approximate estimates based on historical data analysis. Such a method does not focus on the physical aspects and does not give accurate results. 


\subsubsection{Hybrid or Gray-Box Approach}

A hybrid or grey-box approach is a mixture of physical (white) and empirical method (black). The physical model is used to develop the building's physical configuration, and then the statistical

analysis is used to estimate important parameters. A grey-box method balances the accuracy of the physics-based approach and the speed of the empirical approach.

\subsubsection{Calibrated Simulation Approach}

In a calibrated simulation method, an existing building simulation computer program is used to simulate the building energy performance. If the simulated results do not match the actual energy usage, then the model is calibrated by adjusting various physical inputs to the program until the simulation result matches the actual data. After gaining confidence that the model represents the building parameters and current operating conditions well, the model is used to predict future energy consumption. Such a method requires expertise and time to calibrate the model.

\subsubsection{Energy Modeling Software}

The U.S. Department of Energy (DOE) has listed hundreds of energy software tools on its website. Some of the popular energy modeling software today are eQUEST, EnergyPlus, Trace700, and Transys.

\subsubsection{Quick Energy Simulation Tool (eQUEST) [7]}

eQUEST is a publicly available software of the U.S. DOE. It is user-friendly software to develop a building energy model using simple wizards. However, it is not convenient to perform load designs in eQUEST. More detailed topics about eQUEST are discussed in subsequent sections.

\subsubsection{EnergyPlus [7]}

EnergyPlus is a more advanced building energy modeling software with advanced features like net-zero energy technologies and sub-hourly simulation. However, the software is less userfriendly than eQUEST. The software is based on the popular capabilities of BLAST and DOE2.1E.

\subsubsection{Transient System Simulation Tool (TRNSYS) [8]}

Transys is more complicated than eQUEST but has greater variety in simulations. It is a transient systems simulation program with a modular structure. It is a commercial software package 
developed at the University of Wisconsin. It is generally used for modeling solar systems, lowenergy buildings, HVAC systems, and renewable energy systems.

\subsubsection{TRACE 700 [9]}

TRACE 700 is a commercial energy modeling software developed by Trane. While TRACE 700 can calculate air conditioning loads of a building by simulation and perform life cycle cost analysis, it cannot display the building design model's visual image. TRACE 700 is primarily used in HVAC load calculations and energy calculations. It consists of four calculation phases: design, system, equipment, and economics.

Among the above-listed software, eQUEST and EnergyPlus are the most commonly used software for building energy modeling. Both software applications have their strengths and weaknesses. eQUEST is more user-friendly than EnergyPlus, while EnergyPlus can calculate results with more accuracy than eQUEST. EnergyPlus has less computational efficiency than eQUEST as EnergyPlus performs sub-hourly calculations while eQUEST performs hourly calculations. EnergyPlus performs integrated heat balance for loads, systems, and plants, while eQUEST (DOE-

2) uses sequential calculations from loads to systems to plant without accounting for feedback from plant to systems or from systems to loads. Thus, simulation time for EnergyPlus is higher than that for eQUEST. Moreover, eQUEST has a feature referred to as parametric runs where changes to the base case can be made quickly and its effectiveness compared with the base case without having to cause changes in the base model of the building. Whereas in EnergyPlus, changes must be made to the model itself [7].

\subsection{Introduction to eQUEST}

eQUEST (Quick Energy Simulation Tool) is an energy modeling software that utilizes the U.S. DOE's simulation tool DOE-2. Many versions of eQUEST have been developed since its inception. eQUEST 3.65 is the latest version developed by DOE in October 2018. Its cost-free availability and applicability in every building development stage (from the initial designing phase to the final stages) has made eQUEST one of the most popular energy modeling software in use today.

eQUEST has three different input wizards where users can input various parameters of the building. The three wizards in eQUEST are schematic design wizard, design development wizard, 
and energy efficiency wizard. Schematic design wizard is used in the earliest stages of the design, where little information about the building parameters is known. It only asks for simple inputs from the user. In the detailed development wizard, more specific information about the building parameters is needed. The energy efficiency measure wizard allows users to analyze multiple scenarios for the design model with necessary input information to analyze the building's energy performance.

The accuracy of results from building energy modeling software like eQUEST depends on the accuracy of the information entered into the software. Even the most experienced energy modelers might not accurately obtain results matching $100 \%$ with the actual results. This is because all energy modeling software has some limitations. The energy modeling features available in eQUEST are shown in Table 1. 
Table 1:Energy modeling capabilities of eQUEST [7]

\begin{tabular}{|c|c|}
\hline eQUEST & Capability \\
\hline \multicolumn{2}{|l|}{ General details } \\
\hline Import geometry from CAD programs & Yes \\
\hline Export geometry to programs & No \\
\hline Unlimited zone, system, equipment & Yes \\
\hline Dimming electric lighting controls & Yes \\
\hline \multicolumn{2}{|c|}{ Heat load calculations } \\
\hline Hourly load calculation & Yes \\
\hline Thermal comfort estimation & No \\
\hline Automatic design day calculation & Yes \\
\hline \multicolumn{2}{|l|}{ HVAC } \\
\hline User configured HVAC system & Yes \\
\hline Automatic sizing & Yes \\
\hline Absorption chillers & Yes \\
\hline Air to air energy recovery systems & Yes \\
\hline Seasonal heat and cold storage & Yes \\
\hline Individual zone and system control & Yes \\
\hline Natural ventilation & No \\
\hline \multicolumn{2}{|l|}{ Climate data } \\
\hline Weather data available with the program & Yes \\
\hline Data editing facility & Yes \\
\hline \multicolumn{2}{|c|}{ Economic evaluation } \\
\hline Life cycle cost analysis & Yes \\
\hline \multicolumn{2}{|l|}{ Reports } \\
\hline Graphical & Yes \\
\hline Text & Yes \\
\hline Cost of software & Free \\
\hline Weblink & www.doe2.com/eQUEST \\
\hline
\end{tabular}


eQUEST is also a qualified software for calculating commercial building tax deductions under the PATH Act of 2015. Also, DOE-2.2, the latest version of DOE-2, is qualified software for calculating commercial building tax deductions.

\subsubsection{Limitations of eQUEST}

Some of the limitations of eQUEST are given below:

$>$ eQUEST allows only one HVAC system per zone.

$>$ Only two photosensors per zone are allowed for daylighting.

$>$ Only three different kinds of doors and windows can be assigned per shell.

$>$ eQUEST does not have demand response controls for lighting and equipment. There are some ways to circumvent these modeling features, which might not give accurate results.

$>$ eQUEST cannot model visual comforts and zone thermal comfort.

$>$ It cannot model radiant cooling or heating and moisture migration.

$>$ It can calculate loads on an hourly basis. Sub-hourly calculations and reports are not available.

$>$ eQUEST does not calculate water and sewage usage and costs.

$>$ It cannot model fuel cells and engines.

\subsection{Effective Modeling Capability of eQUEST}

eQUEST is an excellent energy modeling and simulation tool to evaluate the energy performance of various kinds of buildings. However, not all building features can be effectively modeled in eQUEST. The accuracy of eQUEST simulation depends upon whether eQUEST can effectively model these features or not.

\subsubsection{Highly Effective}

eQUEST models can be highly effective for buildings with a maximum of three-season profiles, simple building envelope construction, limited window, and door types, single HVAC system per zone, and location where exact weather profile is available in .bin format. eQUEST only allows assignment of up to a maximum of six layers for roof and wall construction. Thus, if the building consists of a simple roof and wall structure with less than six construction layers, eQUEST can effectively model the envelope. Simple flat roofs or pitched roofs can be effectively modeled in eQUEST. 
There are various options for window and door types, but only three types of windows and doors can be specified per shell in eQUEST. Also, various shading controls like overhangs, fins, and drapes can be effectively modeled. Various glazing options are available. In double or triple-pane windows, insulating materials like air or argon can be modeled. A building with limited windows and doors, common frame types, and insulating inert gases can be effectively modeled in eQUEST.

Also, various HVAC systems like direct expansion (DX) coils, chilled water coils, evaporative coolers, furnaces, electric resistance heating, hot water coils can effectively be modeled in eQUEST. However, eQUEST is effective only for a building with a maximum of one HVAC system serving per zone. The operation can be based on schedule, demand, standby, or sub-hour cycle for chilled water and hot water loops and hot water loops. Various preconditioning and preheating can be effectively modeled. Energy recovery wheels based on counter flow, cross flow, parallel flow, and mixed flow can be modeled. eQUEST is most effective if the schedule of the equipment, occupancy, and HVAC system remains steady on an hourly basis. Schedules of various loads can have a significant impact on the energy performance of a building. Thus, the ability to accurately portray the actual schedules in the model affects the accuracy of the simulation result.

Under lighting systems, fluorescent, metal halide, high-pressure sodium, and incandescent lamps can be modeled. There are options to specify if the lamps are suspended or recesses and vented or not vented. Under lighting controls, daylighting and sky lighting can be modeled. Daylighting can be effectively modeled if the maximum number of daylight sensors in a zone is not more than two. eQUEST can also effectively model photovoltaic arrays, engine generators, gas turbine generators, and steam turbine generators.

\subsubsection{Medium Effective}

eQUEST cannot model advanced lighting systems like LED lights and occupancy sensors. However, the increase in energy efficiency achieved using LED lights and occupancy sensors can be adjusted in the load profile where a lighting load (watt per square foot) has to be entered for each space. Basically, the load profile will be lesser than if the building had a traditional lighting system like incandescent and metal halides. Although this method does not accurately portray the exact scenario in the building, it does not significantly impact the model's accuracy. 
There are several residential and commercial buildings with balconies. A balcony provides shade to the windows and doors below it and might increase the energy efficiency of buildings. Unfortunately, balconies cannot be modeled in eQUEST. However, the shading effect of the balcony can be modeled using overhangs in the windows and doors, which are shaded by the balcony.

For insulating noble gas between double-pane and triple-pane windows and doors, eQUEST only has two options: air and argon. If the building has windows and doors with other insulating noble gases like krypton and xenon, then the U value, SHGC value, and VLT values must be altered to reflect the change in the property of the windows and doors. In addition, eQUEST only allows the assignment of a maximum of three-door types and three window types. If the numbers of these different types of windows are not huge, and if there is only a slight difference in the U-value, SHGC, and VLT of the windows and doors, it will not significantly reduce the model's accuracy.

Moreover, eQUEST only allows eight activity area types per shell. However, if a building has numerous activity area types with an insignificant difference in square footage, HVAC system, temperature setpoints, loads, occupancy, and schedules in those areas, they can be considered a single zone. They can be considered a part of another activity area type.

\subsubsection{Not Effective}

eQUEST is not effective when modeling sub-hourly load calculations, thermal comfort, and visual comfort level of occupants. A building with complex geometry with the conical shape or domeshaped roofs and other structures cannot be modeled effectively in eQUEST. eQUEST performs load calculation on an hourly basis. If the large capacity equipment usage varies within an hour, then there can be significant inaccuracies in the model. Also, if a zone has multiple HVAC systems serving it, then eQUEST cannot model it. Also, eQUEST is ineffective if a building has more than 400 different zones, each with separate zone controls. Also, leaks in air side HVAC and water side HVAC systems cannot be effectively modeled in eQUEST.

Buildings can have a single operational season or multiple operational seasons. For example, a hospital or an office building is operational throughout the year and has a single season. However, a school building might have two or three seasons - highly used in-school sessions, everyday use 
in summer, and no use in winter breaks. In eQuest, the maximum number of seasons that can be specified for any building is three. eQUEST creates an individual schedule for each season. If, for some reason, a building has more than three seasons, then the effectiveness of eQUEST modeling is reduced.

In addition, eQUEST does not consider the location and details of the equipment inside a building. These factors can affect the effectiveness of daylight sensors and the thermal inertia of the building. Although a fraction of space covered by contents and weight in pounds per square feet can be specified in eQUEST, other details like their dimensions, locations, specific heat capacity, and material/equipment cannot be specified.

Moreover, if a building has numerous glass windows and doors of various types (more than three), then the accuracy of the eQUEST is lower. This is because types, sizes, and the number of windows and doors have a significant effect on the energy performance of the building. Thus, if certain windows and doors types that constitute a good portion of the building walls are not correctly portrayed as actual, it can significantly change the solar heat gain, thermal inertia, heat loss to the surroundings, and amount of daylighting available inside a building.

\subsection{Major Energy Consuming Sources in Buildings}

\subsubsection{Heating, Ventilation, and Air-conditioning (HVAC)}

Almost all modern residential and commercial buildings have some type of HVAC system to condition their spaces to meet occupants' comfort level. HVAC is the primary energy-consuming source in modern residential and commercial buildings. Heating, ventilation, and air-conditioning contribute to about $50 \%$ of building energy consumption and $20 \%$ of total consumption in the U.S. [10]. The percentage of energy consumed by end-uses in the U.S., U.K., and Spain category is shown in Table 2.

Table 2:Energy Consumption in Offices by End-Use [10].

\begin{tabular}{|c|c|c|c|}
\hline Energy End Uses & U.S. (\%) & U.K. (\%) & Spain (\%) \\
\hline HVAC & 48 & 55 & 52 \\
\hline Lighting & 22 & 17 & 33 \\
\hline Equipment (Appliances) & 13 & 5 & 10 \\
\hline
\end{tabular}




\begin{tabular}{|c|c|c|c|}
\hline Energy End Uses & U.S. (\%) & U.K. (\%) & Spain (\%) \\
\hline Domestic Hot Water (DHW) & 4 & 10 & - \\
\hline Food Preparation & 1 & 5 & - \\
\hline Refrigeration & 3 & 5 & - \\
\hline Others & 10 & 4 & 5 \\
\hline
\end{tabular}

\subsubsection{Lighting}

After HVAC, lighting consumes the most energy in buildings. Lights also emit heat that adds to the cooling load and reduces the spaces' heating load. There has been significant development in lighting technology over the years. Most commercial buildings no longer use Incandescent lamps. CFLs are gradually being replaced by more efficient Light Emitting Diode (LED) lamps. Also, magnetic ballasts in lights are being replaced by more efficient electronic ballasts. Some LED lamps do not require ballasts at all.

There are various measures to improve the operation of the lighting system in a building. Occupancy sensors can be installed to automate the lights to be turned on when space is occupied and turned off when the space is unoccupied. Besides, daylighting control uses photocells to turn off the lights when enough sunlight is in the room during the daytime. Moreover, an energyefficient lighting system can be installed instead of an inefficient old lighting system. For example, LED lights have higher efficacy, consume less energy, and last longer than compact fluorescent CFL, metal halides, and other lights. The efficacy of the light bulbs can be defined as the lumen output per watt input. Other lighting controls like timers and dimmers can also be installed in a building to save on electricity costs.

\subsubsection{Domestic Water Heating and Plug loads}

Domestic water heating and plug loads also contribute to significant energy consumption in residential and commercial buildings. In addition, various plug loads such as refrigerators, laptops, desktops, television, oven, kitchen stoves, and many more contribute to a building's energy consumption.

Natural gas, propane, electric water heaters, and boilers can be used for Domestic water heating. Water heaters with tanks are generally used for large spaces, whereas, for small areas with small 
hot water demand, tankless water heaters are typically used. Tankless water heaters are more efficient than water heaters with tanks as heat losses occur from the tank surfaces.

\subsection{Major Drivers of Energy Consumption in Buildings}

\subsubsection{Building Envelope}

A building envelope is a boundary between the interior and exterior of a building. It includes the walls, roofs, base, windows, and doors. Since the building envelope directly connects with the surrounding environment, it acts as a physical structure and a thermal barrier between the environment and the building interior. The type of material and insulation in the walls, roofs, and foundation of the building affects the heat transfer between the building's interior and exterior, directly affecting its energy consumption. Well-insulated buildings will lose less heat to the exterior environment in the winter and gain less heat from the external environment in the summer.

Single pane glass windows and doors add more heating and cooling load to the building than double or triple-paned glass windows and doors with glazing and low emissivity coatings. Opaque windows and doors will have less cooling and heating load gain, but the opportunity to employ daylight savings is reduced.

The main factor determining the energy efficiency of the building walls is "Resistance to heat transparency" (R-value) or "Heat transfer value" (U-value). Walls with low U-value or high Rvalue prevent heat from entering or leaving the building. The efficiency of windows and doors is affected by Solar Heat Gain Coefficients (SHGC) and U-value. Double or triple-pane windows or doors have some gas trapped inside them, reducing the heat entering or leaving the glass section. Such glasses with a low-emissivity coating will have less SHGC than plain glass windows and doors. It is ideal to have glass windows with high Visible Light Transmittance (VLT) value and lower SHGC value.

\subsubsection{Thermostat Set-Point}

Thermostat setpoint can affect the thermal comfort level, ventilation requirements, and HVAC system's energy consumption. The thermostat setpoint directly affects the load and the energy consumption of the HVAC system. For example, setting a heating setpoint to a high temperature increases the heating load in the building, so the HVAC system consumes more energy to bring 
the space to the setpoint temperature. If the setpoint temperature is close to the outdoor temperature, then the heating/cooling load is minimal.

The thermostat setpoint can be adjusted to achieve energy savings. However, such adjustments have to be made without impacting people's thermal comfort levels. Decreasing the setpoint in the winter and increasing the summer setpoint can reduce the HVAC systems' energy consumption. In addition, adjusting the thermostat temperature setpoint differently for an occupied and unoccupied period can enhance the energy efficiency of the HVAC system.

Building spaces might have different heating and cooling loads depending upon the space volume, occupancy level, and insulation. Thus, it is an inefficient practice to use the same HVAC setpoint throughout the building. Spaces with less heating and cooling load can be separately set to different setpoints than other spaces using the zone control method. Instead of a single central thermostat controlling all the building spaces, zone control allows multiple spaces or zones to have their independent thermostat setpoint, increasing energy efficiency.

\subsubsection{Occupancy}

The number of people in a building directly affects the energy consumption of the building. In the absence of the people, lights can be turned off, the HVAC setpoint can be adjusted to achieve energy savings, and many plug loads are not operated. So, as more people occupy the building, there is a constant need to turn the lights on and operate the HVAC system. Many modern buildings have occupancy sensors to turn the lights off when the space is unoccupied and programmable thermostats and demand-controlled ventilation (DCV) to adjust ventilation requirements according to the occupancy level. People also give off energy to the surrounding through their skins in sensible heat and latent heat. Depending upon the kind of activity, heat given off by people vary. The rates of heat gain from people when performing various activities are shown in Table 3 .

Table 3:Rates of Heat Gain For Different Activities [11]

\begin{tabular}{|c|c|}
\hline Activity & Total Heat Gain For Male Adults (Btu/hr) \\
\hline Seated at rest & 400 \\
\hline Seated, writing & 480 \\
\hline Seated, typing & 640 \\
\hline Standing, light work or slow walking & 800 \\
\hline
\end{tabular}




\begin{tabular}{|c|c|}
\hline Activity & Total Heat Gain For Male Adults (Btu/hr) \\
\hline Light benchwork & 880 \\
\hline Normal walking, light machine work & 1,040 \\
\hline Heavy work, heavy machine work, lifting & 1,600 \\
\hline \multicolumn{2}{|c|}{ Heat gain from adult females is assumed to be 85 \% of that for adult male } \\
\hline
\end{tabular}

\subsubsection{The Efficiency of Energy Use}

The efficiency of equipment decreases with use over time. Replacing old and inefficient equipment with new and efficient equipment can increase the building's overall energy performance.

\subsubsection{Building Size, Orientation, and Weather Profile}

The size of a building largely determines its energy consumption. The large building will need more energy to condition the spaces and need more lighting. The building's orientation and its impact on the building's energy performance have to be studied to construct a new building. The motive is to maximize the solar heat gain in the winter and minimize the solar heat gain in the summer. This will offset some heating load in winter and a cooling load in summer for the HVAC system. The weather profile in the location of a building predominantly affects its energy consumption. Human beings are thermally comfortable in the temperature range of $68^{\circ} \mathrm{F}$ to $72^{\circ} \mathrm{F}$, and the relative humidity range of $40 \%$ to $60 \%$. A building that experiences mild climatic conditions throughout the year has to expend less energy to condition the space to meet the human thermal comfort level than a building that experiences extreme climatic conditions.

\subsection{Need for Research}

Building energy performance is a function of numerous building parameters. Most of the prevailing studies evaluating the effect of various building parameters on a building's energy performance have focused heavily on the building's design parameters. There is minimal research carried out to compare the impacts of various parameters and identify the parameters with the most significant impact on building energy performance.

Maintenance and operation practices in a building can impact its energy performance as much as the design parameters over the long term. Without proper maintenance and operation practices, the building parameters degrade in quality over time. Also, the operations within the building might 
change over a long period. As the building ages, its envelope might not be functioning as well as it was initially. The infiltration rate will increase as the envelope become lose over time. Also, the efficiency of the heating and cooling units might decrease over the long run. Without considering these factors, energy models will not give an accurate prediction of existing building energy performance.

Moreover, there are a plethora of parameters that affect the energy performance of buildings. Some of the parameters that affect a building's energy consumption are envelope insulation, HVAC capacity, lighting power density, thermostat setpoint, fenestration, infiltration, and many more. Most importantly, some parameters have a higher impact on a building's energy performance than the other parameters. It might not always be feasible for the building owners and engineers to focus their resources on maintaining these building parameters. Thus, it is critical that the building owners and engineers focus their resources on a few critical parameters than the many trivial parameters.

This research aims to fulfill this need by identifying the top three building parameters that affect building energy performance. The research evaluates the energy performance for the degraded and upgraded building parameters compared to the base case. Such research will help building owners identify the major building parameters to prioritize and focus their resources on to improve the building energy performance.

Furthermore, by implementing findings from this study, the market penetration of energy savings achieved in buildings can be evaluated. There were 5.9 million commercial buildings in the U.S. in 2018 [12] and 140.8 million residential buildings in 2020 [13]. However, only 36,000 buildings achieved the Energy Star® rating by the end of 2019 [14], and only 67,200 buildings had received LEED certification at the end of 2018 [13]. Energy Star is awarded to those buildings whose energy performance is better than $75 \%$ of buildings nationwide. This shows that many buildings in the U.S. still have low energy efficiency. According to a report published by the National Association of the Home Builders, 1.2 million new homes are built every year in U.S., and it is estimated that at the stated rate of new homes construction, $45 \%$ of the total homes would still consist of housings built before 1970 in 2037 [15]. 
If the new and existing building were to focus their resources on the top three building parameters as identified by this research, it is estimated that approximately $5 \%$ to $10 \%$ of energy savings can be achieved.

\subsection{Objectives}

The primary research objectives are:

$>$ To develop model of two commercial buildings using eQUEST. The model will be created with the actual building parameters recorded during the assessment.

$>$ To perform a simulation to determine the yearly energy consumption of the building and match it with the actual utility bills.

$>$ To investigates the impact of various building parameters on building's energy consumption. The parameters are evaluated for three cases: base case, low performance, and high performance. The parameters studied are:

1. HVAC System

- Energy Efficiency Ratio (EER)

- Overall efficiency of the drive motor, supply fan and motor

- Supply fan static pressure

- Economizer

2. Building Envelope and infiltration

- Roof insulation

- Wall insulation

- Infiltration

3. Windows and doors

- U-value

- $\mathrm{SHGC}$

- Overhangs

- Fins

4. Lighting system

- Lighting power density (LPD)

- Daylight control

5. Thermostat setpoint controls 
- Cooling setpoint

- Heating setpoint

- Thermostat setback control

6. Demand Controlled Ventilation (DCV)

7. Occupancy and plug load

- Occupancy

- Plug load

8. Building orientation

9. Climatic condition

- Dry Bulb Temperature

To perform sensitivity analysis on the building parameters and identify the top three building parameters that affect building energy performance.

\subsection{Conclusion}

This chapter introduces various building parameters affecting the energy consumption of residential and commercial buildings. The types of energy modeling and the standard software used for building energy modeling are also discussed. This chapter also explains the need for research and also states the objectives of this study. It can be seen that residential and commercial buildings consume a significant percentage of overall energy consumption in the USA and the world. Also, the number of buildings and energy consumption associated with them are expected to grow further. However, significant energy savings in the building sector can be achieved by adopting various energy efficiency measures. There are a plethora of parameters that affect the energy performance of buildings. It might not always be possible for building owners and engineers to identify the main parameters affecting their building's energy performance and focus their resources on all the parameters. Some parameters have more impact on building energy performance than the other parameters. Thus, it is critical for building owners to focus their resources on these parameters. The building owners and engineers can use the findings from this research to identify the top three building parameters affecting their building's energy performance and focus their resources on those parameters to improve the building's energy performance. 


\section{Literature Review}

The major areas of energy consumption in buildings are heating, ventilation, and air-conditioning (HVAC) (35\% of total building energy), lighting (11\%), major appliances (water heating, refrigerators, dryers, freezers - 18\%), and miscellaneous equipment (36\%) [2]. Various parameters affect the energy performance of buildings. The existing research on various building parameters is discussed in this section.

\subsection{Heating, Ventilation, and Air-Conditioning System}

HVAC is the primary energy consumption source in the residential and commercial sectors. Thus, the HVAC system's design, operation, and maintenance parameters primarily affect the whole building's energy performance. The thermostat setpoint in a space directly affects the energy consumption of HVAC systems. Cai et al. [16] performed a study on the impact of HVAC setpoint adjustment on energy savings and peak load reductions in buildings under various outdoor weather conditions. The simulated electrical consumption data closely resembled the actual electrical consumption data with a monthly average error of $2.21 \%$. The base-case temperature was set at $70^{\circ} \mathrm{F}$, and the setpoint was increased by $1{ }^{\circ} \mathrm{F}$ until $75^{\circ} \mathrm{F}$ between $12 \mathrm{PM}-3 \mathrm{PM}$ every day from mid-April to mid-October. The results showed that when the average outdoor temperature is lower than the base-case set point $\left(70^{\circ} \mathrm{F}\right)$, the building had neither energy savings nor peak demand savings through setpoint adjustments. This is because the AC unit does not operate on those days. When the average outdoor temperature is above a particular threshold value, daily energy savings and peak demand reduction potential are relatively constant and somewhat predictable. If the outdoor temperature is too high, increasing the HVAC setpoint might not produce any savings as HVAC will always be required to operate. If the average outdoor temperature falls into the band between the base case setpoint and the threshold value, then the energy savings and peak demand reduction will be random and unpredictable. Experiments on setpoint adjustments are inefficient and practically infeasible in an actual -building. Thus, its impact on building energy performance can be investigated quickly in energy modeling software like eQUEST.

D. Ardiyanto et al. [17] performed a detailed study on the impact of occupant-based HVAC setpoint intervention on energy consumption of a commercial building in Virginia using eQUEST. 
Up to $14.58 \%$ savings in HVAC electricity consumption were achieved by adjusting the HVAC setpoint based on occupants' thermal comfort, and additional $8.79 \%$ savings were achieved by incorporating occupancy information to change the HVAC setpoint. HVAC setpoints can be increased in the summer and decreased in the winter when the space is unoccupied and brought back to the normal setpoint based on thermal comfort level when the room is occupied. The development of programmable thermostats has enabled scheduled heating and cooling of spaces automatically without manual intervention to adjust the setpoints time and again. Integration of occupancy sensor, programmable thermostat, and a controller can enable the HVAC to achieve a more refined control during the occupied and unoccupied duration.

By reducing the thermostat setpoint in the winter and increasing it in the summer, K. Mininni et al. [18] found in their study that energy savings were more significant when the building was occupied compared to when it was unoccupied. The authors also found that replacing the natural gas natural draft with a forced draft boiler would save energy by $7.26 \%$, while replacing the electric, natural draft boiler with an electric forced draft boiler would consume 17\% more power than the base case. Furthermore, the replacement of a constant air volume (CAV) HVAC system with a variable air volume (VAV) system can yield energy savings up to $22.6 \%$ [19]. However, a study by J. Heller et al. [20] shows that the impact of the VAV system varies according to climatic conditions. In dry climates, energy use of the VAV system increases due to an increase in reheating demands and fan energy. The greatest increase in energy consumption of the VAV system is in a hot dry climate where fan heat from VAV operation increases cooling loads. VAV systems yield energy savings in humid climates due to the ability of VAV systems to be set up to capture heat from the air conditioning system to reheat air during dehumidification. The study also shows that heating and cooling equipment efficiency improvements caused energy savings across all climates but had a relatively small impact except for extreme climates.

Jiafan Song et al. [21] performed a controlled variable method to study the impact of four factors on a university library building's energy consumption using eQUEST. The authors generated a linear inverse relationship between summer indoor design temperature and annual power consumption. It is shown that the higher the summer indoor design temperature, the lesser the building loads and yearly power consumption. Increased personnel density increases the cooling load and energy consumption in summer. Whereas in winter, heating load decreases which results 
in lesser energy consumption. Moreover, summer supply air temperature will directly impact the energy consumption of the air conditioning system. The authors obtained a linear inverse relationship between the summer supply air temperature and annual power consumption. So, the higher the summer supply air temperature, the higher the energy savings.

\subsection{Building Envelope}

Among all building envelopes, glass windows are responsible for the maximum percentage of heat ingress into the building. Furthermore, this is more pronounced for large offices and commercial places with large glass windows and envelopes [22]. Heat transmittance through windows is five times larger than other building envelope components, with the energy lost from windows being up to $40 \%$ of the total building energy consumption [23].

A. K. Dilshad et al. [19] performed a detailed analysis of a commercial building's energy performance using eQUEST. The impact of four energy efficiency measures was studied individually at first, and then all four energy efficiency measures were combined to examine the overall net energy savings achieved. The simulation results showed that $1.69 \%$ of current energy consumption could be saved by adding a 1-inch layer of polystyrene insulation to the exterior wall. Replacing single-paned windows with glazed double-paned windows resulted in a 3.75\% energy saving. Also, 2.84\% of energy can be saved by installing daylight controls. Moreover, $22.6 \%$ of energy savings was achieved by replacing the CAV system with a VAV system. Adding all the four energy efficiency measures resulted in $30.6 \%$ energy savings, which is $0.28 \%$ less than the sum of energy savings achieved from individual energy efficiency measures. This is because some of the energy efficiency measures are interrelated.

A. Dutta et al. [22] performed a detailed study to determine the factors affecting heat gain through the windows using eQUEST. The study found that the U-value and SHGC value have more impact on the building electrical energy consumption compared to Visible Transmittance (VT). Furthermore, the authors found that any glass's SHGC value is a more critical factor than U-value. Although visible light transmittance affects the lighting system's energy consumption, compared to SHGC and U-value, it has a negligible impact on energy savings. Using eQUEST, A. Dutta et al. [23] studied the effect of building orientation, wall window ratio, and shading (overhangs and fins) in an office building's energy consumption. The modeled structure was facing north which 
receives minimum solar heat gain compared to other directions for that climate zone. Thus, changing the building orientation resulted in a slight increase in energy consumption. The result showed that a north-facing window with a Window-to-Wall Ratio (WWR) of $20 \%$ is the optimum passive architectural design in terms of energy performance for the hot and humid climate. Also, retrofitting overhangs and windows on the glass windows resulted in energy savings of $2.60 \%$.

The amount of solar heat gain can be reduced by using shading like overhangs and fins. M. Dehghani et al. [24] used eQUEST to determine the impact of overhangs and fins on the overall energy consumption of a four-story office building in Ohio, U.S. The results showed that installing overhangs and fins of $90 \mathrm{~cm}$ reduced the building energy consumption by $1.3 \%$ with a simple payback period of 1 year.

A. K. Masood et al. [25] evaluated the impact of WWR on energy consumption in a commercial building in Pakistan using heat, mass, and energy balance. It was found that reducing WWR can reduce building's energy consumption and increase energy efficiency. Siddhartha et al. [26] performed a simulation study of a hostel building in India to compare and determine some of the window types with the greatest energy efficiency and best payback period. Among the glass types investigated, green float glass of thickness $6 \mathrm{~mm}$ gave the best payback period of 0.80 years, followed by a single clear glass of $6 \mathrm{~mm}$ thickness and a single clear glass of $3 \mathrm{~mm}$ thick with simple payback periods 0.92 years and 1.2 years respectively. Also, windows with $6 \mathrm{~mm}$ Optiwhite glass (U-value=1.02, SHGC=0.91, VLT=0.91) contributed most to the cooling load of the building, followed by $6 \mathrm{~mm}$ Green float glass type $(\mathrm{U}$-value=1.03, SHGC=0.59, VLT=0.76) and $3 \mathrm{~mm}$ single clear glass type $(\mathrm{U}-\mathrm{value}=1.654, \mathrm{SHGC}=0.233, \mathrm{VLT}=0.884)$ in sequential order.

Qiong et al. [27] studied the impact of different window glazing types on total building energy load in high-rise residential buildings in different climatic regions of China using software Design builder and Revit. Heat gained through solar radiation can reduce the heating load in a cold climate where heating loads are more significant than cooling loads. Whereas in hot climatic zones, cooling loads are more significant than the heating loads, and the heat gained through solar radiation will increase the cooling load. Thus, low-E glazing may not always be the best answer for improving a building's energy efficiency for all climatic zones. The study results demonstrated that $6 \mathrm{~mm}$ low-e double-glazing with $13 \mathrm{~mm}$ air fill serves best to reduce energy consumption in all the three climatic zones studied (hot summer/warm winter, hot summer/cold winter, and cold 
climates). The tinted glass gave the highest energy savings for hot summer/warm winter (i.e., $8.38 \%$ ) and hot summer/cold winter (i.e., 15.20\%) climatic regions. For cold climatic conditions, the clear glass gave the highest energy savings (i.e., 18.40\%). The relative benefits of using efficient windows are more pronounced in cooler climate regions than in hotter climates. Double glazed windows filled with some gas compared to air-filled window gives more savings in cold climates, then in hot summer/cold winter regions and least in hot summer/warm winter regions. The thickness of the filled gas has approximately half the impact. Also, installing single low-E, double low-E, and triple low-E windows can reduce overall building consumption by $0.14 \%$, $0.44 \%$, and $0.71 \%$, respectively, compared to general glass windows.

Reinforced concrete (RC) walls, double walls, Plain cement concrete walls (PCCW) reduced the overall energy consumption by $1.66 \%, 0.68 \%, 0.09 \%$, respectively, in a study performed by Ming et al. [28] in an office building using eQUEST. The building envelope's insulating properties and construction quality control the way heat and moisture flow into or out of the building. The building envelope color and other optical properties govern how solar energy is reflected and how thermal energy (heat) is radiated from the building. Windows bring sunlight and the sun's energy into the building. About $50 \%$ of the heating load in residential buildings and $60 \%$ in commercial buildings results from flows through walls, foundations, and the roof [29]. For calculating the Ufactor of the uninsulated portions of the building envelope, ASHRAE 90.1 standard recommends either developing a separate model of each of these assemblies within the energy simulation model or calculating the area-weighted average U-factor for all the assemblies [30].

\subsection{Lighting}

eQUEST does not have the feature to model the occupancy sensors to control the lighting directly. The common workaround as per the recommendation provided ASHRAE standard 90.1-2007 is to reduce the lighting power density or lighting schedule by $10 \%$ and $15 \%$ for facilities with more than 5,000 sq. $\mathrm{ft}$. and less than or equal to 5,000 sq. $\mathrm{ft}$, respectively [30].

Table 4: Power Adjustment Percentages for Automatic Lighting Controls, ASHRAE 90.1

Table G3.2 [30]

\begin{tabular}{|c|c|c|}
\hline Automatic Control Device(s) & $\begin{array}{c}\text { Non-24-h and } \leq \mathbf{5 , 0 0 0} \mathbf{~ f t}^{\mathbf{2}} \\
\left(\mathbf{4 6 0} \mathbf{~ m}^{\mathbf{2}}\right)\end{array}$ & All Other \\
\hline Programmable Timing Control & $10 \%$ & $0 \%$ \\
\hline
\end{tabular}




\begin{tabular}{|c|c|c|}
\hline Occupancy Sensor & $15 \%$ & $10 \%$ \\
\hline $\begin{array}{c}\text { Occupancy Sensor and } \\
\text { Programmable Timing Control }\end{array}$ & $15 \%$ & $10 \%$ \\
\hline
\end{tabular}

Jiafang Song et al. [21] used eQUEST to simulate energy savings analysis of a University library in China. The authors achieved a linear relationship between annual power consumption and lighting power density. The authors found that the yearly energy consumption grew by approximately $10 \%$ for every $5 \mathrm{~W} / \mathrm{m}^{3}$ increase in the lighting power density. A. K. Dilshad et al. [19] used eQUEST to model daylight control in a commercial building and achieved $2.83 \%$ energy saving. Ming et al. [28] found using eQUEST that when the lighting power density was changed from $-50 \%$ to $+50 \%$, energy consumption changes ranges between $-30 \%$ and $31 \%$.

M. Dehghani et al. [24] used eQUEST to calculate energy savings by retrofitting daylight and skylight control systems. The results showed that daylight controls reduce electricity consumption and $\mathrm{CO}_{2}$ consumption but increase natural gas consumption. However, the increase in natural gas usage was insignificant compared to the savings in electricity usage. Overall, the daylight control system saved $10.2 \%$ of overall energy usage, whereas installing skylights on roofs increased the building's overall energy consumption. The daylight control system gave a simple payback period of 2.5 years.

\subsection{Miscellaneous Parameters and Controls}

Various other parameters affect the overall building energy performance. A significant percentage of building energy use is driven directly by operational and occupant habits entirely independent of building design.

Best practices in envelope and lighting design can save about $40 \%$ of total building energy use, while poor practices can increase energy use by about $90 \%$ in all climate zones. When the effects of HVAC system selection are added, best design practices can lead to a 50\% savings, and worst practices can lead to a 60-210\% increase in energy use, depending on climate [20]. Annual energy and peak design loads are more sensitive to internal loads, window systems, temperature setpoints, and HVAC equipment efficiency [31].

In a study performed by K. Mininni et al. [18], energy savings of $10 \%$ of the total miscellaneous equipment electricity usage and about $0.2 \%$ of the overall electricity usage was achieved by 
replacing inefficient equipment and devices with Energy Star-rated appliances in a public building in New York. Reducing the natural gas Domestic Hot Water (DHW) heater setpoint by $10^{\circ} \mathrm{C}$ resulted in energy savings of 3.76\%. Furthermore, installing a demand-controlled ventilation system is estimated to save around $20 \%$ to $30 \%$ of the total energy bill. Moreover, there is a linear relationship between indoor personnel density and annual power consumption in a university building [21].

M. Dehghani et al. [24] studied the energy-saving potential of passive solar measures such as unvented Trombe wall and Photovoltaic (PV) arrays using eQUEST. The results showed that installing an unvented Trombe wall on $50 \%$ of the south wall reduced the overall energy consumption by $9.3 \%$, with a simple payback period of 1.5 years. Thus, significant energy and cost savings can be realized with a PV system, but the total capital investment required is very high, making the simple payback period unattractive.

\subsection{Sensitivity Analysis}

Yunyang Ye et al. [32] performed a detailed sensitivity analysis of nine energy efficiency measures (EEM) for retrofit projects in a medium office building in 15 different climatic regions in the U.S. The standard Regression Coefficient (SRC) sensitivity analysis method was used to evaluate the relative sensitivity of each EEM. The results show that replacing windows (U-value and SHGC), replacing lighting fixtures with higher-efficiency fixtures, and replacing office equipment with higher efficiency equipment are the three EEMs with the highest sensitivity ratios in most climatic zones. Moreover, the sensitivity ratios of some of the EEMs varied by climate. Adding wall and roof insulation have higher sensitivity ratios in cold climates (climate zone 7 and 8). However, replacing a cooling system with a higher efficiency system is more sensitive in hot climatic zones (zones 1A, 2A, and 2B). The SHGC of windows is more sensitive in temperate climatic zones (zones 4A, 4B, and 4C), while the $\mathrm{U}$-factor is more sensitive in hot climatic zones (zones 1A,2A, and $2 \mathrm{~B}$ ), and cold climatic zones (5A, 5B, 6A, 6B, 7, and 8). However, all the nine EEMs studied in the research focused on the building's design parameters only. It did not focus on operating factors like occupancy, plug loads, DCV, zone controls, temperature set-back controls, and many more. 
J. Heller et al. [20] performed a detailed study on the impact of 28 building parameters on building energy performance for 16 different climatic zones in the U.S. The authors changed each variable while all other variables were kept at the baseline values. The variables' range was determined from a range of published building characteristic studies, field research, and professional judgment of the authors. The relative impact of each parameter was measured as a percentage change in energy consumption with respect to the baseline level. One of the main drawbacks of the research is that the range of input values for the parameters is not uniformly distributed. Some parameters have a more considerable range, while some have a smaller range. Such inconsistency in input values will definitely impact sensitivity analysis. Also, no particular statistical sensitivity analysis was performed to account for the variation in input values.

There are some differences between the research study done by J. Heller et al. [20] and this research study. This research evaluates the energy performance of two buildings in the same climatic region, whereas J. Heller et al. [20] performed the study for 16 different climatic regions. An attempt is made in this research to address the drawback in Heller's study by making the range of input values consistent. The baseline values are changed by $\pm 20 \%$ for the quantitative parameters except for temperature setpoint, outdoor air temperature, and lighting power density. Varying the temperature values by $\pm 20 \%$ would be unrealistic even though it would make the range consistent with other parameters. Lighting power density is varied by $\pm 10 \%$ as per the ASHRAE recommendations [30] for the effect of occupancy sensors. Also, a statistical method (Fractional factorial design) has been performed in this study to understand better the relative impacts of individual parameters as well as the interaction effects of some of the parameters. In addition, this research paper evaluates the impact of server load on the energy efficiency of buildings.

\subsection{Thermal Zones}

Defining thermal zones and developing load profiles and schedules in large spaces is a tedious task. ASHRAE 90.1 standard has provided some guidelines to ease the process of assigning thermal zones in a building. For existing buildings, different HVAC zones may be combined to create a single thermal block or identical thermal blocks provided that all of the following conditions are met [30]: 
- The space usage classification is the same throughout the thermal block.

- All HVAC zones in the thermal block adjacent to glazed exterior walls face the same orientation, or their orientations vary by less than 45 degrees.

- All of the zones are served by the same HVAC system or by the same kind of HVAC system.

\subsection{Validation of eQUEST Simulation Model}

Three standards determine the boundary of calibration of the simulation model [33]:

- ASHRAE Guideline 14, 2002

- International Performance Measurement and Verification Protocol (IPMVP)

- Federal Energy Management Program (FEMP)

However, these standards do not describe the methodology to perform the calibration. Several methods have been developed to calibrate the simulation model, but they have not been accepted as standard procedures [33].

As per the ASHRAE guideline 14, 2002, a commercially available hourly computer simulation program is used to create a model of energy use and demand of the facility in a whole building calibrated simulation approach. The model is usually a whole-building model of pre-retrofit conditions. The model is calibrated or checked against actual measured energy use data, demand data, measured weather data, and possibly other operating data. After the model has been calibrated, the model is used to predict the post-retrofit conditions' energy use and demand. The whole building simulation approach can be used when either pre-retrofit or post-retrofit metered data are not available and when energy efficiency measures interact with other building systems and the impact of the interaction needs to be determined. The general steps involved in calibrating whole building simulation models are given below:

- Develop a calibrated simulation plan to select an appropriate simulation program and determine the right calibration approach (yearly, monthly, hourly) and tolerance for calibrated simulation.

- Collect data in detail about the building characteristics, parameters, equipment, operation, utility data, and many more. 
- Develop a simulation model with the data obtained using a simulation program.

- Run and compare the model output to the measured data. Use graphical or statistical tools to compare the results.

- $\quad$ Produce baseline and post-retrofit models and estimate the savings.

One of the crucial parts of building energy modeling is to check the utility bills from the model and match them to the actual bills [18]. It is vital to match the bills on an annual basis as well as a monthly basis. Matching the annual bills allows a more accurate prediction of building energy performance and precise estimation of the savings. The monthly bills can be allowed to vary to some extent because when using eQUEST, it is nearly impossible to accurately portray specific inputs for each month.

A. Dutta et al. [22], [23] used various statistical tests such as t-test, Pearson correlation coefficient, mean absolute error and coefficients of variance of root mean square error (CV(RMSE)) on the actual and simulated energy consumption data to validate and calibrate the simulation model of the building generated by eQUEST. Ming et al. [28] performed a detailed study of energy savings measurement for an office building using eQUEST. They verified the simulation result using the International Performance Measurement and Verification Protocol (IPMVP) Option D. IPMVP is a standardized measurement and verification method to confirm energy-saving measures' energy efficiency. The IPMVP provides four measurement and verification $(\mathrm{M} \& \mathrm{~V})$ options which are similar to the M\&V options in ASHRAE 14 guidelines for M\&V [34].

- Option A: Retrofit isolation (Key parameter isolation)

- Option B: Retrofit isolation (All parameters measurement)

- Option C: Whole Facility (Continuous measurements of entire facility's energy use)

- Option D: Calibrated simulation (Savings are determined through simulations)

The first two options can be used for isolated retrofitting measures, whereas the last two can be used for holistic retrofitting projects. In Option D, the simulated model should be calibrated with monthly or hourly utility billing data. The major challenges associated with Option D are accurate computer modeling and calibration with measured energy data. Xing et al. [35] investigated the predictive accuracy for the major factors in the energy consumption of hotel buildings. They found that the schedules of the internal loads have the most significant impact on the accuracy of the 
simulation model followed by occupancy rate and coefficient of performance (COP) of chillers. The authors used the mean bias error (MBE), and CV(RMSE) to validate the model. The authors accepted results with an error of $\pm 5 \%$ for MBE and $\pm 15 \%$ for CV (RMSE) value.

Results obtained from eQUEST can also be verified by comparing the results from other building energy modeling software. Bellos et al. [36] compared the heating and cooling loads in a building in Athens, Greece using TRNSYS and eQUEST. The study involved comparing the heating and cooling load for the base case and then when various building parameters were changed. For the base case, TRNSYS gave 5\% more heating and cooling loads than eQUEST. Such difference can be attributed to the different ways these two programs calculate the load.

TRNSYS calculates the exact load to keep the temperature at the setpoint level, whereas eQUEST uses standard equipment such as a heat pump covering the loads. TRNSYS chooses to select the material properties in every case, while eQUEST uses a library for the building materials. The authors also performed four parametric studies by changing the infiltration rate, building orientation, insulation thickness, and windows area. Both the programs gave similar results with a low difference in the infiltration rate, building orientation, and window area. As infiltration rate increases, heating load increases, and cooling load decreases.

As the building had more windows facing south than in other directions, the facility experienced

minimum heating load and maximum cooling load when the south azimuth was set at zero degrees. Both the program shows that higher window area leads to lower heating load and higher cooling load. This is because of the solar heat gain through the windows. The main difference between TRNSYS and eQUEST was seen when the insulation thickness was varied. Both the program showed that higher insulation thickness led to lower heating energy consumption. However, eQUEST shows that the cooling load also decreases with an increase in insulation thickness, but TRNSYS shows that the cooling load increases with insulation thickness. Although the difference in values is slight, the results show that the two programs have some discrepancies in how each performs the heat and mass balance calculation.

\subsection{Energy Efficiency of Building Codes}

K. Joshua [37] compared buildings' performance to meet current state energy codes to their performance when meeting alternative building energy standard editions to determine if more strict 
energy codes are cost-effective in achieving savings in energy consumption and carbon emission. The study pointed out that adoption of ASHRAE 90.1-2007 led to savings in energy use, energy costs, and energy-related carbon emissions in the 19 states that have not yet adopted ASHRAE 90.1-2007 state energy code. The average savings in energy usage, energy costs, and carbon emissions were $9.6 \%, 12.2 \%$, and $12.4 \%$, respectively, for ten years. Besides, the average life cycle costs also decreased by $0.7 \%$. However, compared to older versions of ASHRAE 90.1, ASHRAE 90.1-2007 did not improve energy efficiency for all U.S. locations. This is because of the less stringent SHGC rules and simplification of climatic zones in ASHRAE 90.1-2007. The author extended his research to compare state energy codes to a "Low Energy Case" (LEC), where the building's energy efficiency was increased beyond the ASHRAE standards. Such improvement led to more significant energy usage reduction, energy-related costs, and carbon emissions in all 50 states than ASHRAE 90.1-2007.

ASHRAE, US Green Building Council (USGBC), and Illuminating Engineering Society (IES) have developed ASHRAE standard 189.1-2009 for a high-performance building. ASHRAE 90.12010 is the baseline or the minimum energy efficiency standard for commercial buildings, whereas ASHRAE 189.1-2009 is a more stringent code for building with higher energy efficiency than the ASHRAE 90.1-2010. Leadership in Energy and Environmental Design (LEED) rating system developed by USGBC is approximately 32\% more efficient than ASHRAE 90.1-2004 [38].

\subsection{Retro-commissioning/Re-commissioning}

Commissioning is the process of ensuring that systems are designed, installed, functionally tested, and capable of being operated and maintained according to the owner's operational needs. Retrocommissioning is a form of commissioning applied to existing buildings that have never been commissioned, whereas re-commissioning applies to a building that has been commissioned previously. According to Energy Star's building manual, re-commissioning is performed every three to five years to maintain top levels of building performance and after other stages of the upgrade process to identify new opportunities for improvement. The manual also gives results from an exhaustive study of retrofitting in 224 new and existing buildings. It shows that the median $15 \%$ energy savings were achieved with the median cost of commissioning of $\$ 0.27$ per square, giving a simple payback period of 0.7 years. The re-commissioning projects were found to be cost-

effective even for relatively new buildings. The most common problem was found to be related to 
the HVAC system. Over time, temperature sensors or thermostats may experience sensor drift. Such sensors can increase heating and cooling load and cause occupant discomfort. According to the occupancy schedule, several tuning actions like calibrating the sensors, regular inspection of dampers and valves, and adjustment of HVAC schedule can help reduce HVAC-related costs by $30 \%$. Also, the accumulation of dirt decreases the heat transfer surfaces' efficiency and increases pressure loss across filters. Regularly cleaning coils and filters can reduce fan or pump energy consumption up to $10 \%$ [39].

According to a report by Jennifer Thorne and Steven Nadel [40], most new buildings in the U.S. are not commissioned during design, construction, and start-up. Also, as buildings age, changes in their use and operation can lead to degraded building performance. In a study performed by Lawrence Berkeley National Laboratory (LBNL) on 60 commercial buildings, more than half had problems with the control systems, $40 \%$ had HVAC system problems, $30 \%$ had sensors that were not functioning correctly, $25 \%$ had energy management systems, economizers, and variable speed drives that did not operate properly, and $15 \%$ were missing equipment. The report states that proper retro-commissioning can yield $5 \%$ to $20 \%$ energy savings with a typical payback of 2 years or less.

John et al. [41] investigated how long the savings from 100 retro-commissioning (RCx) measures lasted. The three RCx measures failed after the first year, nine failed in the second year, and seven failed in the fourth year. Cumulatively, this represented failure rates of $3 \%, 13 \%$, and $20 \%$ for the first three years, respectively. The authors linearly extrapolated the data to find that $50 \%$ of the measures failed in 8 years. Such data highlight the need for regular recommissioning.

\subsection{Degradation Aspects of Building Parameters}

As the building ages, its components degrade in their quality due to wear, decay, corrosion, usage, climatic conditions, and many other reasons. The degradation rate depends upon the building operation, maintenance practice, quality of the installed materials, and climatic conditions. Also, different parameters have a different life span, so the frequency of replacement will vary for different components of the building. For example, some light bulbs have very short life span compared to other components like doors and windows and need to be replaced every few years. Whereas parameters like windows, doors and insulation last for decades if maintained properly. 
In a review paper by Georgios et al. [42], the authors provided the summary of HVAC components and building envelope degradation. It is stated that in 20 years, boiler efficiency degrades by $5 \%$ to $24 \%$, chiller COP degrade by $4 \%$ to $30 \%$, split AC EER will degrade by $18 \%$ to $33 \%$, electric water heater efficiency will degrade by $2 \%$ to $4 \%$, and general HVAC efficiency will degrade by $30 \%$. The following two equations are used in several studies to predict the degradation of various HVAC components, including DX coils, chillers, boilers, heat pumps, constant and variablevolume fans, and gas heating coils [42]:

$$
\begin{gathered}
E F F=B a s e E F F(1-M . A g e) \\
\boldsymbol{E F F}=\boldsymbol{B a s e \boldsymbol { E F }}(\mathbf{1}-\boldsymbol{M})^{\wedge} \boldsymbol{A g e}
\end{gathered}
$$

Where, EFF is efficiency (SEER, EER, HSPF, AFUE) of the HVAC component at a certain age, BaseEFF is the original/nominal efficiency of the HVAC component, and $\mathrm{M}$ is the degradation factor which is dependent upon the technology and maintenance practice, and Age is the age if the HVAC component in years. The maintenance factor $(\mathrm{M})$ is 0.01 for expertly maintained equipment and 0.03 for unmaintained equipment [43].

Also, polyisocyanurate insulation degrades in its thermal resistivity by $12 \%$ to $27 \%$ in 2 to 6 years, extruded polystyrene degrades by $18 \%$ to $26 \%$ in 3 to 15 years, polyurethane insulation degrades by $14 \%$ to $17 \%$ in 15 years, and vacuum insulation panel degrade by $10 \%$ to $80 \%$ in 5 to 31 years [42].

Karen et al. [43] evaluated the air conditioner performance degradation in 56 homes in Florida. The results showed that the median compressor age was nine years and the average air handler unit was 9.5 years, and the overall typical system life of about 18 years. Also, it was found that the cooling-related air conditioning performance falls between $3 \%$ to $7 \%$ per year on average. The air handler age was significant to the degradation rate at a $95 \%$ confidence interval. The capacity (size) of the HVAC system was found to be the most significant factor affecting the degradation rate. Higher capacity systems operated at high load factors appear to degrade more quickly and have a shorter life expectancy. Also, the degradation rate decreased with increasing the EER/SEER rating of the HVAC system.

Doors and windows typically last for the lifetime of the building, and their need for replacement is seldom. However, doors and windows too degrade over time, and their replacement might be 
sought in order to improve the energy performance of the building. The service life of wood frame windows and doors can be different for buildings in different climatic conditions. According to Athena Sustainable Materials Institute, wood frame windows can survive the life of the building if adequately maintained but tend to last 15 to 16 years on average. The coating on wood frame windows and doors plays an essential role in protecting against the weather. The maintenance interval (repainting/recoating) of the coatings depend upon the exposure to the environmental conditions and is in the range of 4 to 7 years [44].

For the lighting system, the life cycle is shorter compared to other components of the building. For example, an incandescent bulb has a life expectancy in the range of 750 to 2,000 hours, halogen lamps have a life span of 2,000 to 4,00 hours, and Compact Fluorescent Light (CFL) Bulbs lasts around 8,000 hours. LED lamps, however, have a higher lifespan and last for around 50,000 hours. In incandescent lamps, the filament which heats up and emits light gets oxidized as it is used. In LED lamps, the diodes degrade over time, and the light gets continuously dimmed before the lamp fails.

\subsection{Thermal Inertia in Buildings}

Thermal inertia can influence the energy performance of buildings. The mass of the building envelope and the interior equipment affect the energy performance of the building. The thermal inertia effect causes a delay in heating the building and slows down the temperature decay during the night [45]. The building envelope can gain/lose energy to the building's outside environment/inside space depending upon the temperature difference between the indoor and outdoor conditions. However, the amount of energy gained or lost from the envelope or interior mass of the building also depends upon the mass of the envelope or equipment. For example, when the interior spaces are heated to a certain temperature setpoint, the envelope mass (roofs, walls, and floors) and interior mass (partition walls, furniture, and other equipment) will heat through the air. Also, the envelope will store energy from solar radiation before transferring it to the indoor air. The higher the mass, the higher the amount of energy it can store. Exposed heavyweight construction with a high specific heat capacity can dampen and delay transient heat flows in buildings [45]. The thermal mass of construction can also have potential negative impacts on the energy performance of a building. In intermittent thermostat setpoints, heavy mass might require 
more time to reach the cooling or heating setpoint temperature. Thus, additional energy is required to reach the temperature setpoint in a building.

Although eQUEST does consider the effect of envelope mass and the mass of the interior equipment in calculating energy consumption, it does not report the effect of thermal inertia on the energy performance of the building. In the building creation wizard and the detailed data edit mode in eQUEST, the building envelope can be created as layers of materials of various thicknesses, densities, and U-value. Also, the fraction of the floor covered by furniture and the type of furniture (heavy or light) can be specified. However, other equipment, their mass, and their locations cannot be specified in eQUEST.

Stijn et al. [45] explored the dynamic effects of various construction assemblies and the effect of different temperature control strategies concerning the thermal mass. The study demonstrated that the impact of the thermal mass on the heating demand is limited in a temperate climate. Also, lightweight timber frame construction displayed an annual heating energy demand of up to $6.6 \%$ higher than a heavy mass concrete and limestone construction in the case of fixed thermostat setpoints. The lower energy consumption of the heavy mass construction can be explained by their ability to better store heat gains from occupants and their activities and solar gains than lightweight constructions. If the thermostat schedule is highly varying, the energy use of the lightweight construction can have a lower heating energy consumption, with a reduction up to $4.5 \%$. The lower energy demand for intermittently heated buildings can be explained by their faster cool down. For the fixed thermostat setpoint, reducing the thermal mass of construction led to an average of $4.80 \%$ increase in energy consumption. However, the overall effect of the thermal inertia on the yearly heating energy consumption was relatively moderate for the moderate climatic condition. The thermal mass was a less influential factor than other design characteristics such as thermal insulation, window size, and glazing properties.

K.W. Childs et al. [46] have reviewed the past research studies and have summarized the findings. One of the study results showed that the two factors that influence the mass effect the most are the mass relative to the insulation and the rate of heat loss relative to internal heat gains by a building. A mass layer on the inside permitted a more significant reduction in the thermal resistance than the mass on the outside. Also, a building with a low rate of heat loss relative to internal gains allowed a more significant reduction than a building with high relative loss. Another study showed 
that the heavy structure had $4 \%$ to $6 \%$ higher peak heating loads than the light structure but had $0 \%$ to $6 \%$ lower peak cooling loads. The light structure with setback controls had the lowest annual heating loads, and the heavy structure with setback controls had lower annual cooling energy use. Moreover, another study concludes that insulation outside of thermal capacitance offers energy savings for continuously heated buildings. While for intermittent heating, inside placement is preferable.

\subsection{Conclusion}

This chapter reveals the prevalence of research works in the field of building energy modeling using various simulation software. The energy efficiency of building energy codes, retrocommissioning, and validation methods of energy modeling has been discussed. It can be seen that numerous research studies evaluating the energy performance of buildings exist currently. Most of the prevailing research focuses on design parameters only, and very few have evaluated operating parameters' impact. Also, the quality of building components degrades or fails over time, and not recognizing them can significantly impact the building's energy performance.

In comparison, retro-commissioning and re-commissioning can enhance the energy efficiency of existing buildings. The inability to incorporate such factors in energy modeling will result in an inaccurate portrayal of the building and give the wrong output. However, minimal research is performed to identify the main parameters affecting the building energy performance using sensitivity analysis and simulation tool eQUEST. This need has been addressed in this research by evaluating the impact of various building parameters on whole-building energy performance to identify the top three building parameters affecting the building energy performance. The lowperformance case is used to reflect a building that has its components degraded over time due to aging, improper operation, or lack of maintenance. A high-performance scenario reflects the building which has recently been upgraded or recommissioned, or retro-commissioned. 


\section{Research Methodology}

\subsection{Overview of the Research Approach}

The research aims to identify the top three building parameters that impact building energy performance the most. For this purpose, data collected from two fully functional commercial buildings in Fairmont, WV, has been used to generate a baseline simulation model in eQUEST. The baseline model is tuned and validated with the actual utility bill over a year. In order to evaluate the impact of various building parameters on the building's energy performance, baseline values of parameters to be studied are varied to two levels: Low values and High values. The top three parameters with the highest impact on building energy performance are identified. The overview of the research methodology is shown in Figure 2. 


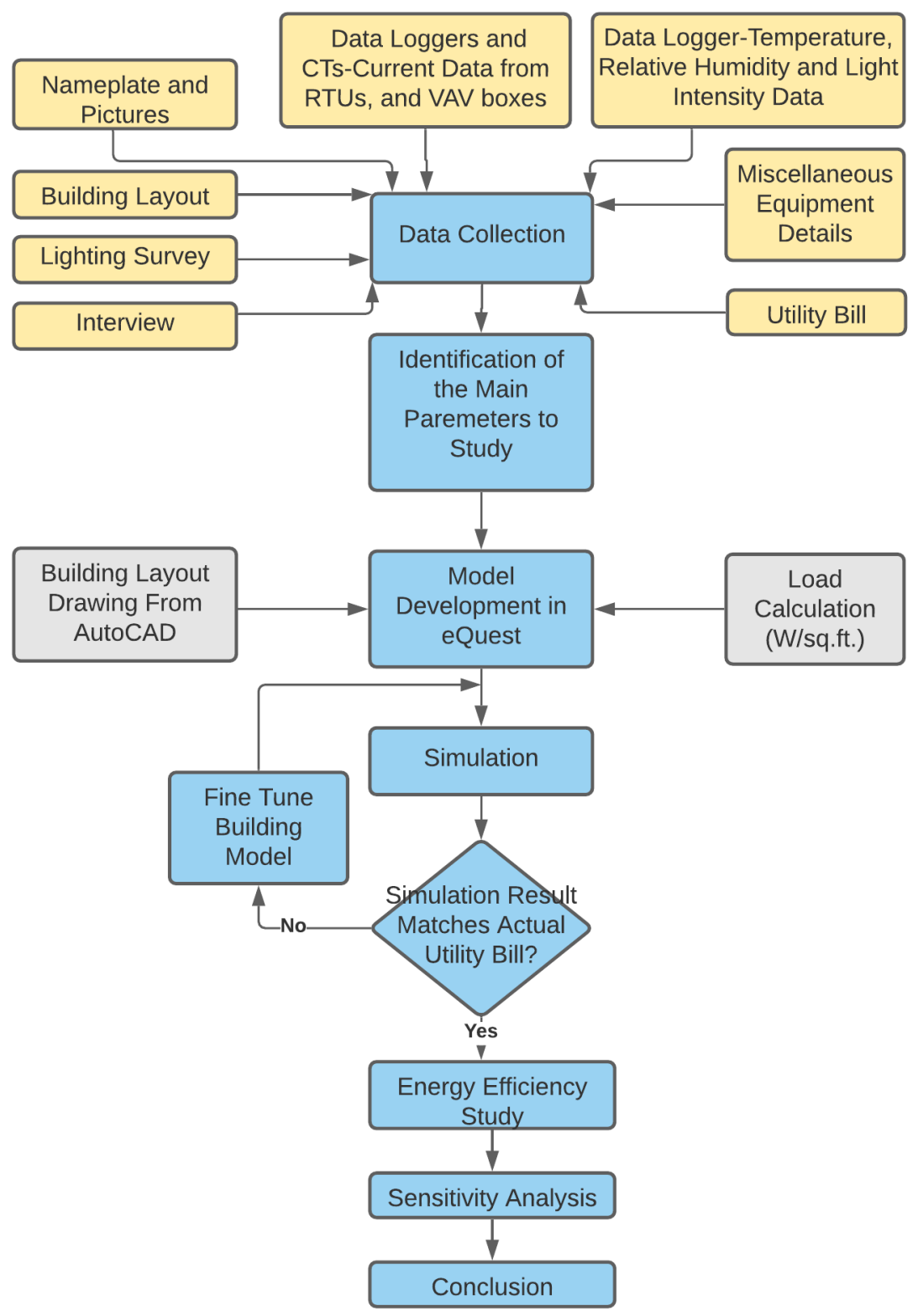

Figure 2: Overview of Research Methodology

\subsection{Data Collection}

Detailed data were collected on various building parameters during the two-day energy assessment of the facility. A lighting survey was carried out to determine the current energy consumed by lighting. As the building has a high window-to-wall ratio (WWR), it was identified that there could be substantial energy savings opportunities by implementing daylight controls during the assessment. Pictures of the existing Roof Top Units (RTUs), VAV boxes, auxiliary A/C systems, 
and water heaters nameplates were taken. Data of current being drawn by the RTUs and VAV boxes were collected with data loggers and current transducers (CTs) over a week. The CTs collected and recorded the electrical current drawn at 16 seconds intervals for one week. At the time of installation of the CTs, an instantaneous power factor (PF), voltage (V), and current (Amps) were measured with the help of a multimeter and were recorded. Also, the room temperature profile of some rooms was measured with data loggers over a week. The current drawn by the VAVs and the RTUs help understand the existing operating conditions of those units, and the temperature data can be used to check how well the thermostat responds to the temperature in the room. The recorded data was uploaded to HOBOware ${ }^{\circledR}$ software, from which graphs were obtained. Such data is crucial for analysis and in identifying energy-saving opportunities.

Moreover, a preliminary survey of the existing miscellaneous energy-consuming equipment like computers, servers, freezes, and microwaves was carried out. The building layout was provided in electronic format by the plant personnel. The details of the building's operations and schedules were collected from the interview with the plant personnel. The utuility bills for both the buildings were collected for the period of September,2019 to August,2020.

\subsection{Determination of Parameters to be Studied}

Different building parameters that include design, control, and building operation, and one external parameter (weather condition) have been selected for the study. Various parameters that affect the energy performance of buildings are discussed in Chapter 1. A literature survey has been carried out on those parameters and controls and is mentioned in Chapter 2. These parameters were found to have a significant impact on the energy performance of the building. The major parameters to be studied are:

1. HVAC system

- Energy Efficiency Ratio (EER)

- The overall efficiency of the drive motor, supply fan, and motor

- Supply fan static pressure

- Economizer

2. Building envelope and infiltration 
- Roof insulation

- Wall insulation

- Infiltration

3. Window and door

- U-value

- $\mathrm{SHGC}$

- Overhangs

- Fins

4. Lighting system

- $\quad$ Lighting power density (LPD)

- Daylight control

5. Thermostat setpoint and setback controls

- Cooling setpoint

- Heating setpoint

- Temperature setback control

6. Demand controlled ventilation (DCV)

7. Occupancy and plug load

- Occupancy

- Plug load (Server Room)

8. Building orientation

9. Climatic condition

- Dry bulb temperature

\subsubsection{Dependent and Independent Parameters}

Some of the parameters listed above are independent, while some are dependent on others. Parameters like cooling and Heating setpoint, setback control, and economizer are dependent on climate. The dimensions of the fins and overhangs are dependent on the size of the windows and the average position of the sun in the summer and winter. The amount of insulation required is also determined by the climatic condition. For example, a building in a moderate climate will need lesser insulation than a building in an extreme climate. The operation of plug loads, thermostat setpoint, light power density is dependent upon the occupancy level. Increasing the occupancy 
level will increase the energy consumption associated with heating and cooling the spaces and plug loads.

Also, task lighting demands might increase with increasing occupancy in a building. The daylighting potential is also dependent upon the climatic condition, the area covered by glass windows and doors, and the visible transmittance of the windows and doors. On a clear sunny day, daylighting potential is maximum, whereas it is minimum on a cloudy and rainy day. The selection of windows and doors and hence the U-value and SHGC value of the glass windows and doors might be dictated by the climatic conditions. Other parameters like EER, overall efficiency of supply fan and motor, server room, and dry bulb temperature are independent parameters.

\subsection{Model Development}

eQUEST version 3.65 was used to develop the building model. When the eQUEST software is opened, it offers two wizards to choose from.: Schematic Design Wizard (SDW) and Design Development Wizard (DDW). The SDW is generally used for pre-design phase studies of smaller/simple structures with simple schedules and limited data. The DDW is used for later stages of design or studies of existing buildings of complex shapes and sizes with complicated schedules. Thus, more input of data is required in the DDW. Since the study is being performed on an existing building with detailed data availability, the DDW was selected. The wizard opens a set of seven windows that require general information about the building address, project information, and several seasons. Then the wizard takes users to the navigator, where users can input more information about the building. The values of the parameters for building A and building B are given in Table 5 and Table 6, respectively. 
Table 5:Baseline Values for Building A

\begin{tabular}{|c|c|c|c|}
\hline SN & Block & Description & Baseline Value \\
\hline 1 & \multirow{4}{*}{ HVAC } & EER & 9 \\
\hline 2 & & $\begin{array}{l}\text { The overall efficiency of supply } \\
\text { fan and motor }\end{array}$ & $53 \%$ \\
\hline 3 & & Supply fan static pressure & 2.97 inch water \\
\hline 4 & & Economizer & None \\
\hline 5 & \multirow{3}{*}{ Building Envelope } & Roof Insulation & $25.693\left(\mathrm{~h} \mathrm{ft}^{2}{ }^{\circ} \mathrm{F}\right) / \mathrm{Btu}$ \\
\hline 6 & & Wall Insulation & $17.561\left(\mathrm{~h} \mathrm{ft}^{2}{ }^{\circ} \mathrm{F}\right) / \mathrm{Btu}$ \\
\hline 7 & & Infiltration & $0.038 \mathrm{cfm} / \mathrm{sq} . \mathrm{ft}$. \\
\hline 8 & \multirow{4}{*}{$\begin{array}{l}\text { Windows and } \\
\text { Doors }\end{array}$} & U-value & $0.4 \mathrm{Btu} /\left(\mathrm{h} \mathrm{ft}^{2}{ }^{\circ} \mathrm{F}\right)$ \\
\hline 9 & & SHGC & 0.62 \\
\hline 10 & & Overhangs & None \\
\hline 11 & & Fins & None \\
\hline 12 & \multirow{2}{*}{ Lighting } & Lighting Power Density (LPD) & Different for each space \\
\hline 13 & & Daylight Control & None \\
\hline 14 & \multirow{3}{*}{$\begin{array}{l}\text { Thermostat } \\
\text { Setpoint }\end{array}$} & Cooling Setpoint & $65^{\circ} \mathrm{F}$ \\
\hline 15 & & Heating Setpoint & $75^{\circ} \mathrm{F}$ \\
\hline 16 & & Setback Control & None \\
\hline 17 & $\begin{array}{c}\text { Demand Controlled } \\
\text { Ventilation }\end{array}$ & $\mathrm{DCV}$ & None \\
\hline 18 & \multirow{2}{*}{$\begin{array}{l}\text { Occupancy and } \\
\text { Plug Loads }\end{array}$} & Server Room & $\begin{array}{c}3 \text { server rooms } \\
\text { (44w/sq.ft; } 42 \mathrm{w} / \mathrm{sq} . \mathrm{ft} ; 36.2 \mathrm{w} / \mathrm{sq} . \mathrm{ft})\end{array}$ \\
\hline 19 & & Occupant Density & Different for each space \\
\hline 20 & Climatic conditions & Dry Bulb Temperature & As per Weather data \\
\hline
\end{tabular}


Table 6:Baseline Values for Building B

\begin{tabular}{|c|c|c|}
\hline Block & Description & Baseline Value \\
\hline \multirow{4}{*}{ HVAC } & EER & 9 \\
\hline & $\begin{array}{l}\text { Overall efficiency of supply fan and } \\
\text { motor }\end{array}$ & $53 \%$ \\
\hline & Supply fan static pressure & $\begin{array}{l}\text { 4.55-inch water.; } 5.86 \text {-inch } \\
\text { water; } 4.39 \text { inch water }\end{array}$ \\
\hline & Economizer & None \\
\hline \multirow{3}{*}{ Building Envelope } & Roof Insulation & $26.294\left(\mathrm{~h} \mathrm{ft}^{2}{ }^{\circ} \mathrm{F}\right) / \mathrm{Btu}$ \\
\hline & Wall Insulation & $24.143\left(\mathrm{~h} \mathrm{ft}^{2}{ }^{\circ} \mathrm{F}\right) / \mathrm{Btu}$ \\
\hline & Infiltration & $0.038 \mathrm{cfm} / \mathrm{sq} . \mathrm{ft}$. \\
\hline \multirow{4}{*}{ Windows and Doors } & U-value & $0.4 \mathrm{Btu} /\left(\mathrm{h} \mathrm{ft}^{2}{ }^{\circ} \mathrm{F}\right)$ \\
\hline & SHGC & 0.62 \\
\hline & Overhangs & None \\
\hline & Fins & None \\
\hline \multirow{2}{*}{ Lighting } & Lighting Power Density (LPD) & Different for each space \\
\hline & Daylight Control & None \\
\hline \multirow{3}{*}{ Thermostat Setpoint } & Cooling Setpoint & $65^{\circ} \mathrm{F}$ \\
\hline & Heating Setpoint & $75^{\circ} \mathrm{F}$ \\
\hline & Setback Control & None \\
\hline $\begin{array}{c}\text { Demand Controlled } \\
\text { Ventilation }\end{array}$ & $\mathrm{DCV}$ & None \\
\hline \multirow{2}{*}{$\begin{array}{l}\text { Occupancy and Plug } \\
\text { Loads }\end{array}$} & Server Room & $\begin{array}{c}3 \text { server rooms } \\
\text { (63w/sq.ft; } 16.5 \mathrm{w} / \mathrm{sq} . \mathrm{ft})\end{array}$ \\
\hline & Occupant Density & Different for each space \\
\hline Climatic conditions & Dry Bulb Temperature & As per Weather Data \\
\hline
\end{tabular}

\subsubsection{Design Development Wizard (DDW)}

In the DDW, preliminary data about the building were entered. In addition, necessary information about the building shell, HVAC systems, domestic water heating, utility information, and heat pumps must be entered.

For creating the building shell components, information about the building area, layout, and zones must be described or constructed in the first few screens. Also, information about shell height, building envelope, details of insulation are entered. The eQUEST library has some simple layout options for building layout. However, the building being studied has a complex V-shaped shell. Therefore, the building's floorplan is drawn in AutoCAD software and then imported into the eQUEST. 
After the information about the building shell is entered, load profiles and their schedules are entered in the design development wizard's subsequent screens. eQUEST requires the input of load in watt per square foot for various space types. To calculate the load in watts per square foot, the total wattage of each type of load (for example, lighting load, office equipment, servers) is calculated and then divided by the total area of the floor space. There are 26 screens in the Design Development Wizard used to input detailed information about the building. The building model generated after the Design Development Wizard is given in Figure 3 and Figure 4.

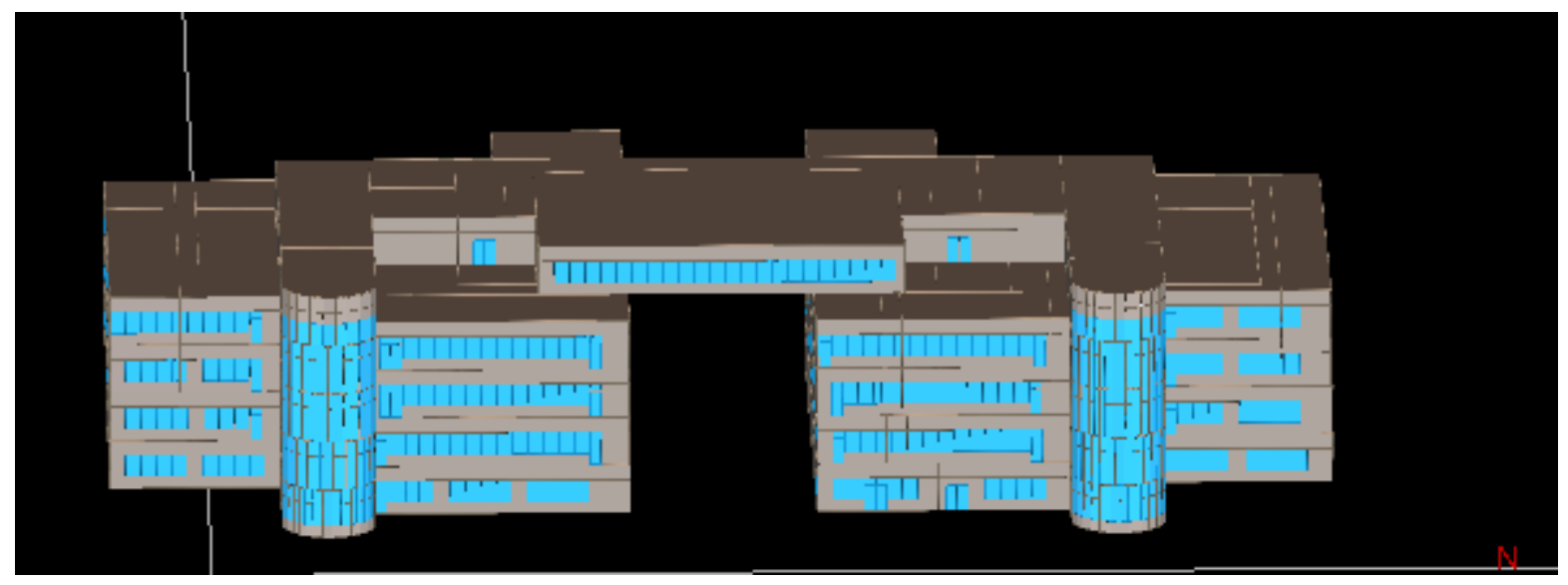

Figure 3:eQUEST Model of Building A

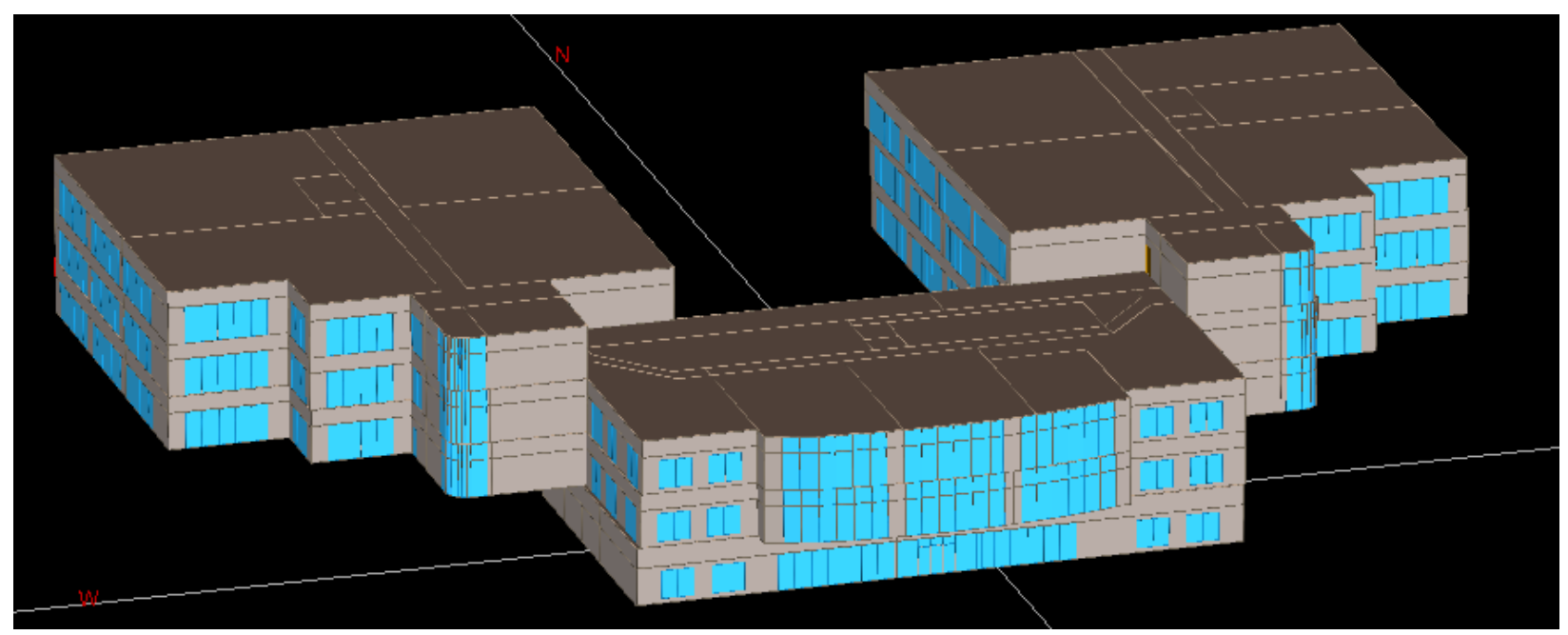

Figure 4: eQUEST Model of Building B

\subsubsection{Detailed Data Edit Mode}


The detailed data edit mode is used to make final adjustments to the building parameters. In-depth information about the building parameters can be entered in this mode. However, switching back to any wizards will undo all the changes made in this mode. Thus, the detailed data edit mode should only be used after all the parameters have been well-defined in the wizard mode. In this paper, the detailed data edit mode is used in adding more detailed information about the building parameters after the completion of the DDW. Then it is used in tuning the building model to match the actual energy usage data. Finally, it is also used while performing energy efficiency studies.

\subsection{Model Calibration}

After the generation of the building model, the building's energy consumption is simulated for a year. If the simulated annual energy consumption result matches the actual energy consumption data, the model is used to perform energy efficiency studies by implementing various energy efficiency measures. If the monthly simulation result does not match the actual utility bill, then the building parameters are explored in more detail in the detailed data edit mode. Normalized Mean Bias Error (NMBE) and Coefficient of Variation of Root Mean Square Error CV(RMSE) values were used to validate the model. ASHRAE Guidelines, Federal Energy Management Program (FEMP), and IPMVP use CV(RMSE) with NMBE to verify the accuracy of the models [47]. The NMBE and CV(RMSE) were calculated using the equation given below:

$$
\begin{gathered}
N M B E=\frac{1}{\overline{A i}} \frac{\sum_{i}^{n}(A i-S i)}{n} \\
C V(R M S E)=\frac{1}{\overline{A i}} \sqrt{\frac{\sum_{(A i-S i)^{2}}}{n}}
\end{gathered}
$$

The actual and simulated monthly energy consumption for Building A and Building B is given in Figure 5 and Figure 6. In addition, the calibration criteria of the FEMP, ASHRAE guideline 14, and IPMVP is given in Table 7. 


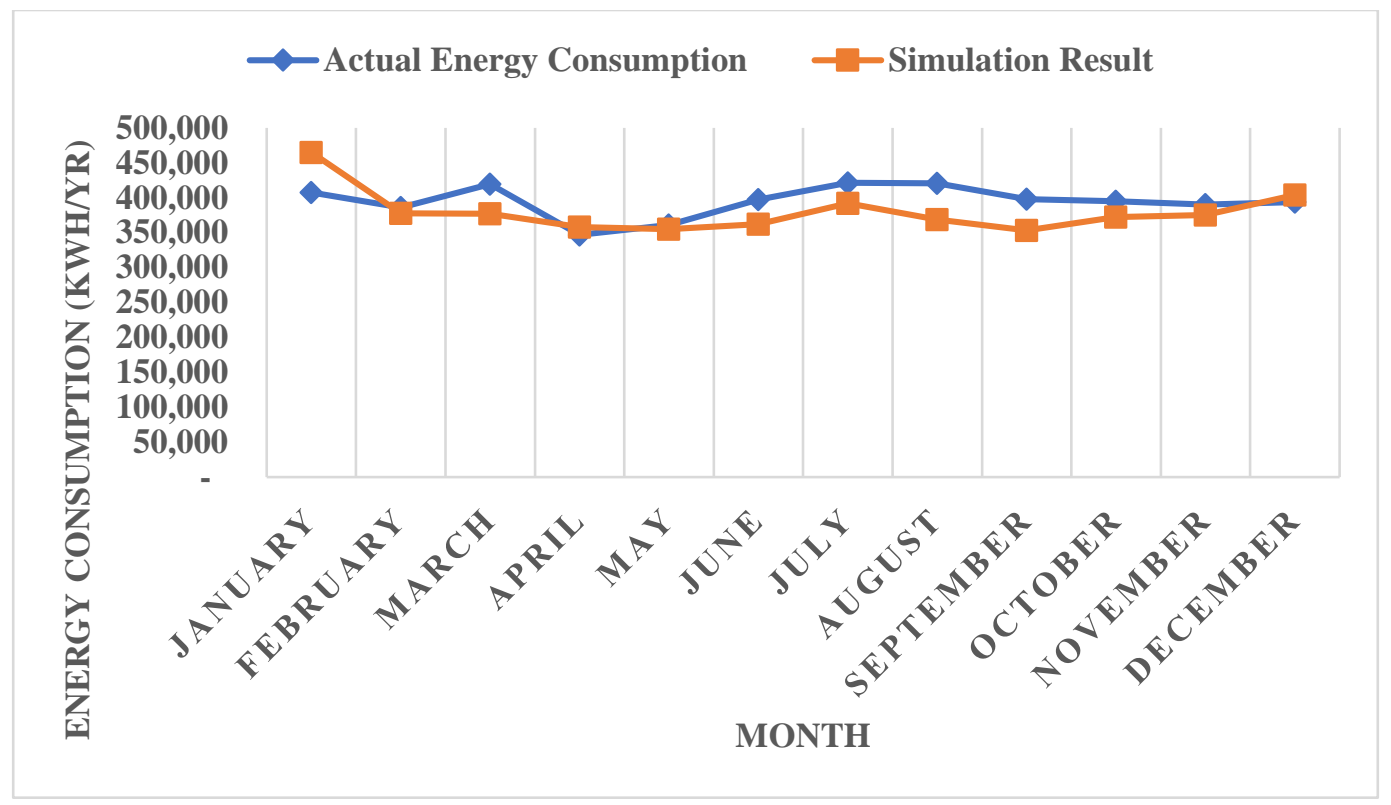

Figure 5: Actual vs. Simulated Energy Consumption of Building A

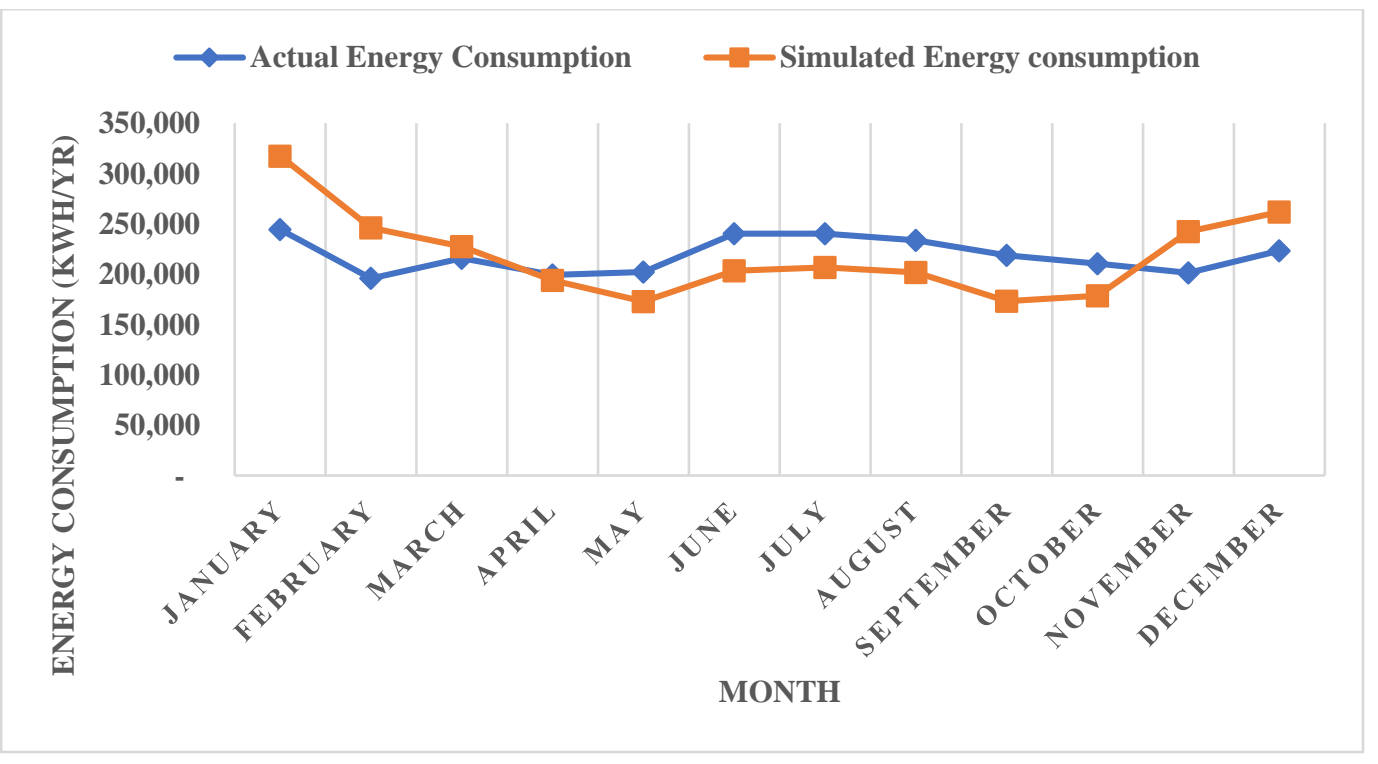

Figure 6: Actual vs. Simulated Energy Consumption of Building B

Table 7: Calibration Criteria of the FEMP, ASHRAE guideline 14 and IPMVP

\begin{tabular}{|c|c|c|c|c|c|c|}
\hline \multicolumn{2}{|c|}{ Index } & $\begin{array}{c}\text { FEMP } \\
\text { criteria }\end{array}$ & $\begin{array}{c}\text { ASHRAE } \\
\text { Guideline } \\
\mathbf{1 4}\end{array}$ & IPMVP & $\begin{array}{c}\text { Building } \\
\text { A }\end{array}$ & $\begin{array}{c}\text { Building } \\
\text { B }\end{array}$ \\
\hline \multirow{2}{*}{ Monthly } & NMBE & $\pm 5 \%$ & $\pm 5 \%$ & $\pm 20 \%$ & $3.7 \%$ & $0.0001 \%$ \\
\cline { 2 - 7 } & CV(RMSE) & $15 \%$ & $15 \%$ & - & $8.3 \%$ & $9.7 \%$ \\
\hline
\end{tabular}




\subsection{Energy Efficiency Study}

After the building model is fine-tuned, the selected building parameters' impact on the building's energy consumption is evaluated. The values for the parameters are varied for two levels. These values are given in Table 8 and Table 9.

Table 8: Parameter Values At Two Levels for Building A

\begin{tabular}{|c|c|c|c|c|}
\hline $\mathbf{S N}$ & Block & Description & Low & High \\
\hline 1 & \multirow{4}{*}{ HVAC } & EER & 7.2 & 10.8 \\
\hline 2 & & $\begin{array}{c}\text { Overall efficiency of } \\
\text { supply fan and } \\
\text { motor }\end{array}$ & $42.4 \%$ & $63.6 \%$ \\
\hline 3 & & $\begin{array}{l}\text { Supply fan static } \\
\text { pressure }\end{array}$ & 2.38-inch water & 3.564-inch water \\
\hline 4 & & Economizer & None & $\begin{array}{l}\text { Dual Temperature } \\
\left(\mathrm{DP} \text { low }=42^{\circ} \mathrm{F}\right)\end{array}$ \\
\hline 5 & \multirow{3}{*}{$\begin{array}{l}\text { Building } \\
\text { Envelope }\end{array}$} & Roof Insulation & $\begin{array}{c}20.5544 \\
\left(\mathrm{~h} . \mathrm{ft}^{2} .{ }^{\circ} \mathrm{F}\right) / \mathrm{Btu} \\
\end{array}$ & $\begin{array}{c}30.8316 \\
\left(\mathrm{~h} . \mathrm{ft}^{2} .{ }^{\circ} \mathrm{F}\right) / \mathrm{Btu} \\
\end{array}$ \\
\hline 6 & & Wall Insulation & $14.0488\left({\mathrm{~h} . \mathrm{ft}^{2} .}^{\circ} \mathrm{F}\right) / \mathrm{Btu}$ & $21.0732\left(\mathrm{~h} . \mathrm{ft}^{2} .{ }^{\circ} \mathrm{F}\right) / \mathrm{Btu}$ \\
\hline 7 & & Infiltration & $0.0304 \mathrm{cfm} / \mathrm{sq} . \mathrm{ft}$ & $0.0456 \mathrm{cfm} / \mathrm{sq} . \mathrm{ft}$ \\
\hline 8 & \multirow{4}{*}{$\begin{array}{l}\text { Windows and } \\
\text { Doors }\end{array}$} & U-value & $\begin{array}{c}0.32 \\
\mathrm{Btu} /\left(\mathrm{h} . \mathrm{ft}^{2}{ }^{\circ} \mathrm{F}\right) \\
\end{array}$ & $0.48 \mathrm{Btu} /\left(\mathrm{h} . \mathrm{ft}^{2} .{ }^{\circ} \mathrm{F}\right)$ \\
\hline 9 & & SHGC & 0.496 & 0.744 \\
\hline 10 & & Overhangs & None & $\mathrm{L}=2 \mathrm{ft} ; \mathrm{h}=1.03 \mathrm{ft}$ \\
\hline 11 & & Fins & None & $0.5 \mathrm{ft}$ distance, $1 \mathrm{ft}$ deep \\
\hline 12 & \multirow{2}{*}{ Lighting } & $\begin{array}{l}\text { Lighting Power } \\
\text { Density (LPD) }\end{array}$ & $\begin{array}{c}10 \% \text { less than the } \\
\text { base value }\end{array}$ & $\begin{array}{l}10 \% \text { more than the base } \\
\text { value }\end{array}$ \\
\hline 13 & & Daylight Control & None & $\begin{array}{c}\text { Two photocells per zone; } \\
\text { switched } 2 / 3-1 / 3 \text {-off }\end{array}$ \\
\hline 14 & \multirow{3}{*}{$\begin{array}{l}\text { Thermostat } \\
\text { Setpoint }\end{array}$} & Cooling Setpoint & $60^{\circ} \mathrm{F}$ & $70^{\circ} \mathrm{F}$ \\
\hline 15 & & Heating Setpoint & $70^{\circ} \mathrm{F}$ & $80^{\circ} \mathrm{F}$ \\
\hline 16 & & Setback Control & None & $\begin{array}{l}\text { Unoccupied (heating: } 68^{\circ} \mathrm{F} \text {; } \\
\text { cooling } 75^{\circ} \mathrm{F} \text { ) }\end{array}$ \\
\hline 17 & DCV & $\mathrm{DCV}$ & None & $\begin{array}{c}\text { DCV sensor present inside } \\
\text { zones }\end{array}$ \\
\hline 18 & \multirow{2}{*}{$\begin{array}{l}\text { Occupancy } \\
\text { and Plug } \\
\text { Loads }\end{array}$} & Server Room & $\begin{array}{c}\text { 44w/sq.ft; } 42 \mathrm{w} / \mathrm{sq} . \mathrm{ft} ; \\
36.2 \mathrm{w} / \mathrm{sq} . \mathrm{ft} \\
\end{array}$ & 0 \\
\hline 19 & & Occupant Density & $\begin{array}{c}20 \% \text { less than the } \\
\text { base value }\end{array}$ & $\begin{array}{l}\text { more } 20 \% \text { more than the } \\
\text { base value }\end{array}$ \\
\hline 20 & $\begin{array}{c}\text { Climatic } \\
\text { Conditions } \\
\end{array}$ & $\begin{array}{c}\text { Dry Bulb } \\
\text { Temperature }\end{array}$ & $-2^{\circ} \mathrm{F}$ from baseline & $+2^{\circ} \mathrm{F}$ from baseline \\
\hline
\end{tabular}


Table 9: Parameter Values At Two Levels for Building B

\begin{tabular}{|c|c|c|c|c|}
\hline $\begin{array}{l}\mathbf{S} \\
\mathbf{N}\end{array}$ & Block & Description & Low & High \\
\hline 1 & \multirow{3}{*}{ HVAC } & EER & 7.2 & 10.8 \\
\hline 2 & & $\begin{array}{l}\text { The overall efficiency of } \\
\text { supply fan and motor }\end{array}$ & $42.4 \%$ & $63.60 \%$ \\
\hline 3 & & Supply fan static pressure & $\begin{array}{c}\text { 3.64;4.688;3.512 inch } \\
\text { water }\end{array}$ & $\begin{array}{l}5.48 ; 7.03 ; 5.27 \\
\text { inch water }\end{array}$ \\
\hline 4 & \multirow{3}{*}{$\begin{array}{l}\text { Building } \\
\text { Envelope }\end{array}$} & Roof Insulation & $21.05\left(\mathrm{~h} . \mathrm{ft}^{2} .{ }^{\circ} \mathrm{F}\right) / \mathrm{Btu}$ & $\begin{array}{c}31.55 \\
\left(\text { h.ft }{ }^{\circ}{ }^{\circ} \mathrm{F}\right) / \mathrm{Btu}\end{array}$ \\
\hline 5 & & Wall Insulation & $19.31\left({\mathrm{~h} . \mathrm{ft}^{2} .}^{\circ} \mathrm{F}\right) / \mathrm{Btu}$ & $\begin{array}{c}28.97\left(\mathrm{~h} . \mathrm{ft}^{2} .{ }^{\circ} \mathrm{F}\right) / \\
\text { Btu }\end{array}$ \\
\hline 6 & & Infiltration & 0.0304 & 0.0456 \\
\hline 7 & \multirow{4}{*}{$\begin{array}{l}\text { Windows and } \\
\text { Doors }\end{array}$} & U-value & $0.32 \mathrm{Btu} /\left(\mathrm{h} . \mathrm{ft}^{2} .^{\circ} \mathrm{F}\right)$ & $\begin{array}{l}0.48 \mathrm{Btu} / \\
\left(\mathrm{h} . \mathrm{ft}^{2} .{ }^{\circ} \mathrm{F}\right)\end{array}$ \\
\hline 8 & & SHGC & 0.496 & 0.744 \\
\hline 9 & & Overhangs & None & $\begin{array}{l}\mathrm{h}=1.54^{\prime} \\
\mathrm{L}=3.02^{\prime}\end{array}$ \\
\hline 10 & & Fins & None & $\begin{array}{l}\mathrm{h}=1.54^{\prime} \\
\mathrm{L}=3.02^{\prime}\end{array}$ \\
\hline 11 & \multirow[b]{2}{*}{ Lighting } & $\begin{array}{l}\text { Lighting Power Density } \\
\text { (LPD) }\end{array}$ & $10 \%$ less than base & $\begin{array}{l}10 \% \text { more than } \\
\text { base }\end{array}$ \\
\hline 12 & & Daylight Control & None & $\begin{array}{c}2 \text { cells per } \\
\text { zone; switched } \\
2 / 3-1 / 3 \text {-off }\end{array}$ \\
\hline 13 & \multirow{2}{*}{$\begin{array}{c}\text { Thermostat } \\
\text { Setpoint }\end{array}$} & Cooling Setpoint & $60^{\circ} \mathrm{F}$ & $70^{\circ} \mathrm{F}$ \\
\hline 14 & & Heating Setpoint & $70^{\circ} \mathrm{F}$ & $80^{\circ} \mathrm{F}$ \\
\hline 15 & DCV & DCV & None & $\begin{array}{l}\text { DCV sensor } \\
\text { present inside } \\
\text { zones }\end{array}$ \\
\hline \multirow{2}{*}{$\frac{16}{17}$} & \multirow{2}{*}{$\begin{array}{l}\text { Occupancy and } \\
\text { Plug Loads }\end{array}$} & Server Room & 63.8w/sq.ft; $18 \mathrm{w} / \mathrm{sq} . \mathrm{ft}$ & 0 \\
\hline & & Occupant Density & less $20 \%$ & more $20 \%$ \\
\hline 18 & $\begin{array}{c}\text { Climatic } \\
\text { Condition }\end{array}$ & Dry Bulb Temperature & $\begin{array}{l}-2^{\circ} \mathrm{F} \text { than the baseline } \\
\text { value }\end{array}$ & $\begin{array}{l}+2^{\circ} \mathrm{F} \text { than the } \\
\text { baseline value }\end{array}$ \\
\hline
\end{tabular}

\subsubsection{HVAC System}

The main parameters affecting the HVAC system's energy consumption are energy efficiency ratio (EER), static pressure setpoint, and drive motor, supply fan, and motor efficiency. Over time, the HVAC system's overall efficiency might decrease due to various reasons such as accumulation of dust in heat exchanger surface, leakage of refrigerant from evaporator coils, connections, and seals, 
and wearing of machine parts like compressor bearing, and many more reasons. However, regular maintenance practices can alleviate the inefficiencies in these systems.

The supply fan static pressure set-point dictates the supply fan's speed and the fan motor's power. The affinity law states that the power drawn by a motor or pump is proportional to the cube of the rotational speed. Therefore, setting supply fans to run at constant peak speed increases the energy consumption associated with the HVAC system.

The use of economizers allows outside air intake when the outside air temperature is below the building's temperature. This will reduce the load on the cooling coil on the cooling degree days. The impact of installing a double temperature economizer is evaluated. A double temperature economizer takes outside air whenever the outside air temperature is below the return air temperature.

\subsubsection{Building Envelope}

The insulating properties and airtightness of the building envelope might decrease as the building ages. Infiltration value for loose construction is valid for older buildings with moderate sealing of seams joints between windows, walls, and doors. New construction with good sealing between joints, windows, walls, and seams has better air-tightness than the old constructions.

\subsubsection{Windows and Doors}

The windows and doors' performance also fade over the years due to exposure to extreme weather and climatic conditions. The intensity of the impact of changes in the vital window and doors parameters like U-value, SHGC, and shading are evaluated at two levels. The higher SHGC value increases a building's energy efficiency in colder regions, while low SHGC increases energy efficiency in the hot climate. Similarly, the effect of the U-value might be different for different climatic conditions.

\subsubsection{Lighting}

Over time, the light bulbs' efficiency degrades, increasing the energy consumption associated with the lighting system. Also, without regular cleaning of the fixture, the dust gets accumulated on its surface, decreasing the fixture's efficacy. The overall efficiency of the lighting system can also be improved by installing occupancy sensors and daylight sensors. Occupancy sensors control the lighting system's operation by turning on the lights when the space controlled by it is occupied by 
people and turns the lights off when the space is unoccupied. Daylight controls utilize the photocell sensors to turn off or dim the lights when the light level from sunlight meets the space's required lighting level.

The main parameters that affect daylighting control are the number of photosensors per zone, percentage of lights controlled by photosensors, design foot candle, and reference location at which light level is measured. The height gives reference location from the floor and depth from the exterior wall. In eQUEST, the default value for the height above the floor is thirty inches or 2.5 feet (also the typical desktop height). This height represents the level above the floor at which daylight illuminance levels are calculated. It does not represent the mounting height of a daylight photosensor. The percent of zone depth represents the depth of the zone from the exterior window/wall to the back of the zone's perimeter at which daylight level is determined. For a zone controlled by a single photosensor, the default value of depth in eQUEST is 50\%, and for a zone controlled by two photosensors, the default value is $83 \%$ for photosensor 1 and $33 \%$ for photosensor 2. When two photosensors are assigned to a zone, one of them controls the perimeter near the window, and the other controls the area far from the window. The default design footcandle is given as 50 foot-candles.

For modeling the occupancy sensors, a 10\% reduction in LPD is estimated as eQUEST does not have the feature to model occupancy sensors.

\subsubsection{Thermostat Setpoint}

For the base case condition, the cooling setpoint is set at $65^{\circ} \mathrm{F}$, and the heating setpoint is set at $75^{\circ} \mathrm{F}$ for Building A. Similarly, the cooling setpoint is set $68^{\circ} \mathrm{F}$ in summer and $75^{\circ} \mathrm{F}$ in winter for Building B. For the server room, the setpoint is set at $68^{\circ} \mathrm{F}$ throughout the year. A setback control is used to change the thermostat setpoint during the occupied and unoccupied periods for building A.

\subsubsection{Demand-Controlled Ventilation (DCV)}

For DCV control, a $\mathrm{CO}_{2}$ sensor is placed in the zone, which detects $\mathrm{CO}_{2}$ in the zone. As the $\mathrm{CO}_{2}$ level rises, the sensor sends a message to the controller to increase the space's ventilation. Each zone requires a programmable thermostat for zoning control, which can be programmed to adjust the temperature at occupied and unoccupied periods. 


\subsubsection{Occupancy and Plug Loads}

Occupancy rate and plug loads directly affect the building's energy performance. A commercial building can have various kinds of office equipment like desktops, printers, TV, servers, and many more. The servers are typically more energy-intensive compared to other plug loads. Therefore, only the impact of server load is evaluated for plug loads.

\subsubsection{Building Orientation}

Its orientation determines the building's exposure to direct sunlight. Originally, Building A is facing West, and Building B is facing south. That means the main entry/exit doors and windows are facing the West for Building A and south for Building B. If the building was facing east or north, the building's energy performance could be different due to varying solar heat gain levels in those orientations. The different orientation of the building used in the study is given in Table 10 and the orientation of Building A and Building B has been labeled in Figure 7 and Figure 8 respectively.

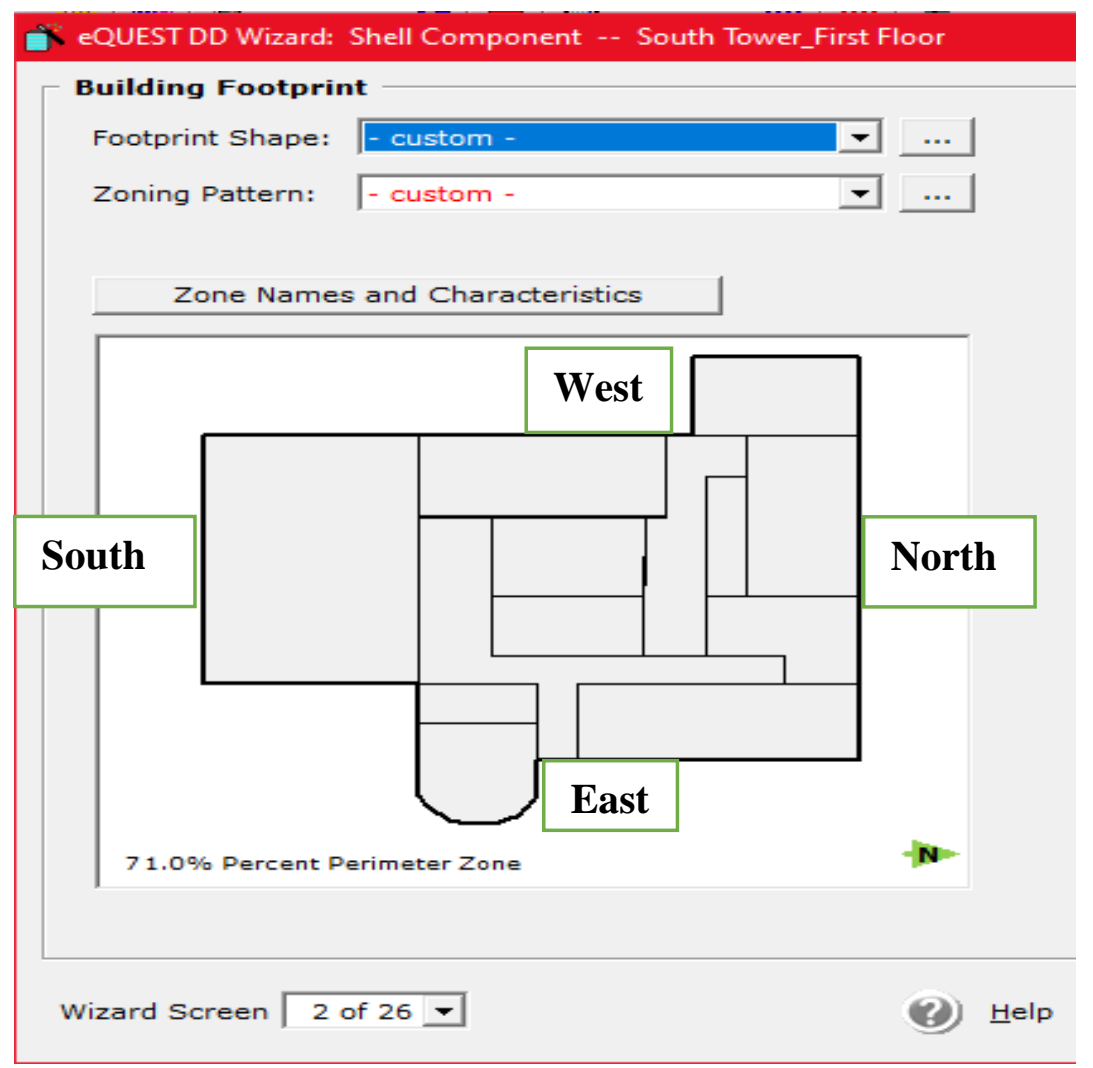

Figure 7: Orientation and Layout of Building A 


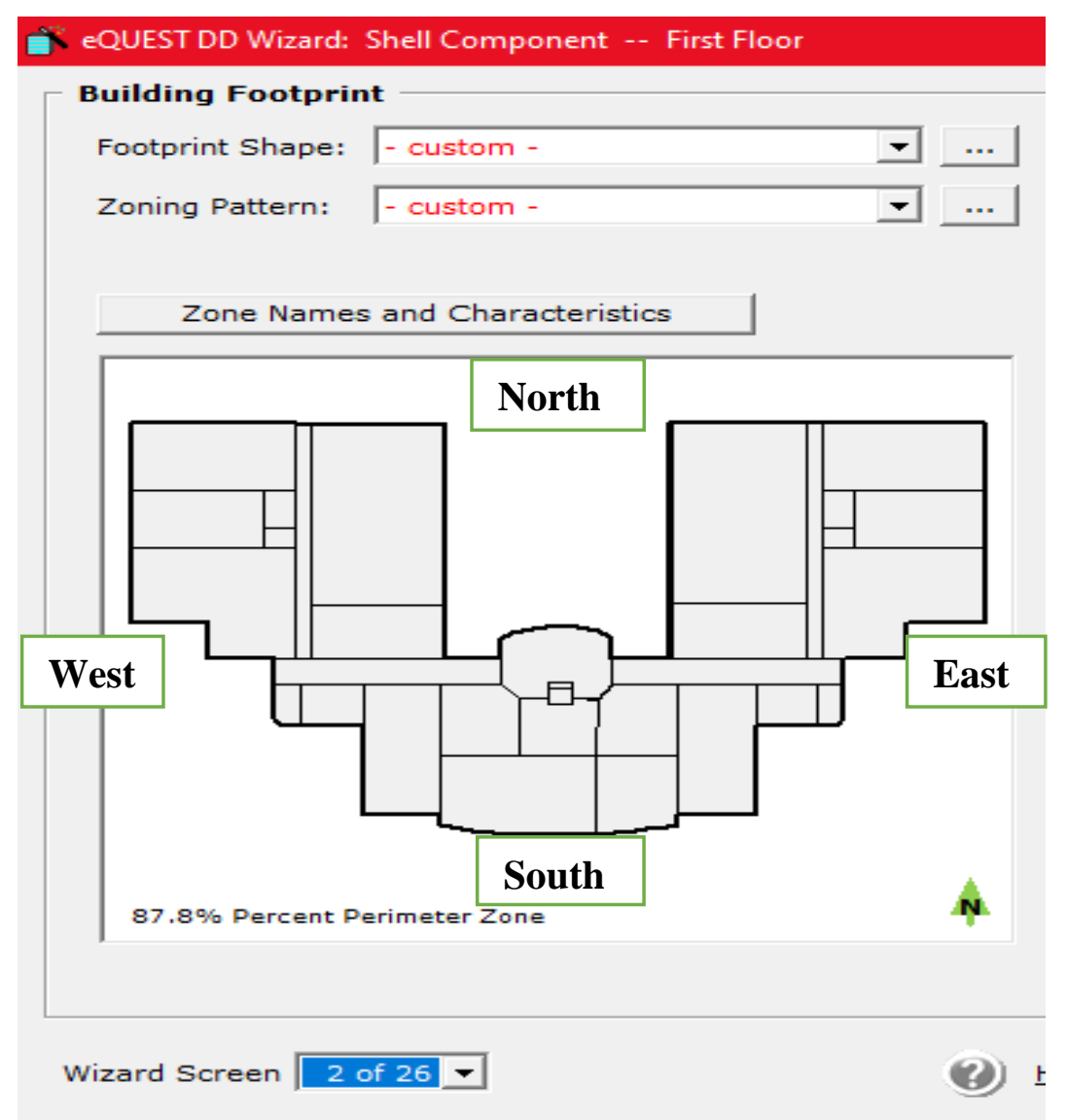

Figure 8: Orientation and Layout of Building B

Table 10:Different Building Orientations to be Studied

\begin{tabular}{|c|c|c|c|}
\hline S.N. & $\begin{array}{c}\text { Azimuth Angle, } \\
\text { Degree }\end{array}$ & $\begin{array}{c}\text { Building A } \\
\text { Faces }\end{array}$ & Building B Faces \\
\hline 1 & 0 & West & South \\
\hline 2 & 45 & South West & South East \\
\hline 3 & 90 & South & East \\
\hline 4 & 135 & South East & North East \\
\hline 5 & 180 & East & North \\
\hline 6 & 225 & North East & North West \\
\hline 7 & 270 & North & West \\
\hline 8 & 315 & North West & South West \\
\hline
\end{tabular}

\subsubsection{Climatic Condition}

The outdoor air temperature, humidity, and wind condition directly impact the building's heating, cooling, and air-conditioning load. Extreme climatic conditions can even degrade the quality of 
the building envelope over time. The effect of outdoor air temperature is evaluated for two cases. First, the bin data containing the actual average hourly climatic condition for the location is used for evaluating the base case. It is sporadic for the average climatic conditions to vary greatly, so the average hourly values are decreased by $2{ }^{\circ} \mathrm{C}$ from the base value for the low case and increased by $2{ }^{\circ} \mathrm{C}$ from the base value for the high case.

\subsection{Sensitivity Analysis}

Two sensitivity analysis methods were used to evaluate the impact of different parameters on the energy performance of two buildings. First, the relative impact of the parameters mentioned above on building energy performance is determined by calculating the percentage difference between the baseline annual energy consumption and annual energy consumption for the low performance and high-performance scenarios. The percentage change method is used as a screening method to identify the eight parameters with the highest impact on building energy performance. The input values for the parameters are varied by $\pm 20 \%$ to get the low-value and high-value. Parameters like heating setpoint and cooling setpoint, the setpoints are varied by $\pm 5^{\circ} \mathrm{F}$ from the baseline value. Whereas outdoor dry bulb temperature is varied by $\pm 2^{\circ} \mathrm{F}$ from the baseline value. Then, fractional factorial design is used to evaluate in detail the significance of the eight selected parameters and some of the interaction terms between the parameters.

Full-Fractional Design is more appropriate to determine the effect of all the interaction terms. However, it would require a huge number of simulation runs. Moreover, the fractional factorial design provides the two-level interaction terms between the most significant parameters, and it is sufficient for the purpose of this study. The impact of higher-level interaction terms are estimated to be insignificant based on the results from the fractional factorial design.

Figure 9 and Figure 10 show the fractional factorial design used to evaluate the relative significance of eight different parameters for building A and building B, respectively. 
Is UUt Analyze Urapn lools view winciow Heip uet started

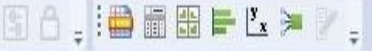

\begin{tabular}{|c|c|c|c|c|c|c|c|c|c|c|}
\hline $\begin{array}{ll}4 & \nabla \\
\nabla\end{array}$ & Pattern & Cooling Setpoint & Heating Setpoint & EER & Eff-supplyfanmtr & $\begin{array}{l}\text { Supply Fan static } \\
\text { Pressure }\end{array}$ & Wall Insulation & Server Room & Setback Control & Energy Consumption \\
\hline 1 & --+++--+++ & 60 & 70 & 10.8 & 63 & 2.38 & 14.04 & No & Yes & $351740 \mathrm{C}$ \\
\hline 2 & +----+++ & 70 & 70 & 7.2 & $42 A$ & 2.38 & 21.07 & No & Yes & $378850 \mathrm{C}$ \\
\hline 3 & ++++-+-- & 70 & 70 & 10.8 & 63 & 2.38 & 21.07 & Yes & No & $420000 \mathrm{C}$ \\
\hline 4 & $\mid--+-++-+$ & 60 & 70 & 10.8 & 42.4 & 3.564 & 21.07 & Yes & Yes & $431940 \mathrm{C}$ \\
\hline 5 & ------ & 60 & 70 & 7.2 & $42 A$ & 2.38 & 14.04 & Yes & No & $424640 \mathrm{C}$ \\
\hline 6 & -+-+-+-+ & 60 & 80 & 7.2 & 63 & 2.38 & 21.07 & Yes & Yes & $417000 \mathrm{C}$ \\
\hline 7 & $\mid-++--++-$ & 60 & 80 & 10.8 & 42.4 & 2,38 & 21.07 & No & No & $385620 \mathrm{C}$ \\
\hline 8 & +++--++-- & 70 & 80 & 7.2 & $42 \mathrm{~A}$ & 3.564 & 21.07 & Yes & No & $631100 \mathrm{C}$ \\
\hline 9 & -+++++--- & 60 & 80 & 10.8 & 63 & 3.564 & 14,04 & Yes & No & $447050 \mathrm{C}$ \\
\hline 10 & $+--++-\cdot+$ & 70 & 70 & 7.2 & 63 & 3.564 & 14,04 & Yes & Yes & $439040 \mathrm{C}$ \\
\hline 11 & ++++++++ & 70 & 80 & 10.8 & 63 & 3.564 & 21.07 & No & Yes & $390590 \mathrm{C}$ \\
\hline 12 & $--\cdot++++-$ & 60 & 70 & 7.2 & 63 & 3.564 & 21.07 & No & No & $338670 \mathrm{C}$ \\
\hline 13 & ++-+--+- & 70 & 80 & 7.2 & 63 & 2.38 & 14.04 & No & No & $604900 \mathrm{C}$ \\
\hline 14 & + +-+-+-+- & 70 & 70 & 10.8 & 42.4 & 3.564 & 14.04 & No & No & $413500 \mathrm{C}$ \\
\hline 15 & -+--+-++ & 60 & 80 & 7.2 & 42.4 & 3.564 & 14.04 & No & Yes & $403870 \mathrm{C}$ \\
\hline 16 & +++----+ & 70 & 80 & 10.8 & 42.4 & 2.38 & 14,04 & Yes & Yes & $441250 \mathrm{C}$ \\
\hline
\end{tabular}

Figure 9: Fractional Factorial Design For Building A

DOE Analyze Graph Tools View Window Help Get Started

\begin{tabular}{|c|c|c|c|c|c|c|c|c|c|c|}
\hline$\frac{v}{1}$ & Pattern & Server Room & Cooling Setpoint & Heating Setpoint & $\begin{array}{l}\text { Supply fan } \\
\text { Overall Eff }\end{array}$ & $\begin{array}{l}\text { Supply Fan Static } \\
\text { Pressure }\end{array}$ & Infiltration & EER & $\begin{array}{l}\text { Dry Bulb } \\
\text { Temperature }\end{array}$ & $\begin{array}{c}\text { Energy } \\
\text { Consumption }\end{array}$ \\
\hline 1 & -+--++-++ & Yes & 73 & 70 & 0.424 & 7.03 & 0,0304 & 10.8 & 2 & 2678800 \\
\hline 2 & $+2+-++--+$ & No & 63 & 70 & 0.636 & 7,03 & 0.0304 & 7.2 & 2 & 1730800 \\
\hline 3 & ++--++-- & No & 73 & 70 & 0.424 & 7.03 & 0.0456 & 7.2 & -2 & 2046200 \\
\hline 4 & +----+++ & No & 63 & 70 & 0.424 & 4.69 & 0,0456 & 10.8 & 2 & 1627500 \\
\hline 5 & $\mid-++-+++-$ & Yes & 73 & 80 & 0.424 & 4,69 & 0,0456 & 10.8 & -2 & 2887300 \\
\hline 6 & --++++-+ & Yes & 63 & 80 & 0.424 & 7.03 & 0,0456 & 7.2 & 2 & 2887000 \\
\hline 7 & --+++-++ & Yes & 63 & 80 & 0.636 & 4.69 & 0.0304 & 10.8 & 2 & 2374000 \\
\hline 8 & ---+++++ & Yes & 63 & 70 & 0.636 & 7.03 & 0.0456 & 10.8 & -2 & 2460100 \\
\hline 9 & +++-+-+- & No & 63 & 80 & 0.424 & 7.03 & 0.0304 & 10.8 & -2 & 1968600 \\
\hline 10 & ++-+--+- & No & 73 & 70 & 0.636 & 4.69 & 0.0304 & 10.8 & -2 & 1651000 \\
\hline 11 & t+++++++t & No & 73 & 80 & 0.636 & 7.03 & 0.0456 & 10.8 & 2 & 1978400 \\
\hline 12 & +++---+t & No & 73 & 80 & 0.424 & 4.69 & 0.0304 & 7.2 & 2 & 2111600 \\
\hline 13 & -+-+-+-+ & Yes & 73 & 70 & 0.636 & 4.69 & 0.0456 & 7.2 & 2 & 2482900 \\
\hline 14 & --.-- & Yes & 63 & 70 & 0.424 & 4.69 & 0.0304 & 7.2 & -2 & 2593200 \\
\hline 15 & -++++--- & Yes & 73 & 80 & 0.636 & 7.03 & 0.0304 & 7.2 & -2 & 2996900 \\
\hline 16 & +-++-+-- & No & 63 & 80 & 0.636 & 4.69 & 0.0456 & 7.2 & -2 & 1806100 \\
\hline
\end{tabular}

Figure 10: Fractional Factorial Design For Building B

\subsection{Assumptions and Limitations}


There are few assumptions made in the study. Those assumptions are listed below:

1. The historical weather bin data for the location (Fairmont, WV) is not available in eQUEST and EnergyPlus. Thus, the weather data for the nearest town (Morgantown, WV) is used for the simulation. The eQUEST weather directory has an hourly weather dataset of 1998 only. Weather data from 1998 might not portray the weather of today.

2. The effect of the layout of equipment and furniture within a room is assumed to be negligible. However, various equipment and furniture layouts and locations might affect daylight controls and occupancy sensors' operation.

3. Occupants use the building in the way it is designed throughout the year. All the parameters are set and used as given in the building model. However, those parameters may vary from time to time due to the rise in various situations and needs.

4. The equipment performs as per the specified schedules and manufacturer's specifications.

5. The building being studied has a meager natural gas bill. Thus, it is assumed that the natural usage is insignificant and is not evaluated in the study.

\subsection{Conclusion}

The study involves the development of a building energy model using eQUEST. All the relevant information about the building shell, building envelope, equipment, occupancy and equipment schedules, and load profiles are entered into eQUEST. The model is simulated to calculate the annual energy usage. The simulated result is verified against the actual energy consumption data from the utility bill over a year. If the results did not match, the building parameters are studied in detail to identify room for improvement. Then the building parameters are adjusted until the simulated result corroborates the actual energy consumption data. Once the model is validated, the impact of various building parameters is evaluated. Finally, the top three building parameters with the highest impact on building energy consumption are identified with the help of sensitivity analyses. 


\section{Results and Discussion}

\subsection{Baseline Model Calibration}

For both the buildings, initial baseline results did not satisfy the calibration criteria. Both the building baseline simulation result had the same pattern of monthly energy consumption as the actual utility bill. However, the entire pattern was lower to the actual utility bills in case of Building A and higher for Building B. Thus, the plug loads were increased for Building A and reduced for Building B until the calibration criteria was met. Figure 11 and figure 12 show the baseline simulation results after calibration for Building A and Building B, respectively.

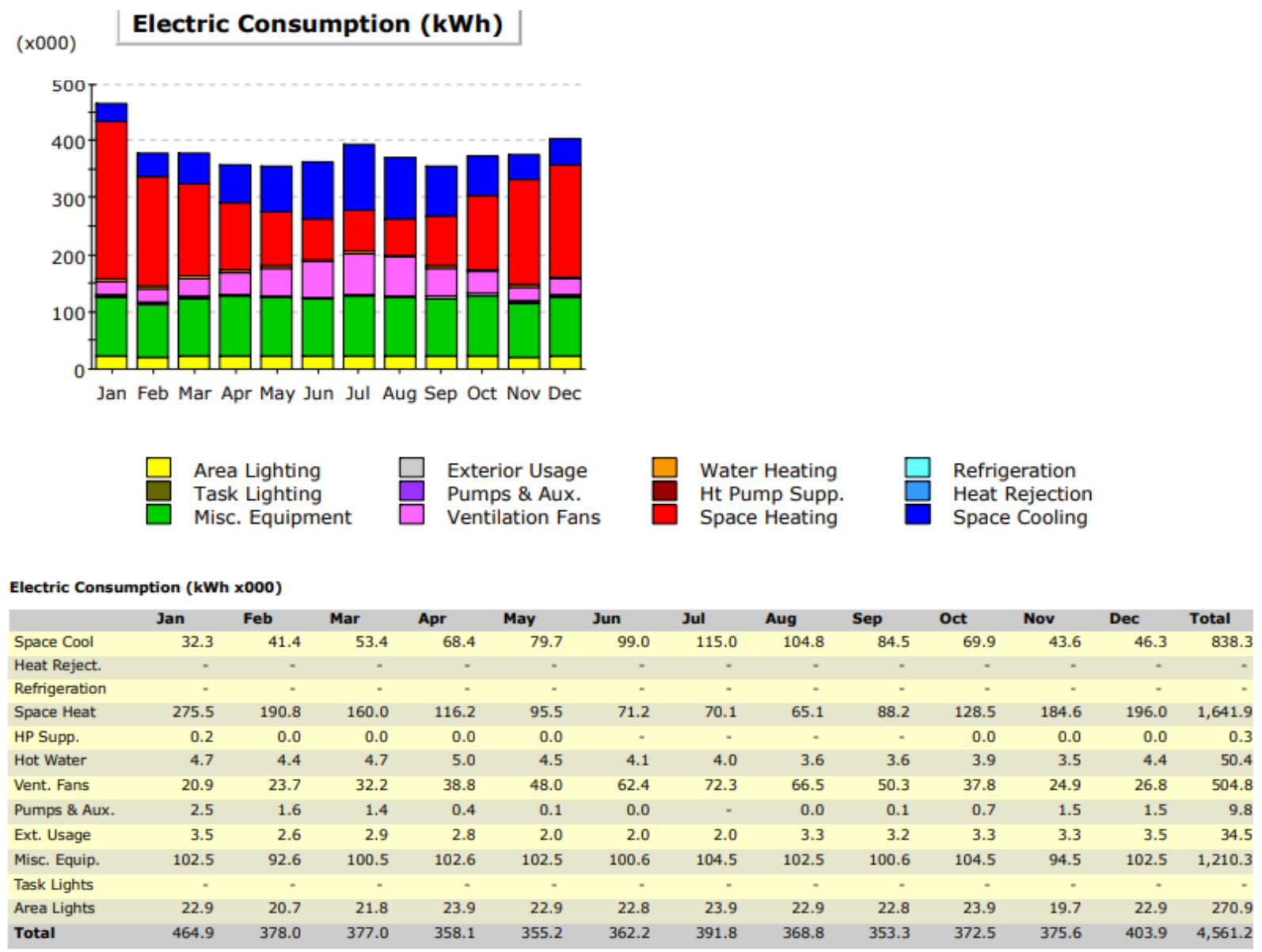

Figure 11: Baseline Simulation Result for Building A 


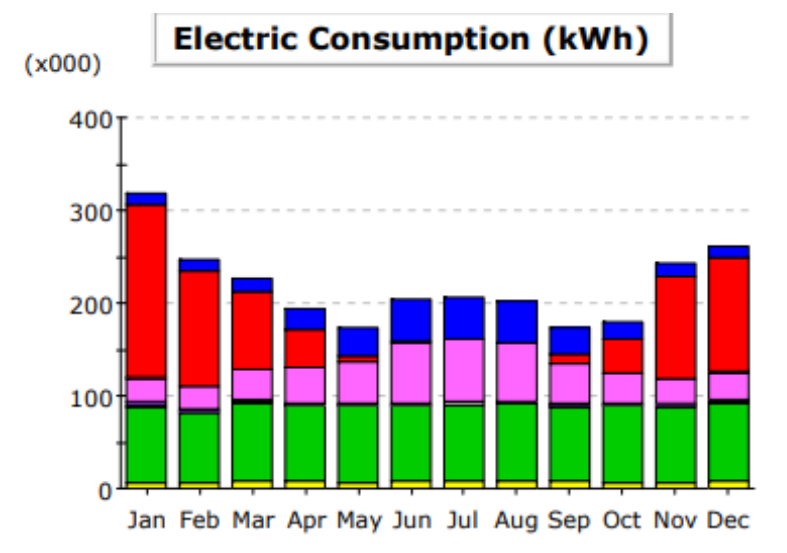
Area Lighting
Task Lighting
Exterior Usage
Pumps \& Aux.
Water Heating
Ht Pump Supp.
Refrigeration
Heat Rejection
Misc. Equipment
Ventilation Fans
Space Heating
Space Cooling

\begin{tabular}{|c|c|c|c|c|c|c|c|c|c|c|c|c|c|}
\hline & Jan & Feb & Mar & Apr & May & Jun & Jul & Aug & Sep & Oct & Nov & Dec & Total \\
\hline Space Cool & 10.5 & 11.3 & 15.7 & 22.9 & 29.9 & 45.1 & 46.2 & 43.9 & 28.2 & 18.2 & 13.0 & 13.7 & 298.7 \\
\hline Heat Reject. & - & - & - & - & - & - & - & - & - & - & - & - & - \\
\hline Refrigeration & - & - & $=$ & - & $=$ & - & $=$ & - & - & - & $\cdot$ & - & - \\
\hline Space Heat & 187.3 & 123.8 & 83.5 & 40.4 & 7.2 & 1.3 & 0.1 & 1.4 & 11.1 & 35.7 & 109.9 & 122.6 & 724.5 \\
\hline HP Supp. & 1.3 & 0.3 & 0.1 & 0.0 & 0.0 & - & $=$ & - & - & 0.0 & 0.2 & 0.3 & 2.3 \\
\hline Hot Water & $\cdot$ & $\cdot$ & $\cdot$ & $\cdot$ & $\cdot$ & $\cdot$ & $\cdot$ & $\cdot$ & $\cdot$ & $\cdot$ & - & $\cdot$ & - \\
\hline Vent. Fans & 24.4 & 24.3 & 32.0 & 37.7 & 43.6 & 65.1 & 67.5 & 62.3 & 43.1 & 31.9 & 27.1 & 29.0 & 488.0 \\
\hline Pumps \& Aux. & 3.1 & 2.3 & 2.0 & 1.0 & 0.3 & 0.0 & $=$ & 0.0 & 0.2 & 1.0 & 2.4 & 2.3 & 14.6 \\
\hline Ext. Usage & 2.9 & 2.7 & 2.9 & 2.8 & 2.9 & 2.8 & 2.9 & 2.9 & 2.8 & 2.9 & 2.8 & 2.9 & 34.6 \\
\hline Misc. Equip. & 81.1 & 74.6 & 83.4 & 81.2 & 81.9 & 81.2 & 82.6 & 83.4 & 80.4 & 81.8 & 79.7 & 83.4 & 974.6 \\
\hline Task Lights & - & $\cdot$ & - & $\cdot$ & - & - & $=$ & - & - & - & - & - & - \\
\hline Area Lights & 6.8 & 6.7 & 7.8 & 7.7 & 7.1 & 7.7 & 7.4 & 7.8 & 7.4 & 7.1 & 7.1 & 7.8 & 88.3 \\
\hline Total & 317.5 & 246.0 & 227.4 & 193.8 & 172.9 & 203.4 & 206.9 & 201.7 & 173.2 & 178.7 & 242.2 & 262.0 & $2,625.6$ \\
\hline
\end{tabular}

Figure 12: Baseline Simulation Result for Building B

Table 11 shows the monthly NMBE and CV(RMSE) values after the models were calibrated.

Table 11: Model Calibration Result

\begin{tabular}{|c|c|c|c|}
\hline Building & Building A & Building B & Required \\
\hline NMBE & $3.7 \%$ & $0.001 \%$ & $\pm 5 \%$ \\
\hline CV(RMSE) & $8.3 \%$ & $9.7 \%$ & $15 \%$ \\
\hline
\end{tabular}

The results show that both buildings satisfy the calibration criteria.

\subsection{Sensitivity Analysis Using Percentage Change Method}

The result for low and high values of parameters when the parameters are varied independently are shown in Figure 13 and Figure 14 for building A and building B, respectively. 


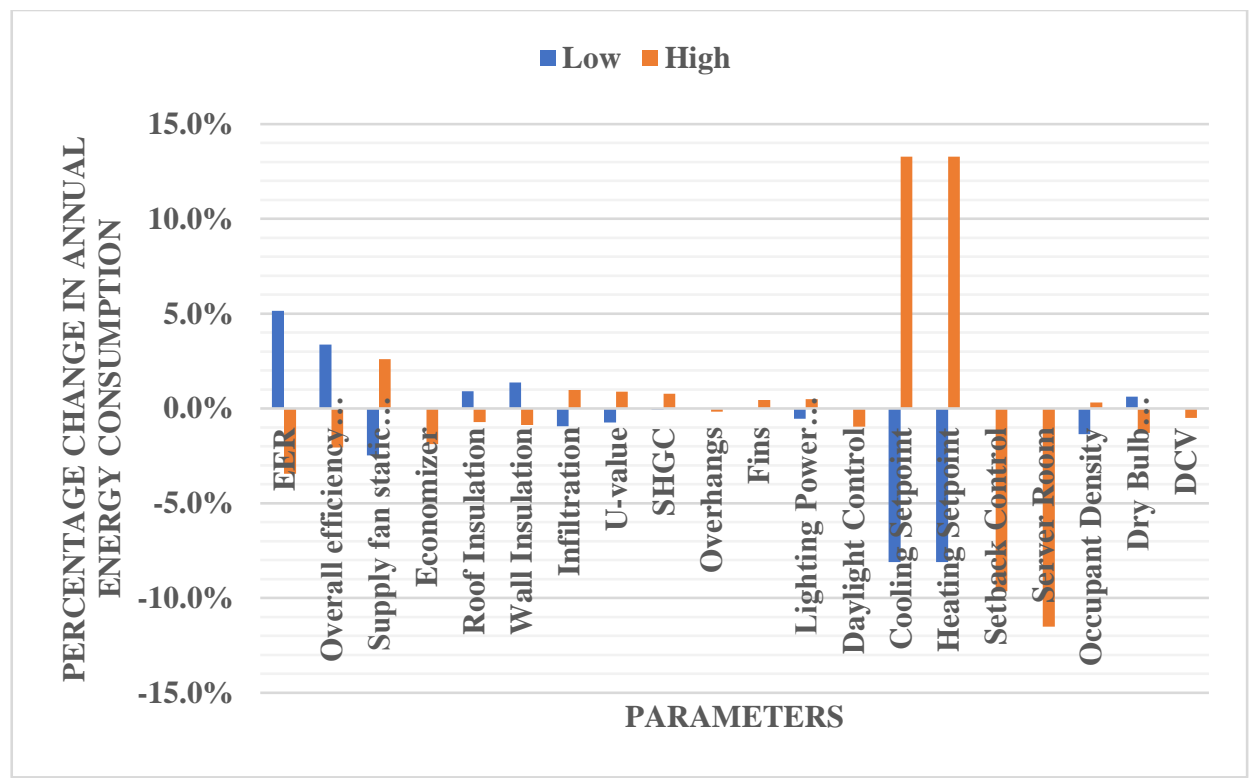

Figure 13: Sensitivity Analysis of Main Parameters of Building A

It can be seen from Figure 11 that cooling setpoint, heating setpoint, server room, setback control, EER, the overall efficiency of supply fan and motor, supply fan static pressure have a higher impact on the energy performance of Building A than other parameters like an infiltration, U-value, SHGC, overhangs, fins, economizer, roof insulation, wall insulation, LPD, daylight control, and outdoor dry bulb temperature. The top three parameters affecting the energy performance of Building A are the cooling setpoint, heating setpoint, and server room. 


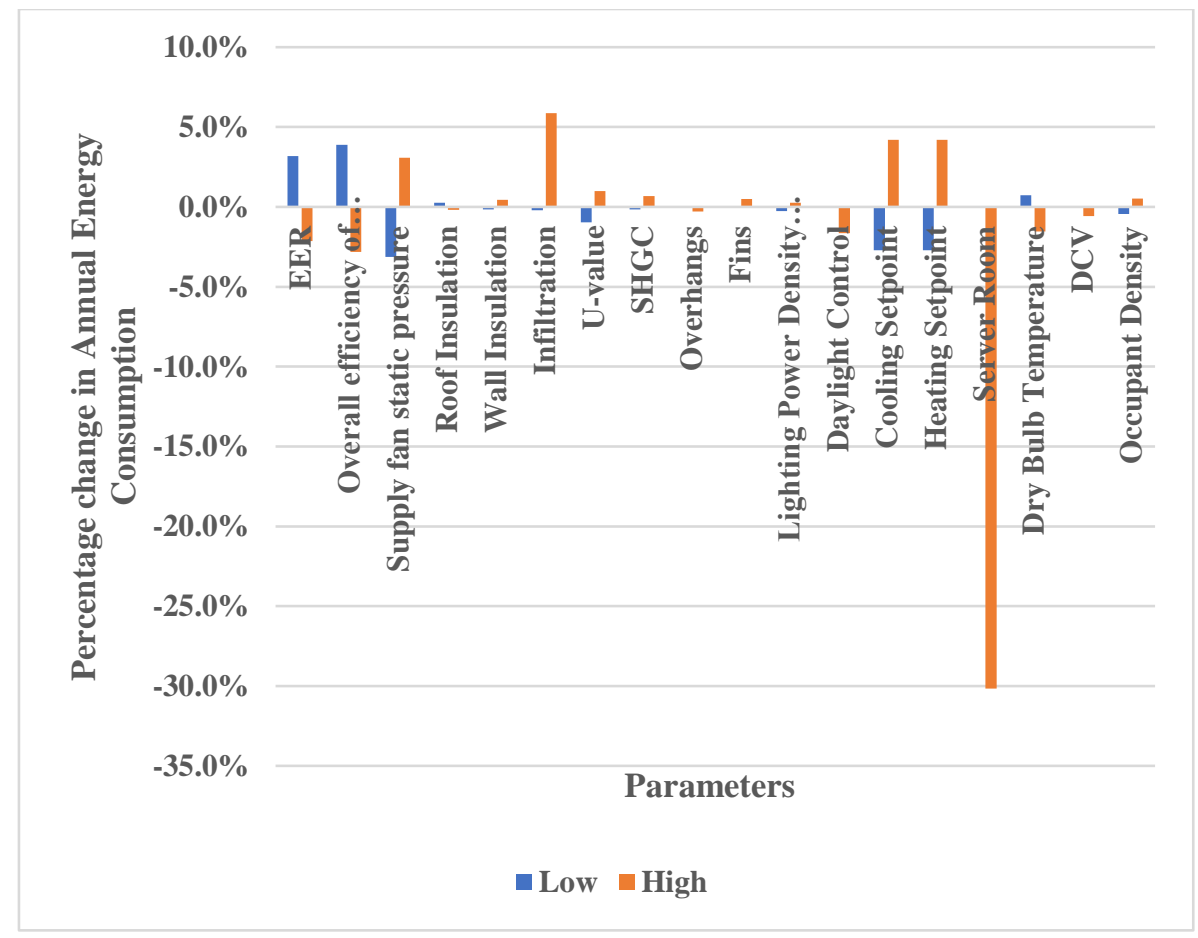

Figure 14: Sensitivity Analysis of Main Parameters of Building B

It can be seen from Figure 12 that the top three parameters affecting the energy performance of Building B are server room, cooling setpoint, and heating setpoint.

\subsection{Sensitivity Analysis Using Fractional Factorial Design}

The fractional factorial analysis obtained in JMP software is given in Figure 15 and Figure 16 for building $\mathrm{A}$ and building $\mathrm{B}$, respectively.

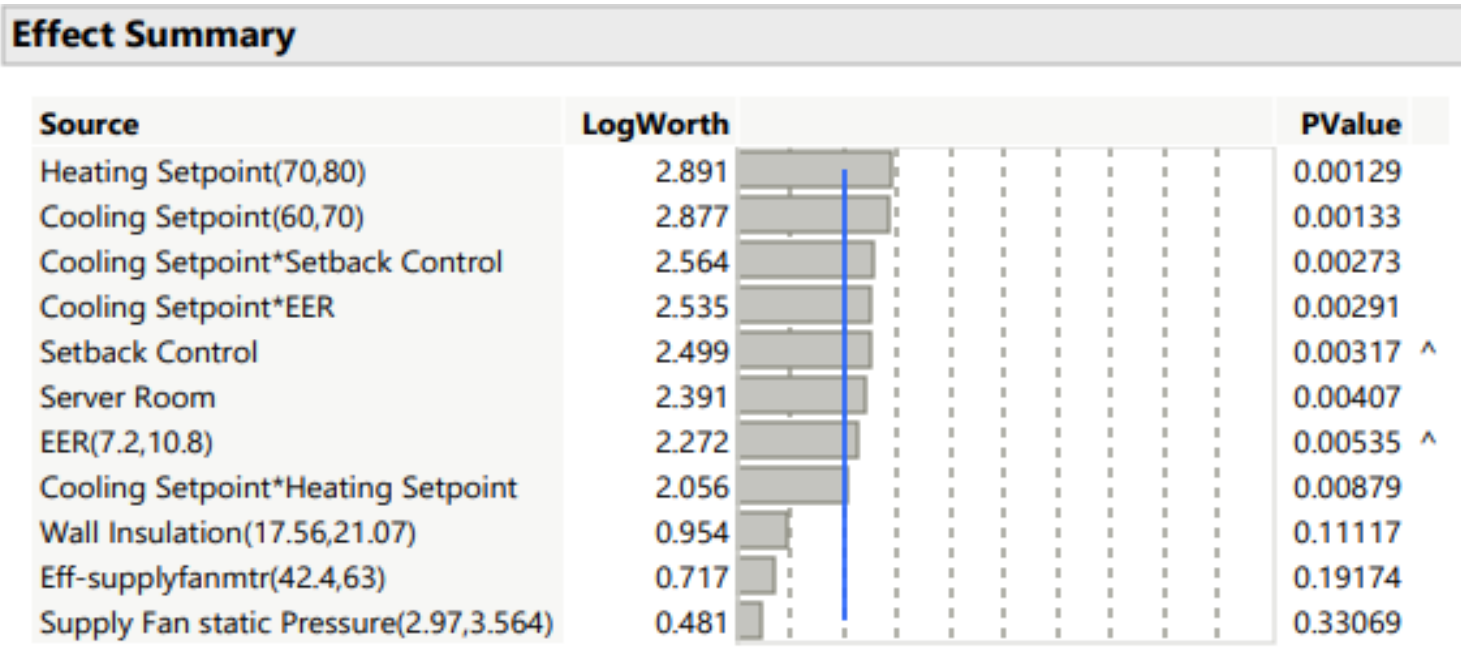

Figure 15: Fractional Factorial Analysis Result for Building A 


\section{Effect Summary}

Source

Server Room

Heating Setpoint $(70,80)$

Cooling Setpoint $(63,73)$

Supply fan Overall Eff $(0.424,0.636)$

Supply Fan Static Pressure $(4.69,7.03)$

$\operatorname{EER}(7.2,10.8)$

Dry Bulb Temperature $(-2,2)$

Cooling Setpoint ${ }^{\star}$ Heating Setpoint

Server Room*Heating Setpoint

Server Room*Cooling Setpoint

Infiltration $(0.0304,0.0456)$
LogWorth

\begin{tabular}{|c|c|c|c|c|}
\hline 6.104 & & & & \\
\hline 3.844 & & & & \\
\hline 3.457 & & & & ! \\
\hline 3.375 & & & & ! \\
\hline 3.233 & & & & ! \\
\hline 2.957 & & & & i \\
\hline 1.929 & & & & \\
\hline 1.795 & & & & \\
\hline 0.421 & & & & \\
\hline 0.250 & & & & \\
\hline 0.225 & & & & i \\
\hline
\end{tabular}

PValue

0.00000

0.00014

0.00035

0.00042

0.00059

0.00110

0.01177

0.01605

0.37956

0.56213

0.59558

\section{Figure 16: Fractional Factorial Analysis Result for Building B}

It can be seen from Figure 15 that the top three parameters affecting the energy performance of building A are heating setpoint, cooling setpoint, and setback control. However, the interaction between cooling setpoint and setback control and cooling setpoint and EER have a greater impact than the setback control. It can be seen in Figure 16 that the top three parameters affecting the energy performance of Building B are server room, heating setpoint, and cooling setpoint.

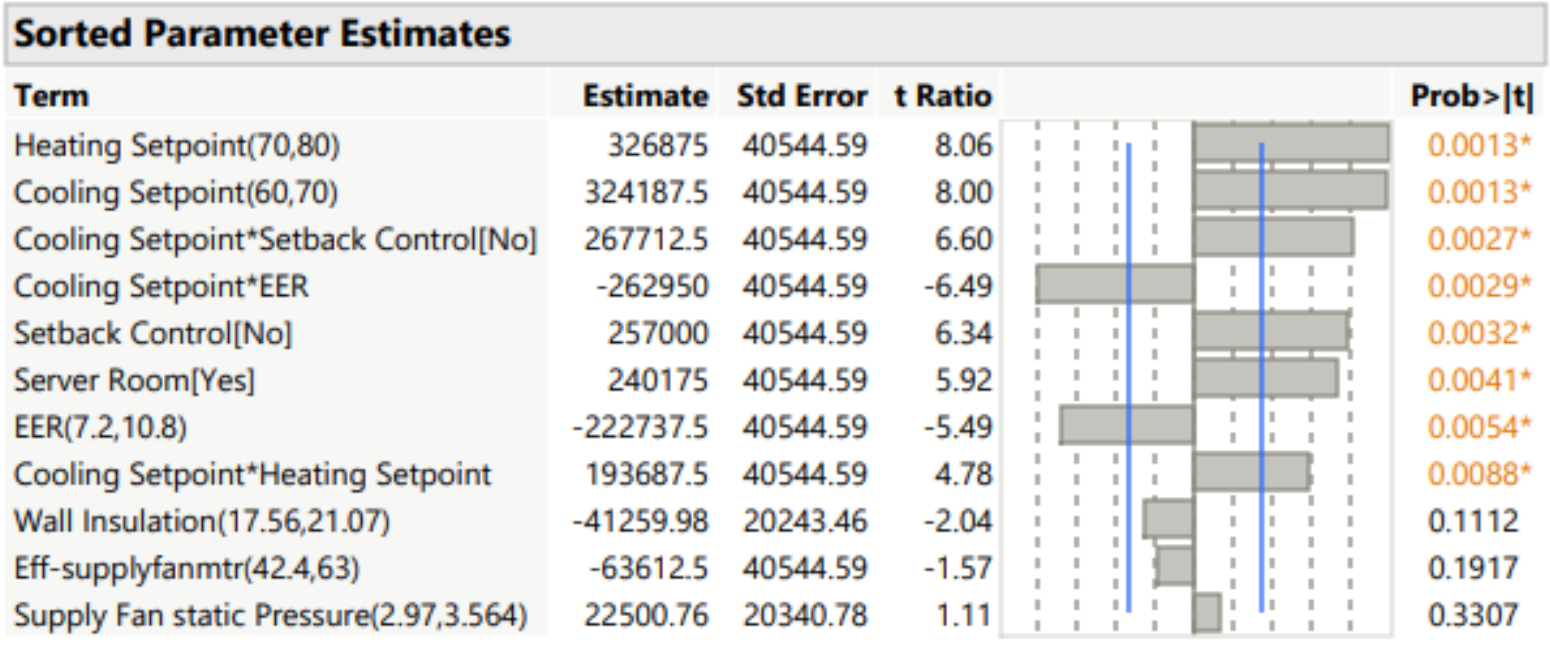

Figure 17: Sorted Parameters for Building A 


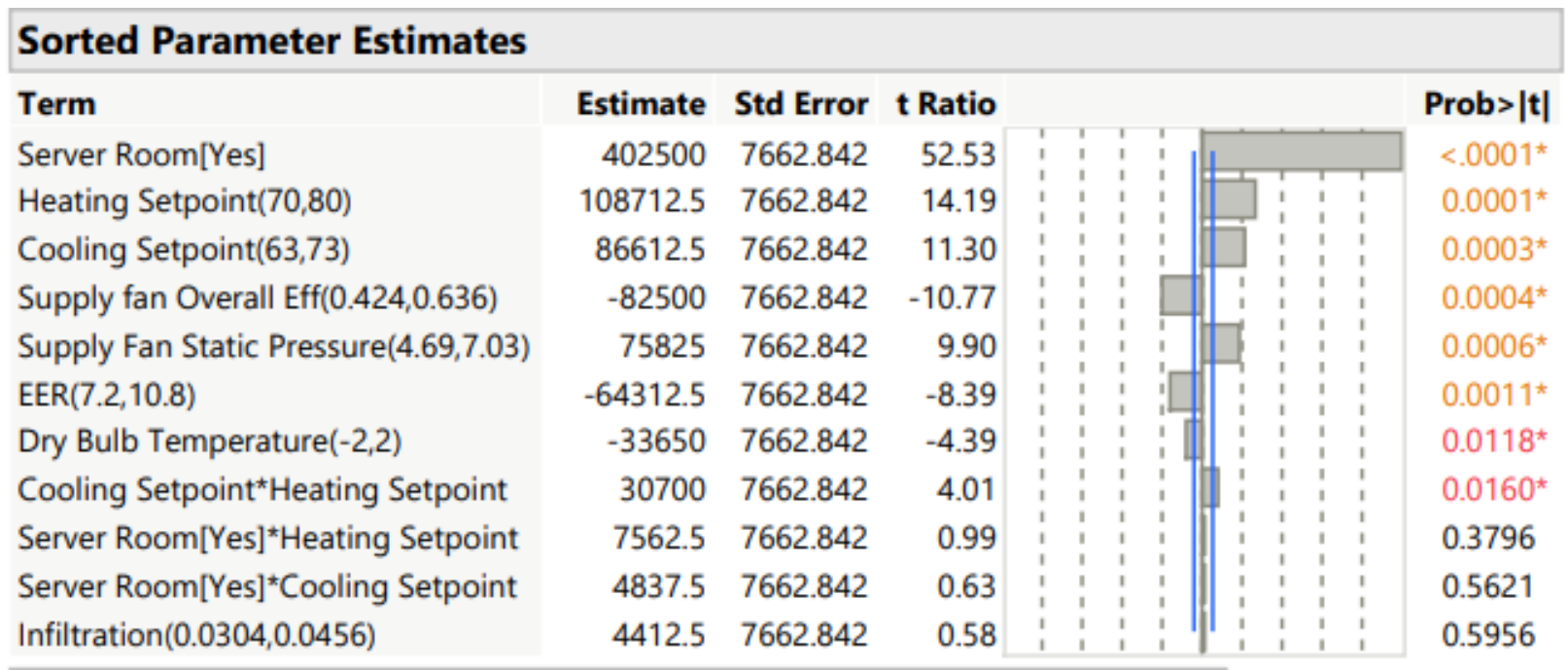

Figure 18: Sorted Parameters for Building B

In Figure 17 and Figure 18, the impact of parameters is sorted from largest to smallest. Also, the significant parameters are given in an asterisk. It can be seen that the interaction terms cooling setpoint * setback control and cooling setpoint * heating setpoint have a significant impact on the energy performance of building A. For building B, the interaction terms do not have a significant impact on its energy performance. Table 12 compares the result obtained from using the percentage change method and fractional factorial design.

Table 12: Comparison of Results from Two Sensitivity Analysis Methods

\begin{tabular}{|c|c|c|c|c|}
\hline \multirow{2}{*}{ S.N. } & \multicolumn{2}{|c|}{ Building A } & \multicolumn{2}{c|}{ Building B } \\
\cline { 2 - 5 } & $\begin{array}{c}\text { Percentage Change } \\
\text { Method }\end{array}$ & $\begin{array}{c}\text { Fractional } \\
\text { Factorial Design } \\
\text { Method }\end{array}$ & $\begin{array}{c}\text { Percentage } \\
\text { Change Method }\end{array}$ & $\begin{array}{c}\text { Fractional } \\
\text { Factorial Design } \\
\text { Method }\end{array}$ \\
\hline 1 & $\begin{array}{c}\text { Heating Setpoint } \\
(13.3 \%)\end{array}$ & $\begin{array}{c}\text { Heating Setpoint } \\
(\mathrm{p} \text {-value=0.00129) }\end{array}$ & $\begin{array}{c}\text { Server Room } \\
(30.2 \%)\end{array}$ & $\begin{array}{c}\text { Server Room } \\
(\mathrm{p} \text {-value=0.0000) }\end{array}$ \\
\hline 2 & $\begin{array}{c}\text { Cooling Setpoint } \\
(13.3 \%)\end{array}$ & $\begin{array}{c}\text { Cooling Setpoint } \\
(\mathrm{p} \text {-value=0.00132) }\end{array}$ & $\begin{array}{c}\text { Heating Setpoint } \\
\text { ** } \\
(4.2 \%)\end{array}$ & $\begin{array}{c}\text { Heating Setpoint } \\
(\mathrm{p} \text {-value=0.00014) }\end{array}$ \\
\hline 3 & Server Room $(11.5 \%)$ & $\begin{array}{c}\text { Setback Control } \\
(\mathrm{p} \text {-value=0.00317) }\end{array}$ & $\begin{array}{c}\text { Cooling Setpoint } \\
\text { (4* } \\
\text { Cooling Setpoint } \\
(\mathrm{p} \text {-value }=0.00035)\end{array}$ \\
\hline
\end{tabular}

****Heating and cooling setpoint have the same rank

The results from both the sensitivity analysis method for both the buildings have heating and cooling setpoint among the top three parameters. For Building A, both the methods show that the heating and cooling setpoint have the same impact on the energy performance of the building. However, the third parameter on the list by the two methods is different. For building B, the results are the same for both methods. 
Figure 19 and Figure 20 show how the energy consumption of building A and building B will vary when different parameters change.

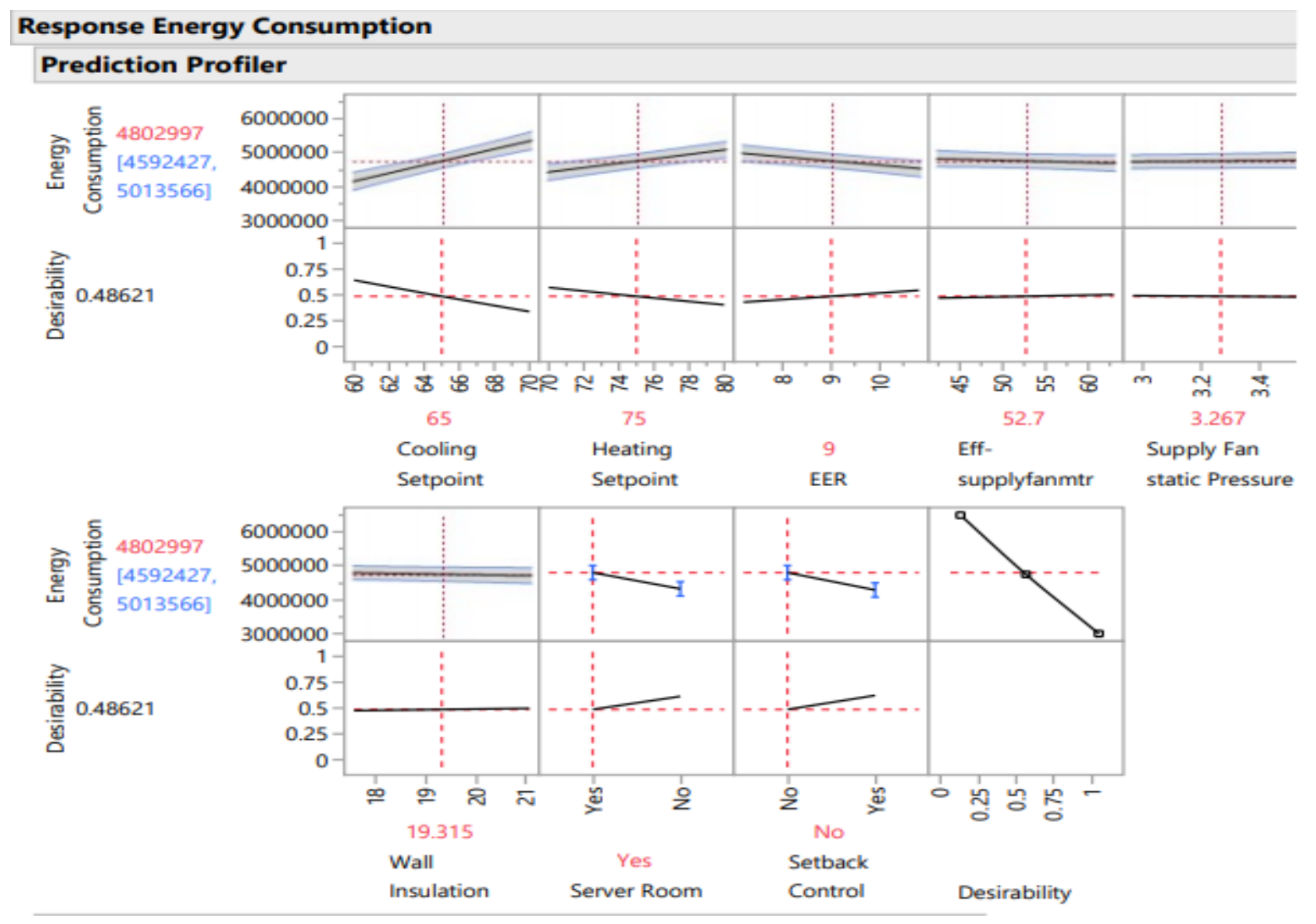

Figure 19: Prediction Profile For Building A 

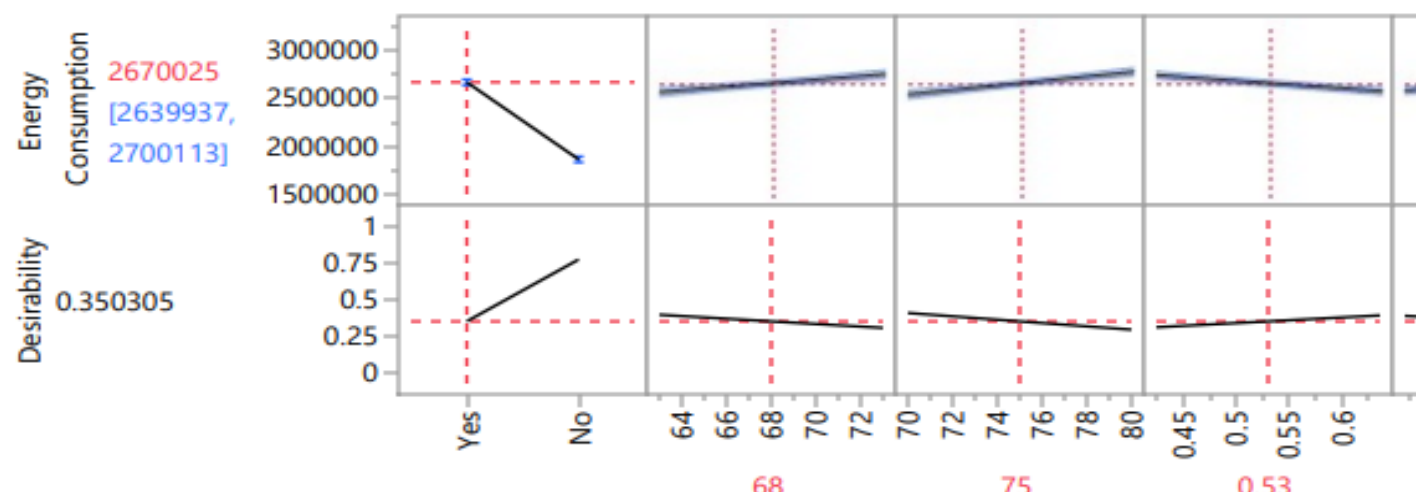

0.53

Supply fan

Heating

Setpoint

Overall Eff

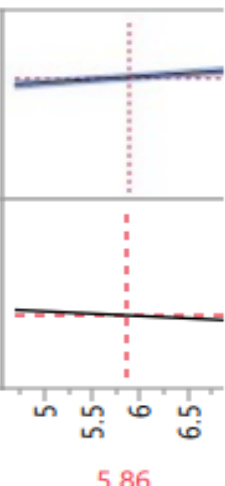

Supply Fan

Setpoint
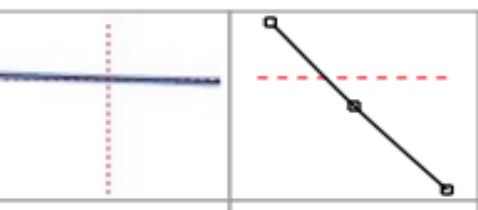

Static Pressure

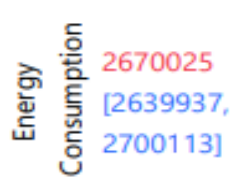

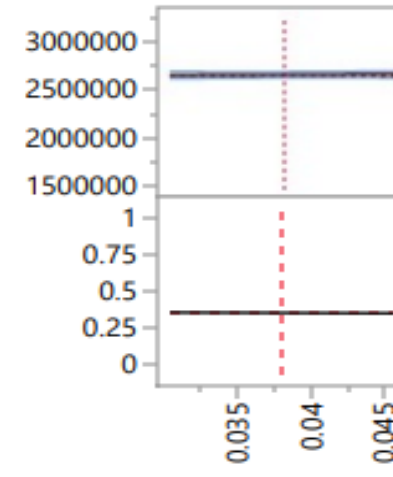

0.038 Infiltration

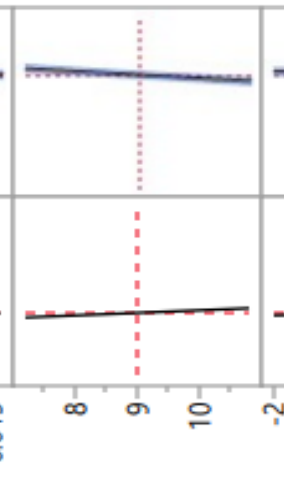

9

EER
Dry Bulb

Temperature Desirability

Figure 20: Prediction Profile For Building B

Figure 19 shows that the energy performance of building A varies more steeply with changes in heating setpoint, cooling setpoint, server room, and setback control. Figure 20 shows that the energy performance of building B varies more steeply with changes in values of the server room. Compared to the effect of the server room, changes in other parameters have significantly less effect on the energy performance of building B.

\subsection{Interaction Effect}

Figure 21 and Figure 22 show the interaction plot obtained from JMP software for Building A and Building B parameters. 


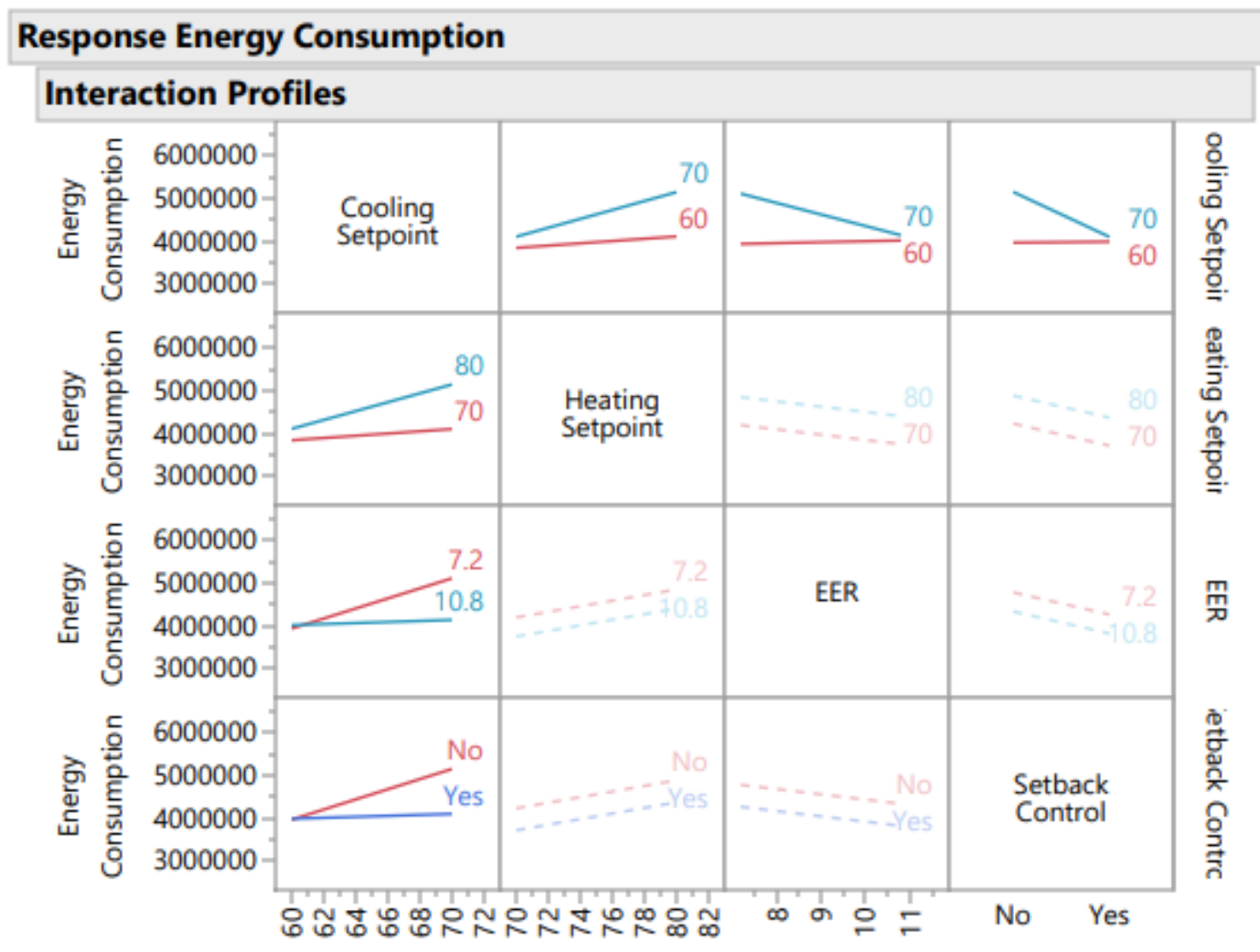

Figure 21: Interaction Plot for Parameters of Building A

The interaction profile for Building A shows that the effect of changing the cooling setpoint is more significant when there is no setback control compared to when setback control was present. Also, the effect of changing the cooling setpoint is more when EER is at low level and heating setpoint is at high level. When the cooling setpoint is at high level, the effect of changing heating setpoint, EER and setback control is more than when the cooling setpoint is at low level. 


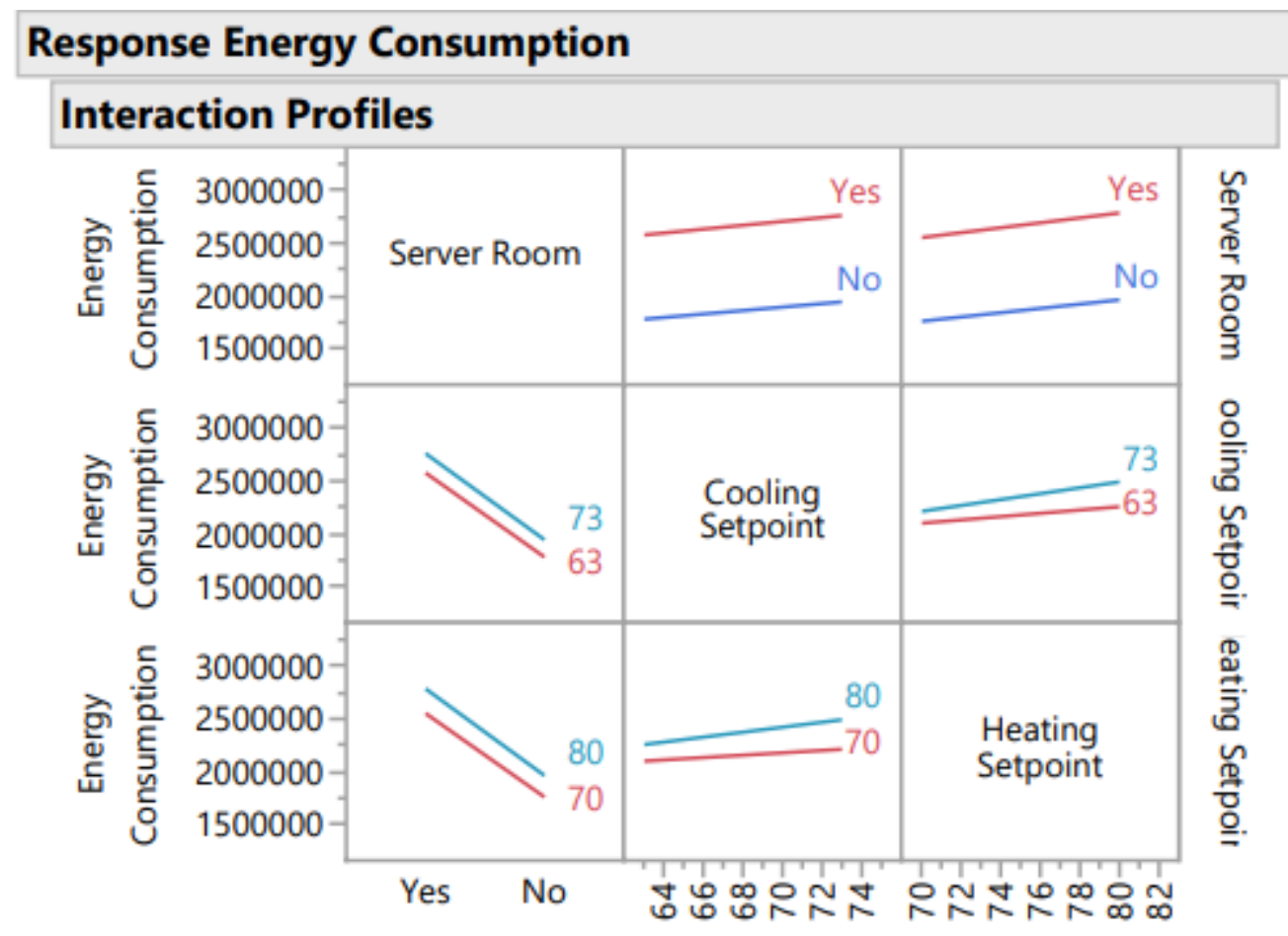

Figure 22: Interaction Plot for Parameters of Building B

The interaction profile for Building B shows that energy consumption is significantly lower when the server room is at a high level (when there is no server room) than at a low level. The energy consumption increases linearly when the cooling setpoint and heating setpoint is increased. This can be explained by the fact that the supply air is constant at $55^{\circ} \mathrm{F}$ so, increasing the cooling setpoint will make the heating coil heat the supply air to the cooling setpoint at a higher level.

Figure 23 and Figure 24 shows how the two buildings' energy performance varies with the change in their azimuth angle. 


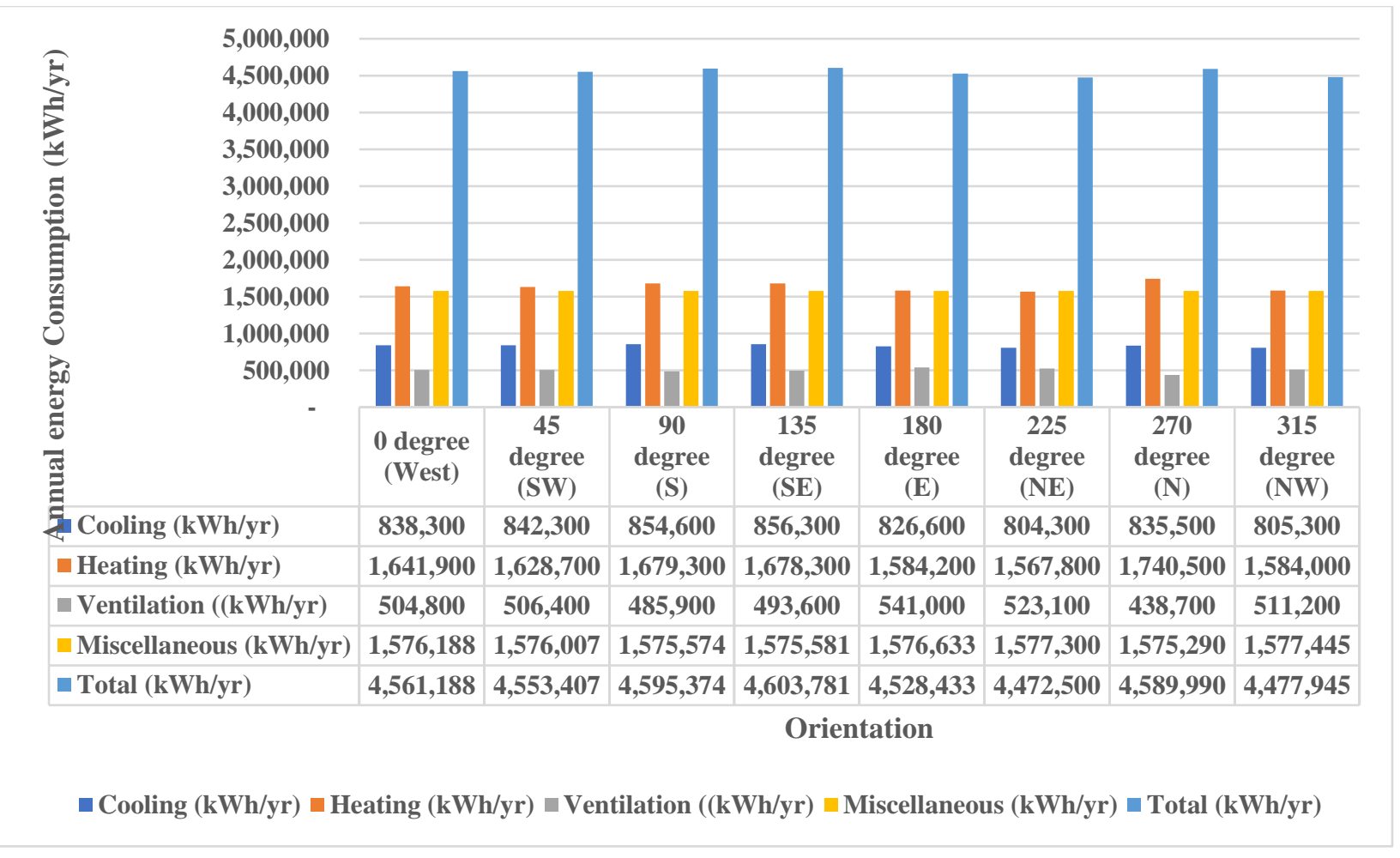

Figure 23: Energy Consumption vs. Building Orientation for Building A

It can be seen from Figure 23 that the total energy consumption of Building A will be the least when the azimuth angle is changed from zero degree to 225 degrees (1.9\% improvement in energy performance compared to the base case), and the total energy consumption is highest when the azimuth angle is changed to 135 degrees $(0.9 \%$ reduction in energy performance compared to the base case). In the baseline case, the building is facing west with the building façade laying along the north-south axis. When the azimuth angle is changed to 135 degrees, the building will face southeast, and the building façade will lie along the southeast and northwest axis. Furthermore, at 225 degrees, the building will face northeast, and the building façade will lie along the northwest and south east axis. 


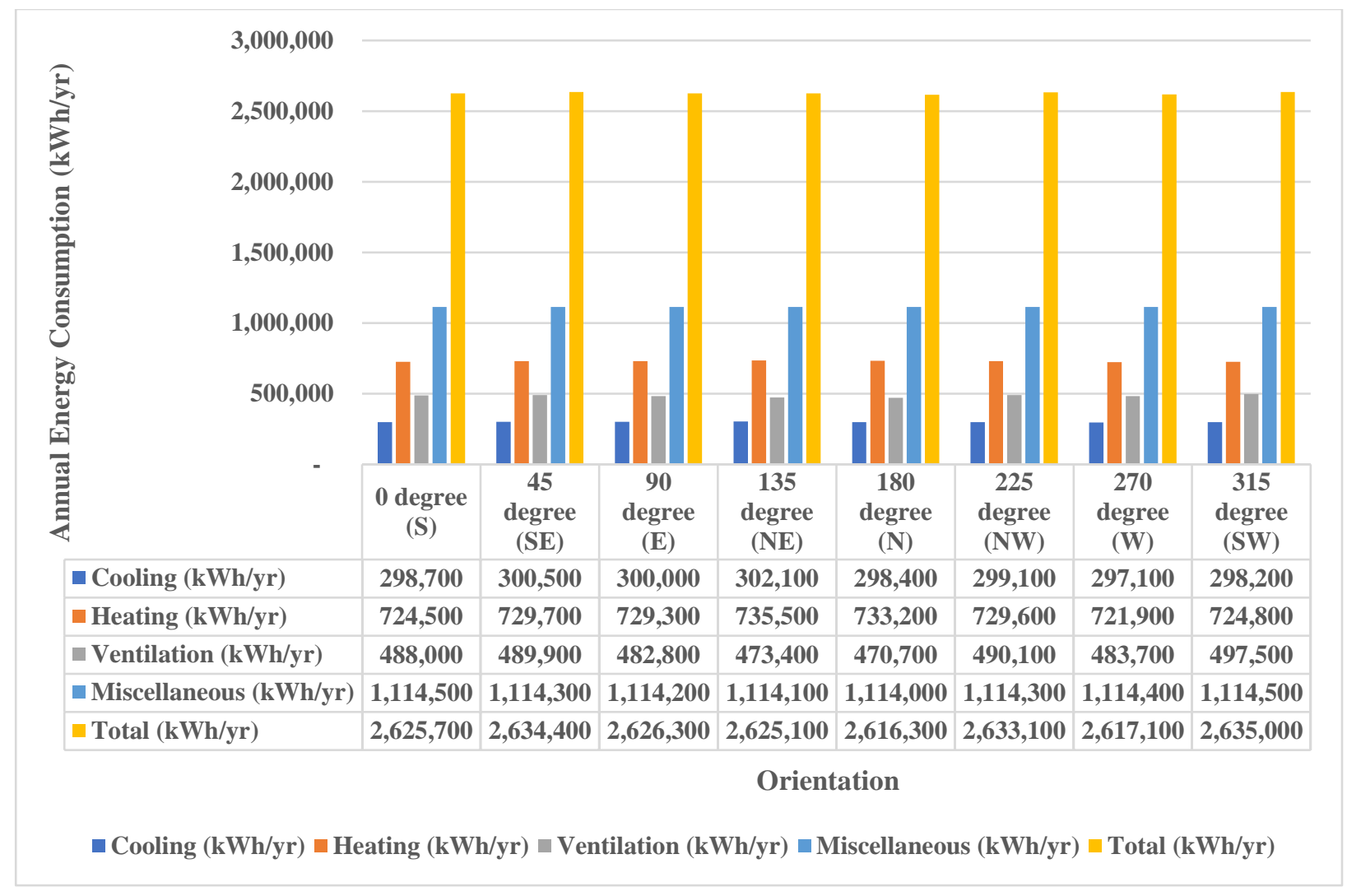

Figure 24: Energy Consumption vs. Building Orientation for Building B

It can be seen from Figure 24 that the total energy consumption of Building B will be the least when the azimuth angle is changed from zero degree to 180 degree $(0.4 \%$ improvement in energy performance compared to the base case), and the total energy consumption is highest when the azimuth angle is changed to 315 degrees ( $0.4 \%$ reduction in energy performance compared to the base case). At the baseline case, the building is facing south. When the azimuth angle is changed to 180 degrees, the building will face North. And at 315 degrees, the building will face southwest.

Figure 25 and Figure 26 show the buildings' energy performance when the doors and windows in four different faces of the buildings were removed. 


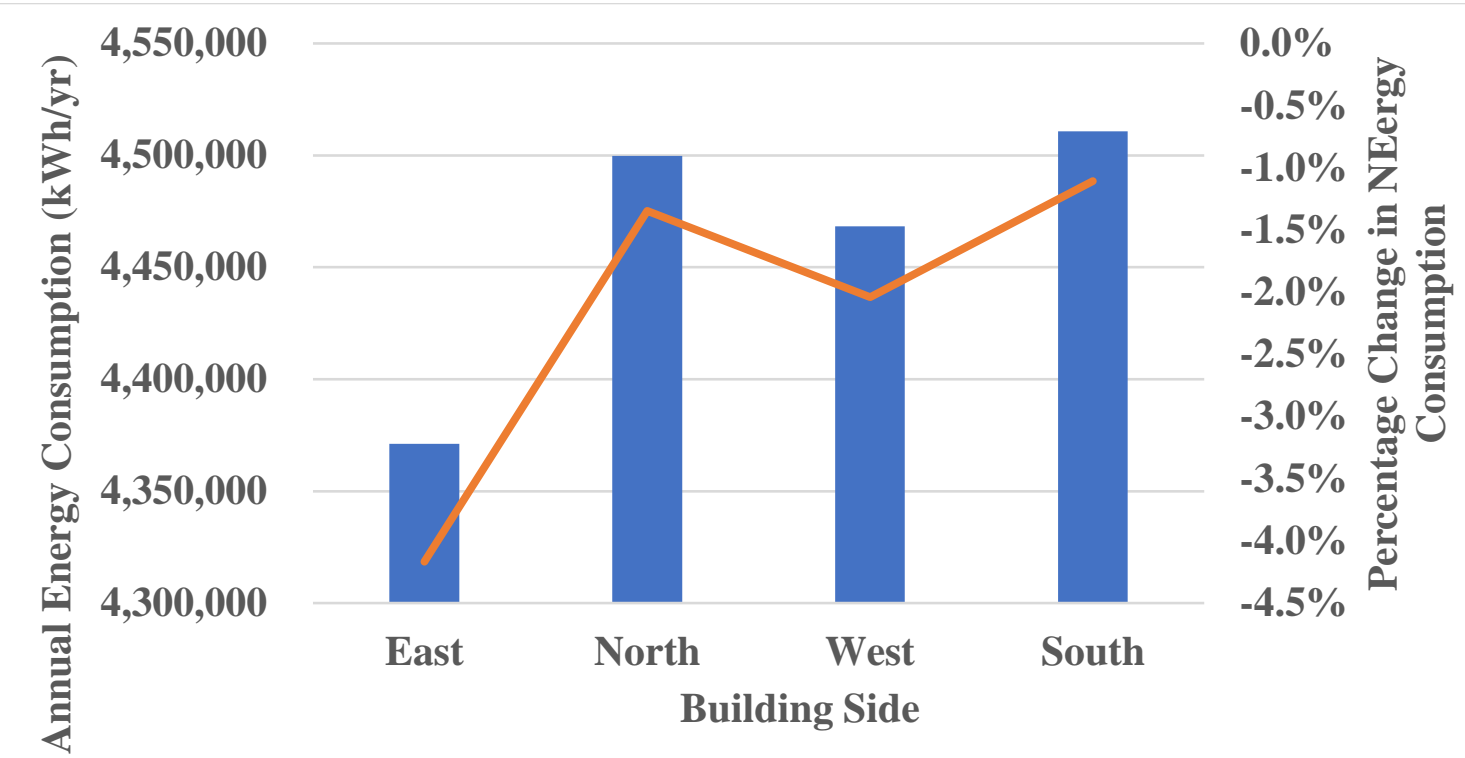

Annual Energy consumption (kWh/yr)

- Percentage Change From Baseline

Figure 25: Energy Performance of Building A When Windows and Doors are Absent in Certain Face of the Building

It can be seen from Figure 25 that the overall energy performance of Building A is the best (4.2\% improvement in energy performance compared to the base case) when there are no doors and windows in the east face of the building. Moreover, the energy performance of building A is least when doors and windows are absent in the south face of the building (1.1\% improvement in the energy performance of the building). Also, cooling energy decreased for all four cases compared to baseline. On the other hand, heating energy has increased for all sides except North. 


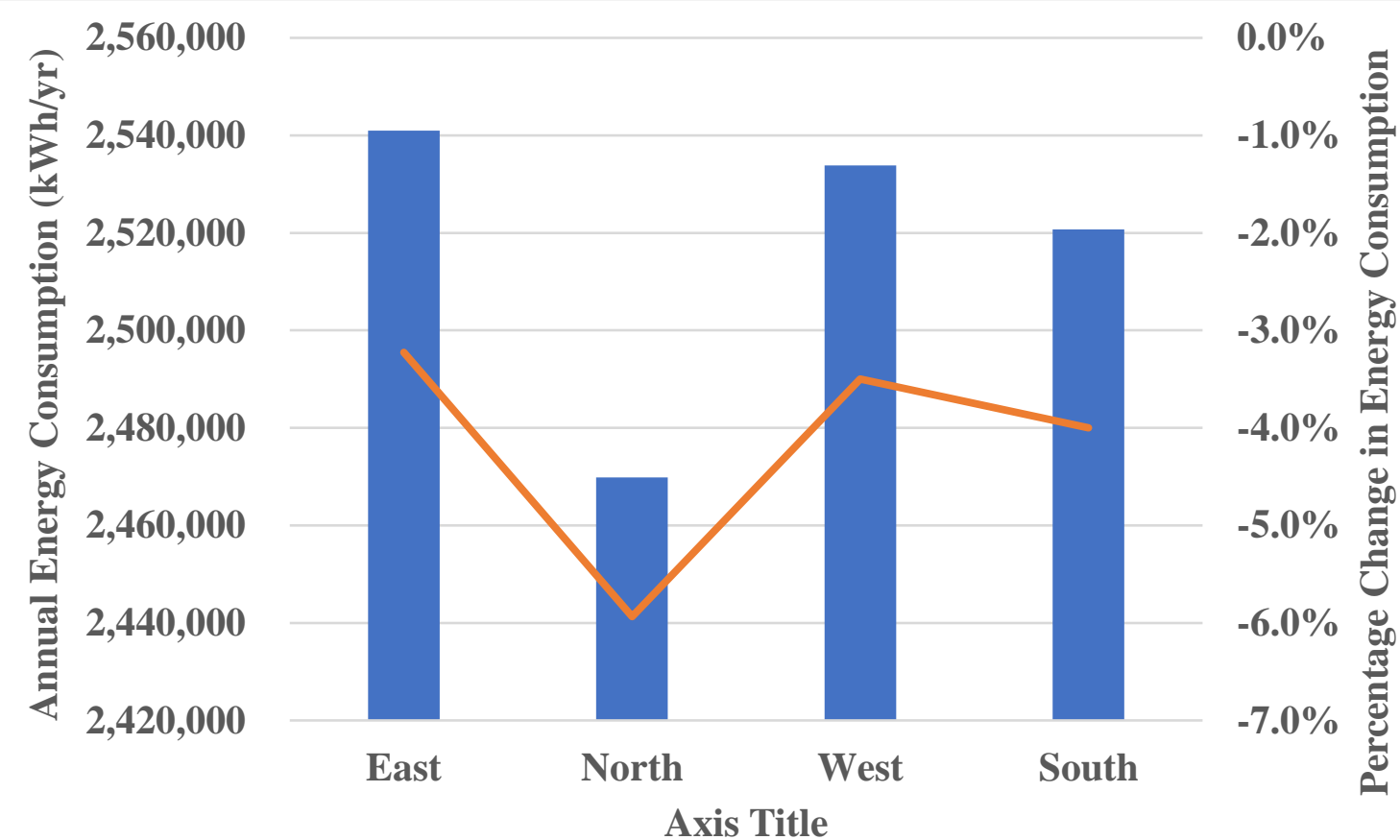

Annual Energy Consumption $(\mathrm{kWh} / \mathrm{yr}) \quad$ Percentage change

Figure 26: Energy Performance of Building B When Windows and Doors are Absent in Certain Face of the Building

It can be seen from Figure 26 that energy performance is best when the doors and windows are absent in the North face of Building B (5.9\% reduction in energy performance compared to the base case. The more significant impact of removing windows and doors on the north side can be attributed to the greater number of windows and doors on this side of the building. 


\section{Conclusion and Future Work}

\subsection{Conclusion}

In this study, the effect of various building parameters on the energy performance of the building is studied. Sensitivity analysis on twenty parameters is performed to determine the top three parameters which have the most significant impact on the energy performance of buildings. Actual data from two fully operational commercial buildings is collected and used to develop a building energy model in eQUEST. The model is calibrated using NMBE and CV(RMSE) method. The model satisfies the NMBE and CV(RMSE) criteria set by the ASHRAE Guideline 14, FEMP, and IPMVP for building energy model calibration. The values of the parameters are varied in two levels, and then the percentage change in output is calculated. Fractional factorial analysis on eight parameters with the highest percentage change in energy performance is performed at two levels in statistical software JMP. The impact of changing the building orientation and removing doors and windows in each face of the building is evaluated. The summary of the key findings are listed below:

$>$ For Building A, top 3 parameters from percentage change method are: Heating setpoint, cooling setpoint and server room. From fractional factorial design, top 3 parameters are: heating setpoint $(\mathrm{p}$-value $=0.00129)$, cooling setpoint $(\mathrm{p}$-value $=0.00133)$, and setback control (p-value $=0.00317)$.

For Building B, top 3 parameters from both methods are: Server room ( $\mathrm{p}$-value $=0.0000)$, heating setpoint $(p$-value $=0.00014)$, and cooling setpoint $(p$-value $=0.00035)$.

For 5-degree Fahrenheit change in cooling setpoint and heating setpoint, building energy consumption changed up to $13.3 \%$ for Building A, and $4.2 \%$ for Building B.

$>$ Absence of server room reduced the energy consumption by $11.5 \%$ and $30.2 \%$ for Building A and Building B respectively.

Setback control reduced the energy consumption by $9.6 \%$ for Building A.

If the best values for all top three parameters are taken simultaneously, energy efficiency improves by $29 \%$ for Building A and $35 \%$ for Building B. 
$>$ Few interaction terms are significant: Cooling setpoint $x$ Setback control, Cooling Setpoint x EER, and Cooling Setpoint x Heating Setpoint.

$>$ Building A was most efficient (1.9\% reduction in energy consumption) at azimuth angle 135 degree (Face: SE) and lest efficient (0.9\% increase in energy consumption) at azimuth angle 225 degree (Face: NE).

Building B was most efficient ( $0.4 \%$ reduction in energy consumption) at azimuth angle 180 degree (Face: $\mathrm{N})$ and lest efficient ( $0.4 \%$ reduction in energy consumption) at azimuth angle 315 degree (Face: SW).

$>$ Changing building orientation and removing windows and doors affected the energy consumption associated with heating, cooling and ventilation for both buildings.

$>$ Effect of removing windows and doors is greater in east side (4.2\%) for Building A and in North side (5.9\%) for Building B.

$>$ The impact of doors and windows is found to have more impact on building energy performance than the building orientation.

The results are valid only for the two buildings modeled and analyzed in this research study. Building energy performance is dependent on numerous sets of parameters and their interaction effects. Thus, buildings with a different range of baseline values compared to the two modeled buildings in this research could find the results to be different from the result from this research study. In order to increase the statistical power of the study, the number of buildings of the same type, design, operation, and location has to be increased.

Due to the limited sample size (two buildings in the same location), the findings from the research study cannot be generalized to be accurate for other buildings. In addition, the findings might not be applicable for different types of buildings located in different climatic zones. Therefore, a more comprehensive study has to be done with multiple buildings in the same locations and also in different climatic regions to determine the effect of the building parameters. In addition, the study should also involve different kinds of buildings to determine if the results vary drastically for different types of buildings. Without an exhaustive study encompassing all these factors, the results cannot be generalized to be true for all buildings. 


\subsection{Future Work}

Future work on this research study involves increasing the number of building parameters to investigate all the building parameters. A summary of possible forthcoming work relating to this study are listed below:

> In this study, only two buildings are modeled. Future research can model different building types in different climatic conditions to determine the impact of building parameters in different buildings and climatic conditions. The impact of building parameters can be different for the different building types and different climatic conditions.

$>$ More building parameters can be studied in the research to perform comprehensive research.

> The building being modeled had meager gas bills. The facility had electric heating, and the natural gas was predominantly used for water heating only. Thus, the analysis of natural gas has been ignored in this study. Future research works can investigate the facility where natural gas is a significant portion of the utility bill.

$>$ The study involves only one type of HVAC system. Future researches can explore different types of HVAC systems. 


\section{Appendix}

\subsection{Preliminary Data}

This section shows the building information that was collected for the facility.

Table 13: General Information about the Building $A$

\begin{tabular}{|c|c|}
\hline Building & Established 2009 \\
\hline Building type & $\begin{array}{l}\text { Commercial office building with several } \\
\text { different clients occupying the spaces. }\end{array}$ \\
\hline Building address & 5000 Technology Dr, Fairmont, WV 26554 \\
\hline Building geometry/orientation & Façade along North-South Axis/ West facing \\
\hline Number of floors & 5 \\
\hline Floor to floor height & $13 \mathrm{ft}$. \\
\hline Floor to ceiling height & $9 \mathrm{ft}$. \\
\hline Total Area & 131,850 sq.ft \\
\hline Door dimension & $3 \mathrm{ft} \times 7 \mathrm{ft}$ \\
\hline Door construction & Double pane, Tinted \\
\hline Door frame & Aluminum, 1 inche \\
\hline Window Construction & Double Pane, Tinted \\
\hline Window type 1 dimension & $4 \mathrm{ft} \times 9 \mathrm{ft}$ \\
\hline Window type 2 dimension & $4 \mathrm{ft} \times 7 \mathrm{ft}$ \\
\hline Window frame & Aluminum, 1.75 inches \\
\hline Operating hours & 8 AM to 5 PM (Monday-Friday) \\
\hline HVAC systems & $\begin{array}{c}2 \text { RTUs /175 Ton } \\
16 \mathrm{~kW} \text { VAVs for heating }\end{array}$ \\
\hline HVAC system fans operating hours & 24 hours/day \\
\hline
\end{tabular}

Table 14: General Information about the Building B

\begin{tabular}{|c|c|}
\hline Building & Established 1995 \\
\hline Building type & $\begin{array}{l}\text { Commercial office building with several } \\
\text { different clients occupying the spaces. }\end{array}$ \\
\hline Building address & 1000 Technology Dr, Fairmont, WV 26554 \\
\hline Building geometry/orientation & Complex V-shape/ South facing \\
\hline Number of floors & 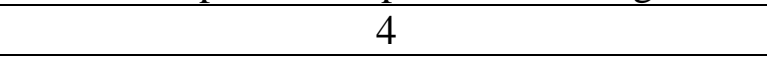 \\
\hline Floor to floor height & $14 \mathrm{ft}$. in the ground floor, $13 \mathrm{ft}$ in other floors \\
\hline Floor to ceiling height & $9 \mathrm{ft}$. \\
\hline Total Area & 119,971 sq.ft \\
\hline Door dimension & $3 \mathrm{ft} \times 7 \mathrm{ft}$ \\
\hline
\end{tabular}




\begin{tabular}{|c|c|}
\hline Door construction & Double pane, Tinted \\
\hline Door frame & Aluminum, 1.75 inches \\
\hline Window construction & Double Pane, Tinted \\
\hline Window type 1 dimension & $4 \mathrm{ft} \times 9 \mathrm{ft}$ \\
\hline Window type 2 dimension & $4 \mathrm{ft} \times 7 \mathrm{ft}$ \\
\hline Window frame & Aluminum, 1 inch \\
\hline Operating hours & 8 AM to 5 PM (Monday-Friday) \\
\hline HVAC systems & $\begin{array}{l}\text { 3 RTUs for cooling } \\
\text { - } \quad \text { East wing RTU :115 Ton } \\
\text { - } \quad \text { Central RTU: } 90 \text { Ton } \\
\text { - } \quad \text { West wing RTU: } 115 \text { Ton } \\
\text { 9 kW VAVs for heating } \\
\end{array}$ \\
\hline HVAC system fans operating hours & 7 AM to 6 PM hours/day \\
\hline
\end{tabular}

\subsection{Data Input in eQUEST}

This section shows the data entered in eQUEST.

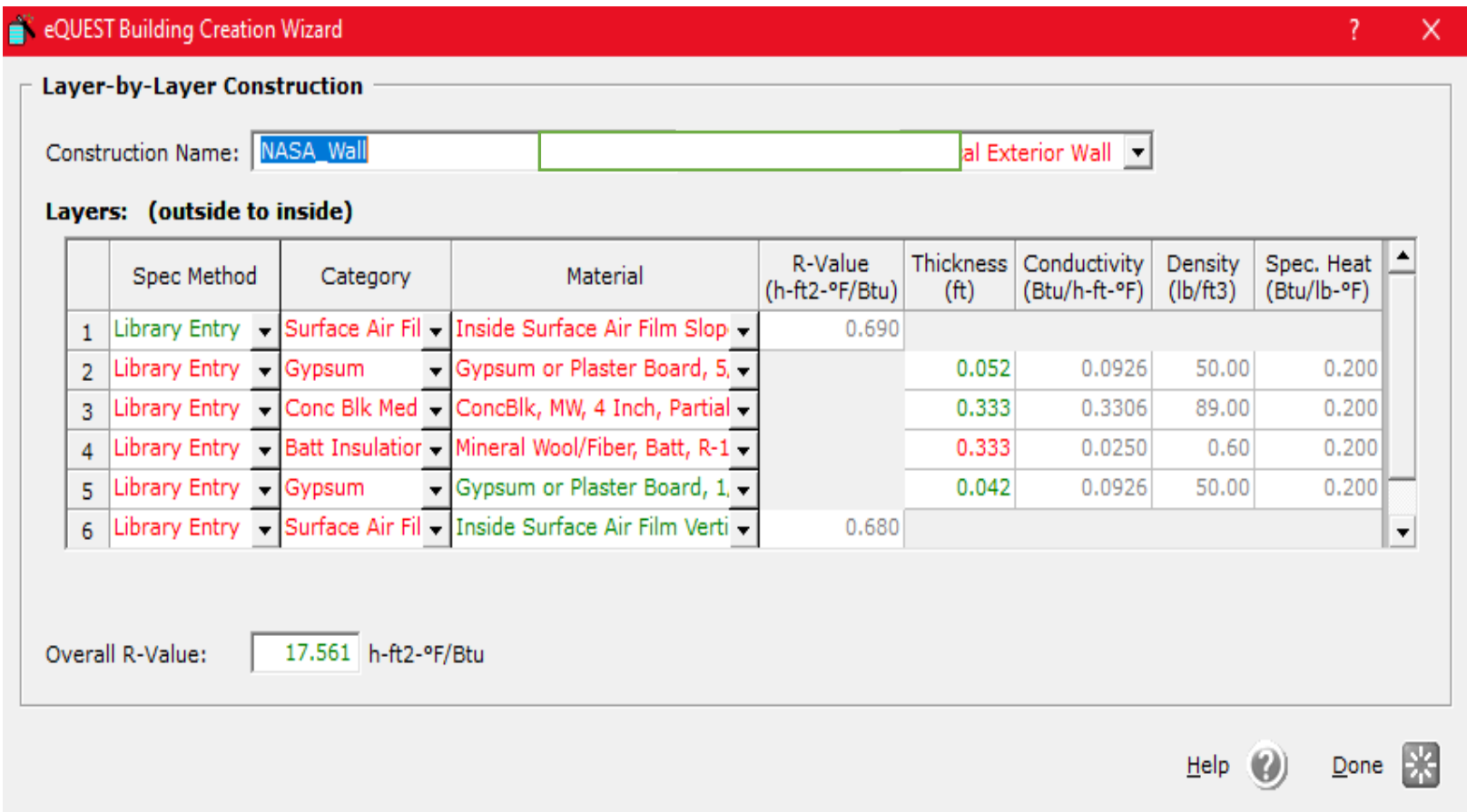

Figure 27:Wall Construction Details-Building A 
Layer-by-Layer Construction

Construction Name: GF Wall Vertical Exterior Wall $\mathbf{}$

Layers: (outside to inside)

\begin{tabular}{|c|c|c|c|c|c|c|c|c|c|c|c|}
\hline & Spec Method & & Category & & Material & $\begin{array}{c}\text { R-Value } \\
\text { (h-ft2- }{ }^{\circ} \text { F/Btu) }\end{array}$ & $\begin{array}{l}\text { Thickness } \\
\text { (ft) }\end{array}$ & $\begin{array}{l}\text { Conductivity } \\
\left.\text { (Btu/h-ft- }{ }^{\circ} \mathrm{F}\right)\end{array}$ & $\begin{array}{l}\text { Density } \\
(\mathrm{lb} / \mathrm{ft} 3)\end{array}$ & $\begin{array}{l}\text { Spec. Heat } \\
\left(\mathrm{Btu} / \mathrm{lb}-{ }^{\circ} \mathrm{F}\right)\end{array}$ & $\Delta$ \\
\hline 1 & Library Entry & & Surface Air Fil & & Inside Surface Air Film Horiz $\mathbf{}$ & 0.760 & & & & & \\
\hline 2 & Library Entry & 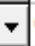 & Gypsum & $\nabla$ & Gypsum or Plaster Board, $1 \overline{\boldsymbol{T}}$ & & 0.042 & 0.0926 & 50.00 & 0.200 & \\
\hline 3 & Library Entry & 7 & Batt Insulatior & & Mineral Wool/Fiber, Batt, R-7 & & 0.500 & 0.0250 & 0.60 & 0.200 & \\
\hline 4 & Library Entry & $\nabla$ & Gypsum & $\nabla$ & Gypsum or Plaster Board, $5, \overline{\mathbf{T}}$ & & 0.052 & 0.0926 & 50.00 & 0.200 & - \\
\hline 5 & Library Entry & $\nabla$ & Surface Air Fil & & Inside Surface Air Film Hori $\overline{\mathbf{Z}}$ & 0.760 & & & & & \\
\hline 6 & Library Entry & $\nabla$ & - select categc & & & & & & & & $\nabla$ \\
\hline
\end{tabular}

Overall R-Value: $\longdiv { 2 4 . 1 4 3 }$ h-ft2- ${ }^{\circ} \mathrm{F} /$ Btu

Figure 28:Wall Construction Details-Building B

eQUEST Building Creation Wizard

- Layer-by-Layer Construction

Construction Name: NASA Roof

: Roof

Layers: (outside to inside)

\begin{tabular}{|c|c|c|c|c|c|c|c|c|c|c|c|}
\hline & Spec Method & & Category & & Material & $\begin{array}{c}\text { R-Value } \\
\left.\text { (h-ft2- }{ }^{\circ} \mathrm{F} / \mathrm{Btu}\right)\end{array}$ & $\begin{array}{l}\text { Thickness } \\
(\mathrm{ft})\end{array}$ & $\begin{array}{l}\text { Conductivity } \\
\text { (Btu/h-ft- }{ }^{\circ} \mathrm{F} \text { ) }\end{array}$ & $\begin{array}{l}\text { Density } \\
\text { (lb/ft3) }\end{array}$ & $\begin{array}{l}\text { Spec. Heat } \\
\text { (Btu/lb- }{ }^{\circ} \text { F) }\end{array}$ & $\triangle$ \\
\hline 1 & Library Entry & $\nabla$ & Surface Air Fil & - & Inside Surface Air Film Hori ${ }_{\bar{i}} \mathbf{-}$ & 0.760 & & & & & \\
\hline 2 & Library Entry & - & Conc Blk Med & $\nabla$ & ConcBlk, MW, 4 Inch, Hollow - & & 0.333 & 0.3003 & 76.00 & 0.200 & \\
\hline 3 & Library Entry & $\nabla$ & Air Layer & $\nabla$ & Air Layer, $3 / 4$ Inch or less $V \overrightarrow{\boldsymbol{V}}$ & 0.900 & & & & & \\
\hline 4 & Library Entry & $\checkmark$ & Batt Insulatior & $\nabla$ & Mineral Wool/Fiber, Batt, R-1 - & & 0.511 & 0.0250 & 0.60 & 0.200 & \\
\hline 5 & Library Entry & $\nabla$ & Gypsum & $\nabla$ & Gypsum or Plaster Board, 1, $\mathbf{\nabla}$ & & 0.042 & 0.0926 & 50.00 & 0.200 & \\
\hline 6 & Library Entry & $\nabla$ & Surface Air Fil & 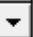 & Inside Surface Air Film Verti - & 0.680 & & & & & $\nabla$ \\
\hline
\end{tabular}

Overall R-Value: $\longdiv { 2 5 . 1 2 2 }$ h-ft2- ${ }^{\circ} \mathrm{F} / \mathrm{Btu}$

Figure 29:Roof Construction Details-Building A 
- Layer-by-Layer Construction

Construction Name: GF_Roof

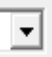

Layers: (outside to inside)

\begin{tabular}{|c|c|c|c|c|c|c|c|c|c|c|c|}
\hline & \multicolumn{2}{|l|}{ Spec Method } & \multicolumn{2}{|l|}{ Category } & Material & $\begin{array}{c}\text { R-Value } \\
\text { (h-ft2- }{ }^{\circ} \mathrm{F} / \text { Btu) }\end{array}$ & $\begin{array}{c}\text { Thickness } \\
(\mathrm{ft})\end{array}$ & $\begin{array}{l}\text { Conductivity } \\
\left.\text { (Btu/h-ft- }{ }^{\circ} \mathrm{F}\right)\end{array}$ & $\begin{array}{l}\text { Density } \\
(\mathrm{lb} / \mathrm{ft} 3)\end{array}$ & $\begin{array}{l}\text { Spec. Heat } \\
\left(\text { Btu/lb- }{ }^{\circ} F\right)\end{array}$ & 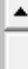 \\
\hline 1 & Library Entry & $\checkmark$ & Surface Air Fil & $\nabla$ & Inside Surface Air Film Hori ${ }^{\top}$ - & 0.760 & & & & & \\
\hline 2 & Library Entry & $\nabla$ & Conc Blk Med & $\nabla$ & ConcBlk, MW, 4 Inch, Concr - & & 0.333 & 0.4456 & 115.00 & 0.200 & \\
\hline 3 & Library Entry & $\nabla$ & Air Layer & $\nabla$ & Ceiling Air Space (HF-E4) & 1.000 & & & & & \\
\hline 4 & Library Entry & $\checkmark$ & Batt Insulatior & $\nabla$ & Mineral Wool/Fiber, Batt, R-1 $\mathbf{v}$ & & 0.500 & 0.0250 & 0.60 & 0.200 & - \\
\hline 5 & Library Entry & $\nabla$ & Gypsum & $\nabla$ & Gypsum or Plaster Board, 1, & & 0.042 & 0.0926 & 50.00 & 0.200 & \\
\hline 6 & Library Entry & 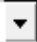 & Acoustic Tile & $\nabla$ & Acoustic Tile (HF-E5) & & 0.063 & 0.0350 & 30.00 & 0.200 & $\checkmark$ \\
\hline era & R-Value: & & 26.294 h-ft2-c & & Btu & & & & & & \\
\hline
\end{tabular}

Help (2) Done

Figure 30:Roof Construction Details-Building B 


\section{Bibliography}

[1] Energy Information Administration, "International Energy Outlook 2019," U.S. Department of Energy.

[2] U.S. Department of Energy, "Quadrennial Technology Review : An Assessment of Energy Technology and Research Opportunity," 2015.

[3] Office of Energy Efficiency and Renewable Energy,US Department of energy, "2018 Renewable Energy Data Book," 2018.

[4] O. Edenhofer, R. P. Madruga, Y. Sokona, J. C. Minx, E. Farahani, S. Kadner, K. Seyboth, A. Adler, I. Baum and S. Brunner, "Climate Change 2014:Mitigation of Climate Change. Contribution of Working Group III to the Fifth Assessment Report of the Intergovernmental Panel on Climate Change," Cambridge University Press, Cambridge, United Kingdom and New York, NY, USA, 2014.

[5] . M. Tobias, "New York Engineers Logo," [Online]. Available: https://www.nyengineers.com. [Accessed 1704 2021].

[6] N. Fumo, "A review on the basics of building energy estimation," Renewable and Sustainable Energy Reviews, vol. 31, pp. 53-60, 2014.

[7] H. S. Rallapalli, "A Comparison of EnergyPlus and eQUEST Whole Building Energy Simulation Results for a Medium Sized Office Building," Arizona State University, 2010.

[8] "TRNSYS Transient System Simulation Tool," TRNSYS, [Online]. Available: http://www.trnsys.com/. [Accessed 0804 2021].

[9] "TRANE TRACE," [Online]. Available: https://www.trane.com/commercial/northamerica/us/en/products-systems/design-and-analysis-tools/trace-700.html. [Accessed 0804 2021].

[10] L. L. Lombard, J. Ortiz and C. Pout, "A review on buildings energy consumption information," Energy and Building, vol. 40, pp. 394-398, 2008.

[11] B. L. Capehart, W. C. Turner and W. J. Kennedy, Guide to Energy Management Sixth Edition, The Fairmont Press, 2008.

[12] U.S. Energy Information Administration, "2018 Commercial Buildings Energy Consumption Survey Preliminary Results," U.S. Energy Information Administration, 2020.

[13] "Statista," [Online]. Available: https://www.statista.com/. [Accessed 2404 2021]. 
[14] Energy Star, "Energy Star," [Online]. Available:

https://www.energystar.gov/buildings/about-us/facts-and-stats. [Accessed 1104 2021].

[15] P. Emrath, "More New Homes Needed to Replace Older Stock," 02 August 2018. [Online]. Available:

https://www.nahbclassic.org/generic.aspx? sectionID=734\&genericContentID=263243. [Accessed 2404 2021].

[16] M. Cai, R. Sneharaj, M. Pipattanasomporn and S. Rahman, "Impact of HVAC Set Point Adjustment on Energy Savings and Peak Load Reductions in Buildings," 2018 IEEE International Smart Cities Conference (ISC2), pp. 1-6, 2016.

[17] D. Ardiyanto, M. Pipattanasomporn, S. Rahman, N. Hariyanto and S. , "Occupant-based HVAC Set Point Intervention for Energy savings in Buildings," in Green Energy for Sustainable Development, Thailand, 2018.

[18] K. Mininni, R. Hudson, M. Pommier, J. Okvath and R. Anderson, "Energy Audit at Fort Stanwix National Monument," in Multi-Disciplinary Senior Design Conference, 2009.

[19] D. A. Khan, M. B. Sajid, S. Gul and W. Khalil, "Energy Performance Analysis of a Commercial Building using eQuest," in High Performance Energy Efficient Buildings and Homes, Lahore, Pakistan, 2018.

[20] J. Heller, M. Heater and M. Frankel, "Sensitivity Analysis: Comparing the Impact of Design, Operation, and Tenant Behavior on Building Energy Performance," New Building Institute, July 2011.

[21] J. Song, X. Zhang and X. Meng, "Simulation and Analysis of a University Library Energy Consumption based on eQuest," Procedia Engineering, vol. 121, pp. 1382-1388, 2015.

[22] A. Dutta and A. Samanta, "Determining Factor/s of Window Glazing Regarding Reduction in Electrical Energy Consumption," Energy Resources Technology, vol. 142, no. 3, 2020.

[23] A. Samanta, A. Dutta and S. Neogi, "Passive Design and Performance Evaluation of Building using eQuest: A Case Study," Journal of Building Performance, vol. 4, no. 1, pp. 59-66, 2013.

[24] M. J. Dehghani, P. McManamnob and A. Ataei, "Toward Building Energy Reduction Through Solar Energy Systems Retrofit: An eQuest Model," Journal of Applied Engineering Sciences, vol. 8, no. 21, pp. 53-60, 2018.

[25] A. K. Masood, S. Muhammad, S. Shabbir, H. Altaf, U. Hafeez, W. Ullah and F. Shabbir, "Impact of Windows to Wall Ratio on Energy Consumption in Building Sector of Pakistan," in International Conference on Energy Systems and Policies (ICESP), 2014. 
[26] Siddhartha, V. Valsan, A. Kapoor and S. Gupta, "Energy conservation in Centrally Airconditioned Buildings Through Energy Modeling," in Advanced Computational and Communication Paradigms, 2019.

[27] Q. He, M. U. Hossain, S. T. Ng and M. Skirtmore, "Energy-Efficient Window Retrofit for High-Rise Residential Buildings in Different Climatic Zones of China," Sustainability, vol. $11,2019$.

[28] M. T. Ke, C. H. Yeh and J. T. Jian, "Analysis of Building Energy Consumption Parameters and Energy Savings Measurement and Verification by Applying eQuest Software," Energy and Buildings, vol. 61, pp. 100-107, 2013.

[29] U.S. Department of Energy, "An Assessment of Energy Technologies and Research Opportunities," 2015.

[30] American Society of Heating, Refrigerating and Air Conditioning, Energy Standard for Buildings Except Low-Rise Residential Buildings, ASHRAE, 2009.

[31] W. Tian, "A review of sensitivity analysis methods in building energy analysis," Renewable and Sustainable Energy Reviews, vol. 20, pp. 411-419, 2012.

[32] Y. Ye, Y. Lou, K. Hinkelman and W. Zuo, "Evaluating the Energy Impact Potential of Energy Efficiency Measures for Retrofit Applications: A Case Study with U.S. Medium Office Buildings," Building Simulation, 2021.

[33] P. Raftery, M. Keane and A. Costa, "Calibration of a Detailed Simulation Model to Energy Monitoring System Data: A Methodology and Case Study," in Eleventh International IBPSA Conference, Glasgow, Scotland, July,2009.

[34] S. Park, V. Norrefeldt, S. Stratbucker, Y. S. Jang and G. Grun, "Methodological approach for calibration of building energy performance simulation models applied to a common "measurement and verification" process," Bauphysik, vol. 35, no. 4, pp. 235-241, 2013.

[35] J. Xing, P. Ren and J. Ling, "Analysis of energy efficiency retrofit scheme for hotel buildings using eQuest software: A case study from Tianjin,China," Energy and Buildings, vol. 87, pp. 14-24, 2015.

[36] E. Bellos, C. Tzivanidis, A. Kouvari and K. A. Antonopoulos, "Comparison of Heating and Cooling Loads of a Typical Building with TRNSYS and eQuest," in Energy, Transportation and Global Warming. Green Energy and Technology, Springer, 2016, pp. 327-338.

[37] J. Kneifel, "Benefits and Costs of Energy Standard Adoption in New," National Institute of Standards and Technology, 2013. 
[38] G. Holness, "On the path to net zero, how do we get there from here?," ASHRAE Journal, vol. 53, no. 6, pp. 50-60, 2011.

[39] Energy Star, "Retrocommissioning," in Energy Star Building Manual, 2007.

[40] J. Thorne and S. Nadel, "Retrocommissioning:Program Strategies to Capture Energy Savings in Existing Buildings," American Council for an Energy-Efficient economy, Washington, D.C., 2003.

[41] J. Roberts and B. Tso, "Do Savings from Retrocommissioning last? results from an Effective Useful Life Study," American Council for an Energy Efficient Economy, 2010.

[42] G. Eleftheriadis and M. Hamdy, "Impact of building envelope and mechanical component degradation on the whole building performance:a review paper," in 11th Nordic Symposium on Building Physics, Trondheim,Norway, 2017.

[43] Fenaughty, Karen; Parker, Danny; Florida Solar Energy Center, "Evaluation of Air Conditioning Performance Degradation:Opportunities from Diagnostic Methods," in 2018 ACEEE Summer Study on Energy Efficiency in Buildings, Washington D.C., 2018.

[44] V. Sousa, T. Dias and . I. Meireles, "Modeling the Degradation Rate of the Wood Frame Doors and Windows of the National Palace and Windows of the Sintra, Portugal," Journal of Performance of Construction Materials, vol. 30, no. 2, 2016.

[45] S. Verbeke, A. Audenaert and I. Verhaert, "Interlinking the effect of thermal mass and temperature control strategies in dwellings," in E3S Web conference, 2019.

[46] K. W. Childs, G. E. Courville, and E. L. Bales, "Thermal Mass Assessment: An Explanation of the Mechanisms by Which Building Mass Influences Heating and cooling Energy Requirements," Oak Ridge National Laboratory, 1983.

[47] G. R. Ruiz and C. F. Bandera, "Validation of Calibrated Energy Models: common Errors," Energies, vol. 10, no. 10, 2017. 